UCRL-CR-122068

B280353

\title{
Assessment of the Effects of Microbially Influenced Degradation on a Massive Concrete Structure Final Report
}

Report 5

Robert D. Rogers

\section{RECEIVED OCT 061995 OSTI} Biodegradation Systems, Inc.

July 8, 1995
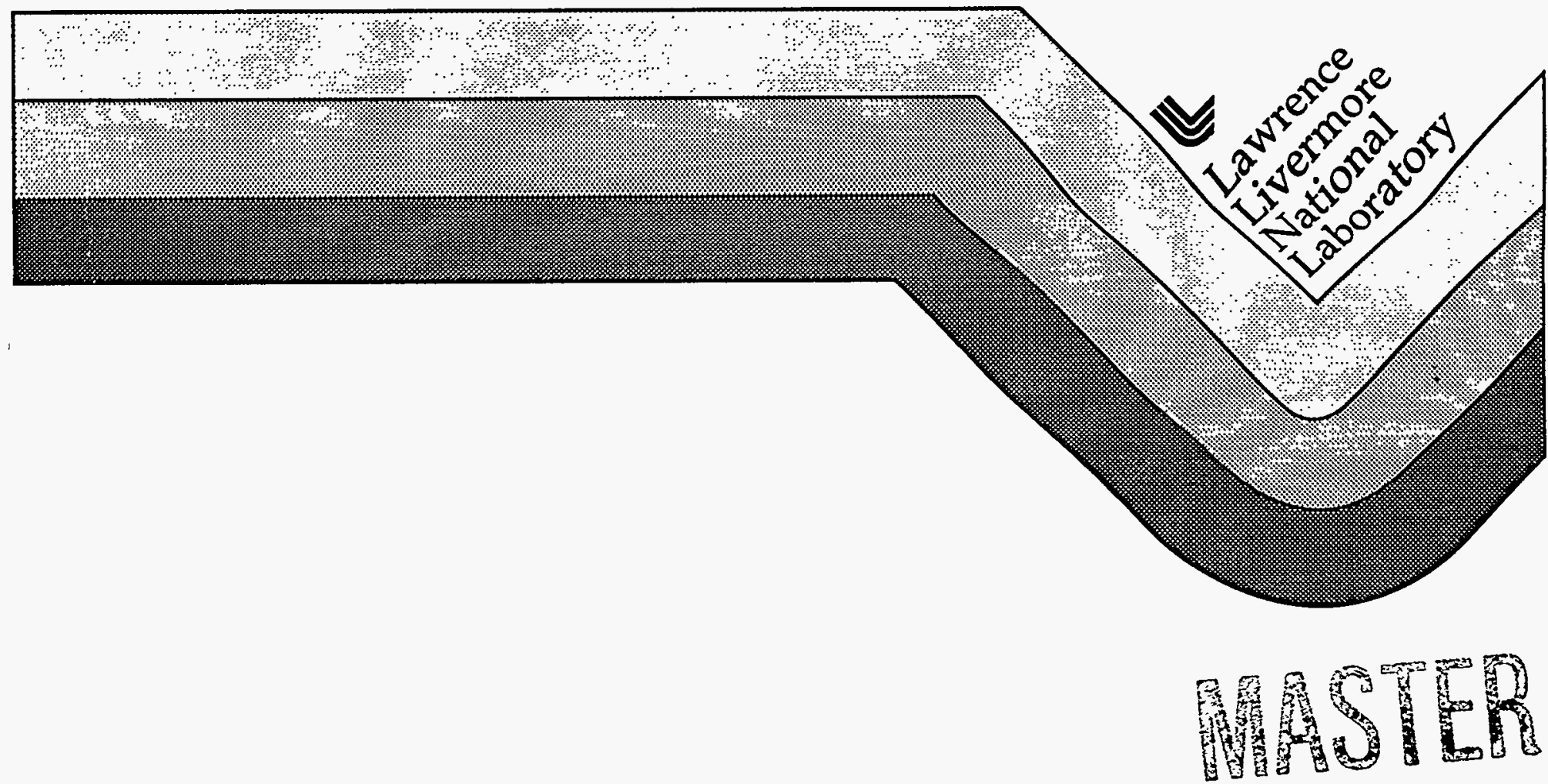
This document was prepared as an account of work sponsored by an agency of the United States Government. Neither the United States Government nor the University of California nor any of their employees, makes any warranty, express or implied, or assumes any legal liability or responsibility for the accuracy, completeness, or usefulness of any information, apparatus, product, or process disclosed, or represents that its use would not infringe privately owned rights. Reference herein to any specific commercial product, process, or service by trade name, trademark, manufacturer, or otherwise, does not necessarily constitute or imply its endorsement, recommendation, or favoring by the United States Government or the University of California. The views and opinions of authors expressed herein do not necessarily state or reflect those of the United States Government or the University of California, and shall not be used for advertising or product endorsement purposes. 


\section{DISCLAIMER}

Portions of this document may be illegible in electronic image products. Images are produced from the best available original document. 


\section{ASSESSMENT OF THE EFFECTS OF MICROBIALLY INFLUENCED DEGRADATION ON A MASSIVE CONCRETE STRUCTURE FINAL REPORT \\ Report 5

\author{
A REPORT PREPARED \\ BY \\ BIODEGRADATION SYSTEMS INC.
}

1206 Norton St.

Idaho Falls, ID

AUTHORED

BY

ROBERT D. ROGERS, PhD.

Revised

July 8, 1995 


\section{TABLE OF CONTENTS}

List of Tables $\ldots \ldots \ldots \ldots \ldots \ldots \ldots \ldots \ldots \ldots \ldots \ldots \ldots$

List of Figures $\ldots \ldots \ldots \ldots \ldots \ldots \ldots \ldots \ldots \ldots \ldots$ ii

Executive Summary $\ldots \ldots \ldots \ldots \ldots \ldots \ldots \ldots \ldots \ldots \ldots \ldots$

Background $\ldots \ldots \ldots \ldots \ldots \ldots \ldots \ldots \ldots \ldots \ldots \ldots \ldots$

Materials and Methods $\ldots \ldots \ldots \ldots \ldots \ldots \ldots \ldots \ldots$

Field Site $\ldots \ldots \ldots \ldots \ldots \ldots \ldots \ldots \ldots \ldots \ldots \ldots$

Isolation and Identification $\ldots \ldots \ldots \ldots \ldots \ldots \ldots$

Accelerated Laboratory Testing $\ldots \ldots \ldots \ldots \ldots \ldots \ldots$

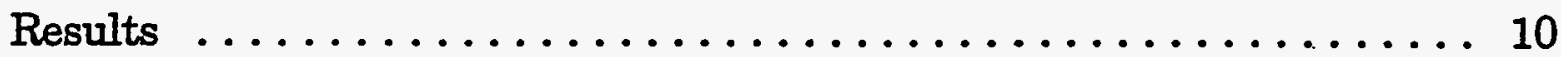

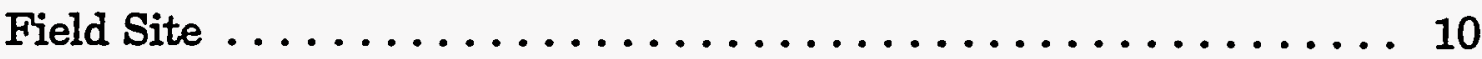

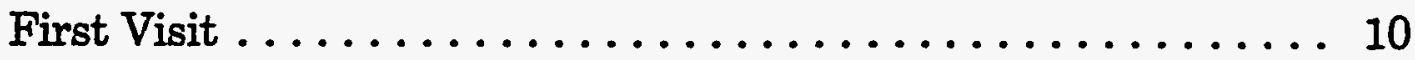

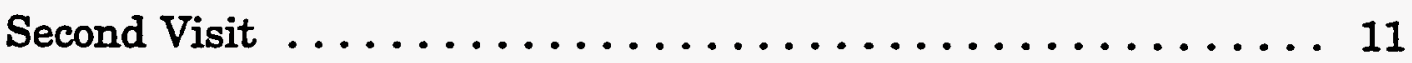

Third Visit $\ldots \ldots \ldots \ldots \ldots \ldots \ldots \ldots \ldots \ldots \ldots \ldots \ldots$

Accelerated Laboratory Testing $\ldots \ldots \ldots \ldots \ldots \ldots \ldots \ldots$

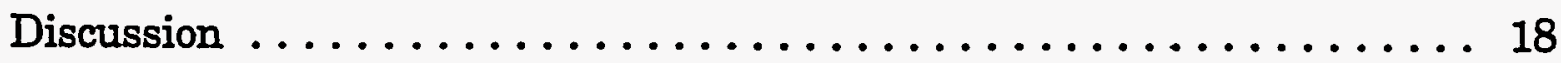

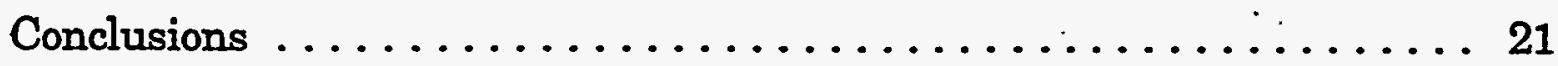

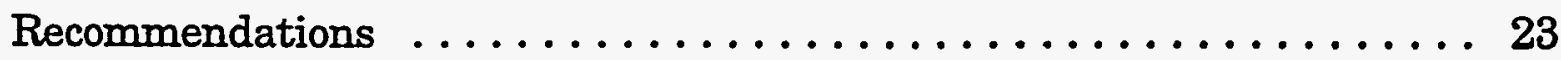

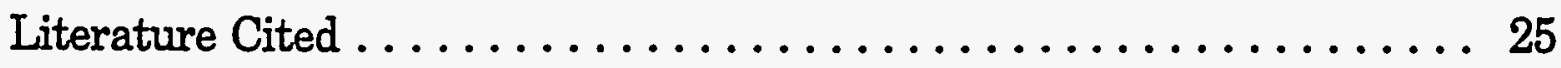




\section{List of Tables}

Table 1. Types and numbers of microorganisms isolated from Ohaaki cooling tower: First visit.

Table 2. Types and numbers of microorganisms isolated from Ohaaki cooling tower: Second visit.

Table 3. Types and numbers of microorganisms isolated from Ohaaki cooling tower: Thrid visit.

Table 4. Total $\mathrm{mg}$ of elements leached from specimens after 60 days of accelerated testing. 
List of Figures

Figure 1. Ohaaki Power Station cooling tower.

Figure 2. Interior perimeter of cooling tower featuring wall-hugging catwalk.

Figure 3. Interior of cooling tower featuring gas dispersion unit.

Figure 4. Interior of cooling tower by a wall looking skyward.

Figure 5. Interior of cooling tower featuring red stain on walls.

Figure 6. Interior of cooling tower with gas dispersion unit in foreground featuring green biofilm on upper walls.

Figure 7. Interior of cooling tower wall featuring thin strips of vertically occurring biomass.

Figure 8. Interior of cooling tower wall featuring uniform removal of 2 to $4 \mathrm{~mm}$ of surface.

Figure 9. Interior of cooling tower featuring extensive loss of concrete $(2$ to $3 \mathrm{~cm})$ at catwalk location $1 \mathrm{a}$.

Figure 10. Cooling tower moat featuring extensive loss of concrete on exposed pillar.

Figure 11. Obtaining core samples using hand-held, gas-powered core driller.

Figure 12. Coring location featuring precast construction hole.

Figure 13. Coring location featuring placement of holes for emplacement of concrete samples.

Figure 14. Interior of cooling tower featuring location of doored opening.

Figure 15. Wall location featuring placement of concrete samples and miniature temperature recording device.

Figure 16. Catwalk location featuring placement of concrete samples and miniature temperature recording device. 
Figure 17. ESEM image of crust from moat wall. Note appearance of "stringy" amorphus material thought to be biofilm.

Figure 18. ESEM image of crust from moat wall. Note appearance of amorphus material, thought to be biofilm, coating surface.

Figure 19. ESEM image of crust from moat wall. Note granular surface with what appears to be embedded algae fragment.

Figure 20. ESEM image of core from interior tower wall. Note amorphus coating containing rod shaped entities thought to be bacteria.

Figure 21. ESEM image of core from interior tower wall. Close up of area presented in Figure 4.

Figure 22. ESEM image of core from interior tower wall. Note amorphus coating containing rod shaped entities thought to be bacteria.

Figure 23. ESEM image of core from interior tower wall. Close up of area presented in Figure 6.

Figure 24. Conditions inside of tower during sampling activities September 24, 1994.

Figure 25. Wall at Site 1 showing emplaced specimens and $\mathrm{X}$ marker used to gauge wall degradation.

Figure 26. Wall at Site 2 showing emplaced specimens.

Figure 27. Wall at Site 3 showing emplaced specimens.

Figure 28. Cat walk at Site 1a showing emplaced specimens.

Figure 29. SEM image of emplaced ASTM specimen at Site 1 showing biofilm and microorganisms.

Figure 30. SEM image of emplaced ASTM- $\mathrm{HgCl}_{2}$ specimen at Site 1 highlighting microorganisms.

Figure 31. SEM image of emplaced ASTM- $\mathrm{HgCl}_{2}$ specimen at Site 1 highlighting microorganisms in biofilm.

Figure 32. SEM image of emplaced YM Type $H$ specimen at Site 1 highlighting microorganisms in biofilm. 
Figure 33. SEM image of emplaced YM Type H specimen at Site 2 highlighting microorganisms in biofilm.

Figure 34. SEM image of emplaced ASTM- $\mathrm{HgCl}_{2}$ specimen at Site 3 showing biofilm and microorganisms.

Figure 35. SEM image of emplaced YM Type $\mathrm{H}$ specimen at Site 3 showing biofilm and microorganisms.

Figure 36. SEM image of emplaced YM Type $\mathrm{H}$ specimen at Site 3 highlighting microorganism presence on aggregate.

Figure 37. SEM micrograph showing close-up view of area shown in Figure 1 showing bacteria (mostly cocci) nestled in biomass and hyphae.

Figure 38. SEM micrograph showing individual bacteria interspersed with amorphus material on the surface of the Site 1 Type $H$ specimen.

Figure 39. SEM micrograph showing numerous rod shaped bacteria on surface of and immersed in biofilm of the Site 1 Type K specimen.

Figure 40. SEM micrograph of individual cocci and rods immersed in biofilm on the surface of the Site 1 ASTM-Hg specimen.

Figure 41. SEM micrograph of rod shaped bacteria on surface of and immersed in biofilm of the Site 2 Type K specimen.

Figure 42. SEM micrograph of cocci and rod shaped bacteria on amorphus material of ASTM specimen at Site 3.

Figure 43. Rod shaped bacteria actively dividing on crystal surfaces present on Type $\mathrm{H}$ specimen at Site 3.

Figure 44. Amorphous surface of Type $\mathrm{K}$ specimen at Site 3 showing some bacterial attachment.

Figure 45. SEM micrograph showing clusters of bacteria immersed in biofilm on surface of Site 2a ASTM specimen.

Figure 46. SEM micrograph showing sheet of dehydrated biofilm occurring on surface of Site $2 \mathrm{a} \mathrm{Ca} \mathrm{Al} \mathrm{specimen.}$

Figure 47. SEM micrograph of rod shaped bacteria in chain formation with 
attachment to mineral surface of Site $2 a$ Type $\mathrm{H}$ specimen.

Figure 48. SEM micrograph showing apparent biofilm containing immersed bacteria on surface of Type $\mathrm{K}$ specimen at Site $2 a$.

Figure 49. SEM micrograph of surface of Site 2aASTM-Hg specimen packed with polar attached rod shaped bacteria.

Figure 50. Test specimens after 1 day immersion in sterile medium.

Figure 51. Test specimens after 1 day immersion in thiobacilli lixiviant.

Figure 52. Test specimens after 29 days immersion in sterile medium.

Figure 53. Test specimens after 29 days immersion in thiobacilli lixiviant.

Figure 54. Test specimens after 61 days immersion in sterile medium.

Figure 55. Test specimens after 61 days immersion in thiobacilli lixiviant.

Figure 56. Cumulative quantity of $\mathrm{Al}$ leached over time from test specimens exposed to thiobacilli lixiviant.

Figure 57. Cumulative quantity of $\mathrm{Ca}$ leached over time from test specimens exposed to thiobacilli lixiviant.

Figure 58. Cumulative quantity of $\mathrm{Fe}$ leached over time from test specimens exposed to thiobacilli lixiviant.

Figure 59. Cumulative quantity of Si leached over time from test specimens exposed to thiobacilli lixiviant. 


\section{EXECUTIVE SUMMARY}

There is a need to estimate the effect of environmental conditions on construction materials to be used in the repository at Yucca Mountain. Previous reports from this project have demonstrated that it is important to develop an understanding of microbially influenced degradation (MID) development and its influence on massive concrete structures. Further, it has been shown that the most effective way to obtain quantitative data on the effects of MID on the structural integrity of repository concrete is to study manmade, analog structures known to be susceptible to MID. The cooling tower shell located at the Ohaaki Power Station near Wairakei, New Zealand is such a structure.

Personnel from Biodegradation Systems Inc. have visited the Ohaaki Site since October 1993. Altogether a total of 176 samples have been recovered and analyzed for the presence of MID microorganisms. Results from examination of those samples clearly demonstrated that the concrete was inhabited, in abundance, by a variety of microorganisms known to promote MID of concrete. Several species of thiobacilli together with nitrifying and heterotrophic bacteria and fungi, were isolated from the samples. The numbers of microorganisms within each of these populations are dynamic. Data are now showing that there is a gradation of MID effects at the three sampling sites within the tower. This is fortunate since additional investigations of the three environments associated with these sites will provide comparable data which will help in the understanding of MID initiation and persistence. Part of the information that will help this process will be background data obtained from the chemical/physical examination of the environment at the sites. This will provide data on temperature regimes and the concentrations of key elements such as reduced sulfur and nitrogen.

Results from this study are confirming that the Ohaaki cooling tower is an excellent choice for examining the development of MID of concrete under natural conditions. Data obtained from SEM micrographs, and selective as well as general isolation methods show that there is a consortium of MID promoting thiobacilli and nitrifying bacteria actively growing at three sampling sites established in the tower. These data show that bacterial species found in the wall consortium have also established themselves on the several emplaced, concrete specimens. Of particular importance to YMSCP is data about the consistent colonization of the YM Type $H$ and $K$ concrete specimens.

These data prove that conditions known to promote MID can be established under natural conditions on YM concrete formulations. The ongoing study at Ohaaki is important because it is providing for a continuing examination of the MID affected, interior tower wall as well as the fresh surfaces of emplaced concrete specimens. Continued study of the consortium of bacteria that inhabit the wall 
and the subsequent colonization of the fresh specimen surfaces will provide answers to the questions surrounding the natural development MID. These data, in turn, will have a direct bearing on developing a consciences opinion on whether the effects of MID will be of any long-term consequence at Yucca Mountain.

The results, therefore, justify continued baseline observations of the effects of MID on the Ohaaki tower structure, developing an understanding of the environment conditions that initiate and promote MID, and continued study of the development and effects of MID on the emplaced specimens. If the tower becomes unacceptable for continued study then another location in the MID rich area should be utilized. Such locations could include other structures or geothermal lakes rich in sulfur.

A suitable lake could be used as a natural, accelerated testing facility to test YM concrete formulations. The lake would allow testing with native thiobacilli growing under natural conditions. In addition, the studies could be conducted under a range of temperatures due to the thermal gradient found in these water bodies. Also, a geothermal lake rich with species of sulfur could provide the ideal site to conduct biological sulfuring cycling studies.

It is suggested that long-term, meaningful laboratory work be initiated that will document the rate of MID progression over time. Such work should be conducted in environmentally controlled chambers or test cells designed to be attached to concrete surfaces. It could be possible to use such cells for in situ studies at the YM site. 


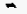

$\rightarrow$ 


\section{ASSESSMENT OF THE EFFECTS OF \\ MICROBIALLY INFLUENCED DEGRADATION \\ ON MASSIVE CONCRETE STRUCTURES \\ FINAL REPORT}

\section{Background}

The U.S. Department of Energy (DOE) is engaged in a suitability study for a potential geological repository at Yucca Mountain, Nevada, for the containment and storage of commercially generated high-level nuclear waste (HLW). The Yucca Mountain Site Characterization Project (YMSCP) Introduced Materials Task desires to understand and predict potential long-term modifications of natural chemistry caused by the construction and operation of a repository that may significantly affect the performance of a radioactive waste package. Based on sheer mass, the major materials used in repository construction and closure will be concrete and the surrounding rock. It is desired to predict the reliability of these materials, under repository conditions, for time periods beyond their presently known service life. The ability to predict how resistance these materials are to attack by chemical and physical agents is therefore necessary. To establish the required confidence in concrete as a prominent component used in the construction of storage structures for $\mathrm{HLW}$, it is necessary to develop an extensive understanding of all possible threats to its durability and service life. There is a growing awareness that biotic factors could affect the integrity of the repository either directly, through microbially influenced degradation of concrete (MID) (analogous to microbially induced corrosion of metals [MIC]), or indirectly by alteration of the geochemical environment.

MID activity could cause breaching of the repository containment by deterioration of the concrete barrier, or enhanced transport of fugitive radionuclide contamination due to the formation of chelating agents or organic colloids. Presently there is no information on the critical issues raised by these possibilities.

MID is thought to occur when microorganisms present in the environment produce mineral or organic acids that dissolve or disintegrate the concrete matrix. The particular mechanisms of acid attack are referenced in most texts concerned with concrete. The attack proceeds as a process of dissolution by chemically converting the constituents of the cement paste into readily leachable soluble salts. Information on the activity of the causative agent, the microorganism, however, is not as available. The presence of active MID microorganisms appears to greatly magnify the intensity of cement dissolution. This phenomenon appears to be the result of a highly reactive microenvironment created by and surrounding individual microbes. No evidence yet exists to suggest that microbes produce enzymes that specifically attack concrete. 
Three groups of bacteria have been isolated from concrete that are conducive to destroying its integrity. They include sulfur-oxidizing bacteria (SOBs), nitrogenoxidizing bacteria (NOBs) and heterotrophic bacteria. SOBs are the bacteria generally associated with MID of concrete structures (most often sewers), and are likely to be active wherever warmth (temperatures above freezing), moisture, and reduced sulfur compounds are present. Their metabolic processes leads to the production of sulfuric acid. NOBs obtain energy by oxidation of inorganic nitrogen compounds, which results in the formation of nitric acid. Both of these types of autotrophic bacteria also produce organic acids which service as a carbon energy source for heterotrophic bacteria capable of biofilm formation. The assimilation of organic carbon compounds by heterotrophic bacteria can also result in the production of organic acids such as lactic, citric, gluconic, malic, and many others as byproducts of their metabolism. It is very important to note that all three groups of bacteria are ubiquitous in the environment Because of that, they will eventually be found in any repository facility, regardless of depth, because of the free movement of environmental contaminates into the confined space. Once introduced, microorganisms will become active if films of moisture and the required sources of metabolizable compounds are present.

In an effort to develop data on the impact of MID, the YMSCP has initiate field and laboratory studies. Field work is being conducted in a massive concrete analog known to be susceptible to MID. Laboratory studies use accelerated testing methodology to evaluate MID resistance of select concrete mixes. Dr. Annemarie Meike, a member of the YMSCP team, through her international contacts arranged for the use of an analogy site at a power production facility at a geothermal field located in New Zealand. It is being used to provide data on concrete exposed to the MID promoting conditions of elevated temperature, moisture, and reduced chemical compounds.

Data obtained from the field site will provide an understanding of MID reactions and reaction rates. When this project is completed, it should be possible to define the significant parameters associated with MID activity. This will lead to an understanding of bounding conditions (i.e. maximum microbial densities, nutrient limitations, other physical and chemical conditions) that permit MID initiation and continence. Ultimately it may be possible to integrate these data into an abiotic model being developed to predict long-term repository performance. This will put MID in context with known physical and chemical processes and help define its relevance as a threat to repository integrity. Such information is vital to a meaningful development of a repository design.

The purpose of the laboratory study has been to determine if MID could have any effect on two concrete formulations which might be used at the Yucca Mountain Site. The method used for the evaluation has been developed to test the effect of MID under accelerated conditions. Testing methodology used in this study was 
based on similar work that researchers associated with BSI have been using for other clients. Data obtained from the procedure has quantified the susceptibility of certain solidified cement grouts to MID induced by sulfur-oxidizing bacteria of the genus Thiobacillus (Rogers et al., 1994).

\section{Materials and Methods}

\section{Field Site}

The field study site is an operational, passive cooling tower shell located at the Ohaaki Power Station near Wairakei, New Zealand (Figure 1). The tower was brought on line in 1988 and is used in conjunction with a $116 \mathrm{MW}$, geothermal, electrical generation plant operated by the Electric Corporation of New Zealand (ECNZ). It has a venturi-like shape which is commonly associated with cooling towers in use at nuclear power plants. Construction is of intertwining, reinforcement bar immersed in pozzolanic, sulphate resistant Portland cement. Tower dimensions include a base diameter of $72 \mathrm{~m}$ which narrows to a $41 \mathrm{~m}$ minimum before increasing to $72 \mathrm{~m}$ at the maximum height of $106 \mathrm{~m}$. The double curvature gives the structure considerable strength which allows for a wall thickness of $16 \mathrm{~cm}$ for the middle $94 \mathrm{~m}$.

The first $12 \mathrm{~m}$ of the tower are taken up with an air inlet ring setting astride a water storage moat, followed by an area filled with a plastic, veined thermal pack. It is possible to access the top of the thermal pack through a doored opening at the $12 \mathrm{~m}$ level. This door provides the only access into the tower. The interior perimeter of the tower at this level can be transverse on a wall-hugging catwalk (Figure 2). No other facilities are provided for accessing other areas of the inside of tower. Also, at this level, is the base of a $8 \mathrm{~m}$ high gas disbursal unit. At the top of this unit are two perpendicular crossarms, with an approximate diameter 24 $\mathrm{m}$, containing outlets for gas dispersion (Figure 3). The location of the dispersal unit in the center of the tower insures that hot $(140 \mathrm{C})$ gas is well mixed within the center of the upward moving air column. During operation the inside of the tower mimics some of the same characteristics expected inside an operational $\mathrm{HLW}$ repository. That is, the interior environment has temperature gradients ranging from warm to hot with accompanying high humidity. In addition, the tower environment contains sources of both reduced sulfur and nitrogen neither of which have been quantified. Therefore, it could serve as an analog of a HLW repository in which sources of reduced sulfur and nitrogen are available.

The purpose of using the Ohaaki facility was two fold. First, to be able to retrieve concrete and biofilm specimens from the interior of the cooling tower and the moat at the base of the tower to document the presence and activity of MID microorganisms. The other purpose was to have the opportunity of affixing various concrete specimens, of known composition, to the interior surface of the 
cooling tower. Thus providing an opportunity of using the tower as a "natural laboratory" for the initiation of a long-term evaluation of MID on a variety of concrete formulations. An additional use of the tower is for collection of data on temperature profiles of the inside atmosphere and wall surface; $\mathrm{pH}$ profiles of the interior wall surface and atmosphere; and chemistry of the interior atmosphere.

The tower has been operating since 1988. ECNZ has been cognizant for a number of years of the occurrence of MID inside the cooling tower structure and in the moat. There has been direct verification that MID related microorganisms are present together with evidence indicating that there are conditions which promote MID though these data were not available for this report. Based on this evidence, ECNZ has attempted to reduce the damage, assumed to be caused by MID processes, by applying epoxy paint to areas of the moat which had extensive damage (concrete which had lost as much as 2 to $4 \mathrm{~cm}$ of its surface). The damage due to MID has occurred in spite of a biocide (amine based) treatment regime for the moat water designed to inhibit bio-film formation. There has not, however, been any attempt at bacterial control in the "vapor zone" of the tower.

The first impression of the inside of tower was one of its immense size and vertical height (Figure 4). The inside surface area of exposed concrete is nearly $22,000 \mathrm{~m}^{2}$. This surface was streaked with a rusty red stain (Figure 5) and at the higher elevations (those exposed to sunlight) it was green due to the growth of algae (Figure 6). Thin strips of what was thought to be biomass (later identified as a setting agent applied to the concrete surface during construction) extended vertically up and down the surface (Figure 7). On close examination the concrete surface appeared to have been altered (Figure 8). There are several locations which have more serious damage than the walls (primarily horizontally placed concrete beams) where up to 2 to $3 \mathrm{~cm}$ of the surface has been removed (Figure 9) as well support pillars exposed to the moat (Figure 10). It is apparent that this massive concrete structure is deteriorating and that the most plausible cause explanation is that it is MID related.

The initial visit to Ohaaki was in October 1993. At that time samples were taken from the interior wall of the tower at three equally spaced sties. At each site five cores, a chiseled, scrapped, and biofilm sample were retrieved. Core samples were obtained through the use of a core driller. This procedure is a standard method used by geologists in the field. The core driller was a hand-held, gas-powered unit the size of a chainsaw (Figure 11). The hollow coring bit had a $2.5 \mathrm{~cm}$ inside diameter and used water as lubricant/coolant. The coring locations were in proximity to a $3 \mathrm{~cm}$ diameter $16 \mathrm{~cm}$ deep hole (penetrated the tower wall) (Figure 12) which had been intentional cast as a consequence of construction of the tower. Core sampling was arranged in a vertical direction above and below one precast hole at each location (three cores above and two beneath) (Figure 13). These locations were necessary because the precast holes served as an identifier of 
locations ( $48 \times 20 \mathrm{~cm}$ ) known to be free of rebar. Caution was necessary since the rebar lattice within the wall was only covered with a maximum of $4 \mathrm{~cm}$ of concrete. As a further precaution, the depth of each core was limited to $3.5 \mathrm{~cm}$. After the core had been drilled, a curved extraction tool was inserted and with the aid of the tool the core was retrieved.

Chiseled samples were obtained using a hammer and chisel $(1.9 \mathrm{~cm}$ face). Scraped samples of designated wall surfaces were taken by rubbing a smaller chisel $(0.5$ $\mathrm{cm}$ face) on the wall surface. Biofilm, cored and chiseled samples were aseptically retrieved with alcohol sterilized forceps and placed into sterile, Whirl Pack@ bags. Scrapped solids were caught directly into bags. Samples obtained near to the coring location were retrieved outside the circular area contaminated with water spray from the coring process. Sampling methods have remained the same for subsequent visits except no other cored samples have been retrieved.

The sampling sites are designated as 1, 2, and 3 starting in a direction 120 degrees on the right of the entrance door way (left of the door as viewed from the interior; Figure 14). They are equal distance from each other (120 degrees) and are coordinated with preexisting numbered locator tags on the catwalk. Site 1 corresponds to Tag number 24 right, Site 2, Tag 17 left, and Site 3, Tag 32 left. In addition to the above locations, two other sampling sites, $1 \mathrm{a}$ and $2 \mathrm{a}$, are located on concrete beams which are used as part of the catwalk support structure. Site 1a is located between Site 1 and Site 2 (reference Tag 24 right) and 2a between 2 and 3 (reference Tag 23 left).

As mentioned before at the time of the first visit, holes left from the removal of cored samples were used for emplacement of five concrete specimens composed of different formulations. These included an ASTM 109 standard hydraulic cement, the ASTM mixture containing mercuric chloride (final concentration of $100 \mathrm{ppm}$ $\mathrm{Hg}$; stained red with vegetable food coloring) to act as a biocide, a commercial calcium aluminate mixture, and two Yucca Mountain formulations designated as type $\mathrm{H}$ and type $\mathrm{K}$. All the samples, except the Yucca Mountain ones, had previously been molded into $2 \times 2.5 \mathrm{~cm}$ cylindrical specimens. The Yucca Mountain samples were sized to $2.5 \times 2.5 \mathrm{~cm}$ by coring larger cylindrical specimens.

The concrete specimens were placed into the tower wall in the following order from top to bottom: ASTM; calcium aluminate; Yucca Mountain Type H; Yucca Mountain type K; and ASTM + Hg. Colored identification tags were also emplaced with the individual specimens. Following the same order described above, the identifying colors were orange, red, yellow, no tag, and green (Figure 15). Specimens were left at each of the three wall sampling locations. They were secured to the tower wall with masonry mortar. In addition, the same five types of specimens were placed at catwalk locations, $1 \mathrm{a}$ and 2a (Figure 16). There were 
no core holes at these locations and the specimens were secured to the concrete support beams with epoxy-cement glue. In addition to the placement of the above specimens, miniature temperature sensing and recording instruments were inserted into the precast holes at each of the three wall locations and in holders at the catwalk sample sites.

During the second visit in September/October 1994 sampling at each of the three wall locations consisted of scraping the wall surface, swipes to retrieve surface material from the emplaced samples, and breaking "chunks" from three of the five emplaced samples. Scraped samples were retrieved from four wall locations at each site. These samples were taken from areas slightly above and to the side of the emplaced cement specimens. The blade of an alcohol sterilized, $9.5 \mathrm{~mm}$ chisel was used to remove loose material from a measured $2 \mathrm{~cm}^{2}$ area. Collected material was placed into $10 \mathrm{~mL}$ culture tubes containing a few drops of sterile, distilled water. A total of 12 samples were retrieved.

Swipes were made by using a $Q$ tip to swab $1 / 3$ of the surface face of each of the five emplaced specimens at each site. The swabbing was repeated a total of three times on each of the $1 / 3$ increments of the exposed surfaces. Each time the exposed end of the $Q$ tip was clipped free and allowed to fall into a $10 \mathrm{~mL}$ culture tube containing either $5 \mathrm{~mL}$ of select media $A$ or $B$ for thiobacilli or $1 \mathrm{~mL}$ of distilled water for nitrifiers. A total of 45 samples were recovered.

The collection of the "chunk" was not part of the original plan for the second sampling trip. It was necessitated because of ECNZ's proposed ASAP application of a water cannon to spray biocide laden water on the wall surface. Therefore, to obtain samples of the specimens before initiation of the treatment it was decided to retrieve 1/2 of the exposed face of the ASTM control, YM H, and ASTM $\mathrm{HgCl}_{2}$ specimens for scanning electron microscopy (SEM) examination and isolation of viable microorganisms. A vertical cut was attempted so as to remove the left side (facing surface) of the specimen. To accomplish this, a hole was made in the side of a sterile Whirl $\mathrm{Pak}^{\circledR}$ bag. A $9.5 \mathrm{~mm}$ chisel was place through the hole with the bit protruding from the mouth of the bag. The mouth of the bag was then held around the specimen and the chisel was used to knock off the sample. The retrieved sample was retained in the bag and later repackaged in a sterile $10 \mathrm{~mL}$ culture tube. The sample was immobilized by placing a foam plug below and above it. The plug was moistened with a few drops of distilled water. Three samples were retrieved from each site for a total of nine.

During the third site visit, February 1995, sampling took place at the three established wall sites. In addition to those locations, samples were obtained from one of the two sampling sites located on concrete beams used as part of the catwalk support structure (Site 2a). This Site is located between Sites 2 and 3 (reference Tag 23 left). 
As during past visits, sampling at each of the three wall locations consisted of scrapings from the wall surface, breaking "chunks" from all of the five emplaced samples and swipes to retrieve surface material from the emplaced samples. Scraped samples were retrieved from wall locations by obtaining two samples from either side of the emplaced cement specimens (a total of four samples). This time two each of these samples were used by BSI, one was sent to the University of Hamburg, Germany for microbial isolation and one was given to NZ IGNS to perform elemental analysis. The samples were obtained in the usual manner with the blade of an alcohol sterilized, $9.5 \mathrm{~mm}$ chisel. With it loose material was removed from a measured $5 \mathrm{~cm}^{2}$ area. Collected material was placed into tared, sterile Whirl Pak ${ }^{\circledR}$ bags. A total of 12 of these samples were retrieved from the three wall sites.

Also, "chunks" of all the emplaced specimens were retrieved from each of the three wall sites as well as from the catwalk $2 a$ site. As mentioned previously, during the September/October 1994 visit one half of the face of the ASTM control, YM Type $\mathrm{H}$ and ASTM $\mathrm{HgCl}_{2}$ specimens at each wall location was recovered for examination. During this visit the remaining half of these specimens was retrieved as well as one half of the exposed surface of the two remaining, unsampled specimens (calcium aluminate, YM Type K). All of these specimens were retrieved for SEM examination and isolation of viable microorganisms by BSI as previously described. In addition, the remaining half of the calcium aluminate and YM Type K specimens were recovered. Specimen recovery at the catwalk site was conducted in the same manner as that of the wall sites. One half of the face of each of the five specimens was collected for analysis. Each sample was packaged in a sterile $10 \mathrm{~mL}$ culture tube with the sample being immobilized by foam plugs below and above it. The plug was moistened with a few drops of distilled water. Seven samples were recovered from each wall site for a total of 21 samples.

During this third visit swipes of all the emplaced wall specimens occurred at each of the wall sampling sites. Samples were obtained from the surface face of each of the five emplaced specimens at each site. The ASTM control and YM Type K specimens from which "chunks" had been previously retrieved (mentioned above) were treated as though they had two faces, original (unsampled) and new (fresh, exposed surface). The swabbing was repeated two times on each of the one half increments of the exposed surfaces. Each time the exposed end of the $Q$ tip was clipped free and allowed to fall into a $15 \mathrm{~mL}$ culture tube containing $5 \mathrm{~mL}$ of sterile, distilled water. A total of 48 samples were recovered with half being used for enumeration of thiobacilli and half for nitrifier enumeration.

Isolation and Identification 
The bacteria were isolated through the use of species' specific media. Verification of bacterial growth in specific medium was sufficient evidence for species identification. For example, microbial growth in a selective, ammonia-oxidizer medium (Schmid and Belser, 1982) was evidence that nitrifying bacteria were present in/on the sample from which the inoculum was recovered. In turn, growth in thiobacilli media A and B (Milde, et. al., 1982) established the presence of the variety of thiobacilli species. Enumeration of the various species was determined by the most probable number (MPN) method used by Schmidt and Belser (1982). The application of this method necessitated the use of nitrifer medium while thiobacilli media A and B were required for those bacteria.

Electron microscopy was used for the purpose of obtaining visual confirmation of the presence of microorganisms on the surface of chunk samples. The process works on those materials which are either naturally electrical conductors or can be made conductive through some pretreatment. Depending on equipment, structures in the submicron range can be resolved. In the field of environmental microbiology it can be used to distinguish the presence of microorganisms attached to the surface of various materials. It provides actual pictures of microorganisms thus validating their occurrence. Not only that, the micrographs can be used to distinguish the morphology of the microorganism thus providing a method for initial genus identification (i.e. fungus, bacterial rod or cocci). This procedure makes it possible also to estimate the condition of the microniches that on the concrete surface. Features such as the presence of biofilm and the orination of individual microorganisms in that matrix provide information on how cells are being attached to the surface.

With time there has been a continued improvement in equipment and techniques used to enhance electron microscopy. Scanning electron microscopy (SEM) is the standard equipment used for examining most biological and environmental samples. Specimens that are not naturally conductive must be coated with a conductive material (generally carbon but for strict nonconductors gold may be required) so that the charge of electrons which bombard the surface will dissipate. In a general sense, the more effective charge dissipation the sharper the resulting image. However, the need for specimen preparation has some disadvantages in that it is time consuming and the process can damage specimens. The environmental scanning electron microscopy (ESEM) attempts to overcome these problems by allowing for the inspection of unprepared environmental samples. However, experience with the instrument convinced BSI that ESEM could not produce the quality micrographs, at this time, required for surface examination of the NZ samples. The difficulty with imaging has been diagnosed as problem with charge dissipation. Concrete is a nonconductor and until some method is developed to increase its conductivity SEM will be the method of choice. BSI is presently using the SEM facility at the Montana State University (MSU) Center for Biofilm Engineering. 
Accelerated Laboratory Testing

The accelerated testing methodology does not attempt to duplicate the conditions that the cementatious material may be exposed to under a natural setting (i.e. it does not duplicate the ecological conditions associated with a massive concrete structure, etc.). Rather, specimens of cement materials are exposed to a pregrown microbial biomass with its associated biologically produced mineral acid (collectively referred to as lixiviant in this report). This method makes it possible to rapidly determine the effects of biological action (MID) on the subject material as if it were being exposed to those natural conditions that promote MID. This is in contrast to other, long-term (12 to 18 months) evaluation methodologies which encourage MID activity by simulating natural conditions. Both accelerated and natural testing procedures provide worthwhile data and their use is dictated by the needs of the testing sponsor.

The laboratory testing program was used to evaluate the MID resistance of two concrete formulations currently under consideration for use at the Yucca Mountain Site. In addition, for comparison purposes, two other specimens based on an ASTM formulation (ASTM, 1990) were included in the evaluation. Specimens used for the testing were the same type emplaced at the field site. They included:

1. ASTM cement formulation.

2. Yucca Mountain concrete formulation $\mathrm{H}$.

3. Yucca Mountain concrete formulation $\mathrm{K}$.

4. ASTM cement formulation with $\mathrm{HgCl}_{2}\left(\mathrm{HgCl}_{2}\right.$ at $\left.200 \mathrm{ppm}\right)$.

Samples of each of the four specimens were exposed to a continuous flow of two different test liquids.

1. Sterilized mineral salts medium (abiotic) used to support growth of the test microorganism. This medium has a $\mathrm{pH}$ of $\sim 3.2$.

2. Lixiviant (biomass and biologically produced sulfuric acid) produced by Thiobacillus thiooxidans grown in the mineral salts medium.

The thiobacilli species was grown in a continuous flow bioreactor. The resulting lixiviant was distributed to contact cells containing the concrete specimens.

Figure 1 provides a schematic of the continuous exposure system. As already mentioned, other specimens were being exposed in a similar manner to a continuous flow of sterile mineral salts medium. Test specimens used in the study were molded $1.8 \mathrm{~cm}$ diameter $\times 2.2$ long $\mathrm{cm}$ (ASTM, ASTM $\mathrm{HgCl}_{2}$ ) cylinders and 
$2.5 \mathrm{~cm}$ diameter $\times 3 \mathrm{~cm}$ long specimens cored from precast $\mathrm{H}$ and $\mathrm{K}$ material. The Yucca Mountain precast (YM) samples were supplied by LلNL while the two types of ASTM formulations were provided by BSI.

Testing was terminated after 61 days. Samples of effluent (spent lixiviants and mineral salts) were collected on a regular basis and analyzed for $\mathrm{pH}$ as well as calcium (Ca), iron ( $\mathrm{Fe}$ ), aluminum ( $\mathrm{Al}$ ), and silica ( $\mathrm{Si}$ ) content. In addition to effluent analysis, the initial and final weights of the specimens were ascertained as were the final surface $\mathrm{pH}$ 's.

$\underline{\text { Results }}$

Field Site

First Visit

Efforts to isolate microorganisms from the various samples have been very successful. Results from the first visit showed that microbes could be found at every sampling location. More importantly, the presence of known MID bacteria was indicated at all locations except Location $2 a$ (catwalk support beam) (Table 1). The occurrence of at least one species of thiobacilli ( $T$. thiooxidans or $T$. ferrooxidans) was confirmed on all the retrieved cored samples. Numbers of these microbes were apparently very low since their presence was only confirmed after enrichment procedures were used. Nitrifying bacteria were not found on the cored samples though enrichment was not attempted for these microbes. Thiobacilli were found on all of the chiseled specimens while nitrifiers were isolated from two of the three samples. For two of the three specimens (locations 2 and 3) T. thiooxidans was present (confirmed with either the enrichment procedure or actual numbers) while $T$. thiooxidans was found by enrichment of the third sample. Surface scraping or biofilm (both nomenclatures were used this visit to refer to surface samples) proved to be rich in both the variety and numbers of MID organisms. T. intermedius, $T$. neapolitanus and $T$. thiooxidans were found with all these samples. T. ferrooxidans was absent. The presence of all the thiobacilli, except $T$. ferrooxidans, was confirmed on concrete retrieved from catwalk location 1a. However, none of these species were recovered from the second catwalk location (2a). No nitrifying bacteria were recovered from either location. The crust sample obtained from above the water line in the moat harbored representatives of all the microbial species except sulfate reducers. On the other hand, the chiseled concrete sample retrieved from the moat had only nitrifiers and heterotrophs present. The bioactivity on the walls appeared to be very dynamic.

At the time of the first sampling, ECNZ personnel indicated that the surface $\mathrm{pH}$ of the interior of the tower wall during operational periods could be as low as $\sim_{1}$. 
(Though there was later information indicating that the $\mathrm{pH}$ values at the sampling location were usually 4 to 4.5 .) When samples were collected $\mathrm{pH}$ determinations were made using $\mathrm{pH}$ sensitive paper tape. The three wall locations where these measurements were taken showed a surface $\mathrm{pH}$ of $\sim 6$. This represented a considerable difference those reported data and these $\mathrm{pH}$ values. Possibly visit values represented variations which are mediated by operational and quiescent conditions.

As part of an initial investigation, a portion of the surface of two of the samples (location 2 concrete core and the moat crust) were examined with environmental scanning electron microscopy (ESEM). This was done to determine if the presence of microorganisms, as confirmed by enumeration techniques, could be substantiated by the visual observance of individual cells and the formation of a biofilm on concrete surfaces. This indeed proved to be so with electron micrographs of some of the specimens showed not only the occurrence of biofilm, but also the presence of attached bacteria (Figures 17 through 23).

\section{Second Visit}

During the second visit, interior photographs (Figures 24 through 28) of the tower during normal operation were obtained. Figure 24 shows sampling activity occurring at Site 2. This photograph highlights the dense, warm mist common in the tower during periods of operation. Figures 25 through 27 show the three wall sampling locations and feature the emplaced cement specimens. A general overview of all three wall locations shows the walls glistening with moisture due to the presence of condensate. Figure 25 shows a close up of sampling Site 1. This view can be compared with photographs taken 11 months previous (Figures 12 and 13). Those photographs show this location during specimen emplacement and detail the features of the wall when dry. Note that Figure 25 provides good evidence of the occurrence of MID as seen by the abundance of exposed aggregate. Compare this surface to that of Site 3 (Figure 27) where the effects of MID are less noticeable. Another perspective of the extent of surface loss at Site 1 is evidenced from the exposure of a plastic rebar spacer (X shaped object in the lower left hand portion of Figure 25) that was emplaced in the wall during construction. As can be seen in this photograph the spacer is easily discernable due to the loss of over $4 \mathrm{~mm}$ of the concrete surface. In areas less affected by MID, these spacers are flush with the surface and their presence is partially obscured.

A close study of the emplaced cement specimens showed that their exposed faces were covered by a thin layer of accumulated material. Examination of this layer showed it to be slimy in nature. The same was also true for specimens at the other two wall locations and at catwalk location 1a (Figures 26, 27 and 28). The surface $\mathrm{pH}$ (as determined by $\mathrm{pH}$ sensitive paper tape) at all three sampling sites was uniform at $\sim 5$. 
Based on data retrieved during the first visit that showed evidence of microbial activity, pieces of the emplaced specimens at each wall site (ASTM, ASTM- $\mathrm{HgCl}_{2}$, and YM Type $\mathrm{H}$ ) were recovered. These specimens were subjected to SEM examination (ESEM analysis was not as useful as had been expected; see Figures 17-23). This effort provided conformation of the presence of biofilm and microorganisms. In contrast to the ESEM examination, high quality micrographs of selected specimens surfaces were obtained (Figures 29 through 36). The ASTM specimen from Site 1 is seen in Figure 29. This surface has numerous interlacing filaments of biofilm as well as cocci and rod shaped bacteria. The morphology of nitrifying bacteria is that of a cocci while thiobacilli are known to be rod shaped. Figures 30 and 31 are of the surface of the Site $1, \mathrm{ASTM}-\mathrm{HgCl}_{2}$ specimen. The results obtained from these micrographs as well as those of the Site 3 specimen, Figure 34, are most interesting. As can be seen their surfaces are covered with rod shaped bacteria. In Figure 30 dividing bacteria, which is proof of the presence of viable cells, can be seen. Figure 31 shows a section of heavy biofilm with bacteria firmly embedded. This micrograph provides a visual image of how microorganisms, protected by a biofilm, could produce individual microsites which allow for coexisting bacteria on concrete. Figure 34 provides a more encompassing view of the Site $3 \mathrm{ASTM}-\mathrm{HgCl}_{2}$ specimen and shows bacteria embedded in biofilm attached to the surface. The presence of microorganisms on the $\mathrm{HgCl}_{2}$ containing specimens was not expected since they were designed to be abiotic controls. These data indicate that either there is not a sufficient quantity of available, leached mercury or the microbes are being protected from its presence, perhaps by the biofilm. Of great interest is the presence of both biofilm and large numbers of bacteria on the YM Type H specimens from all three locations (Figures 32, 33 and 35). These specimens consistently had a more uniform covering of bacteria than those of the other sampled specimens. This is a significant finding since it demonstrates that the surface of this concrete material was sufficiently altered over 11 months to make it suitable for microbial inhabitation. Further it should be noted that habitation occurs not only on the cement matrix of this formulation but also on its aggregate (Figure 36).

To confirm the presence of viable thiobacilli and nitrifying bacteria the collected samples were incubated in selective media. Efforts to isolate these bacteria from the various samples was successful (Table 2). Results for the wall scrapings are given in cells $/ \mathrm{cm}^{2}$ while the other results are presented as cells/g of material. It was apparent that nitrifying bacteria were not only present at every wall site but that they had successfully colonized every emplaced specimen (including both the YM types $\mathrm{H}$ and $\mathrm{K}$ ) at each location. The numbers of nitrifiers on the recovered "chunks" of YM Type H samples ranged from $10^{6}$ at Site 1 to $10^{4}$ at Site 3. Samples obtained by swabbing, while not as definitive as the work with actual material, showed that nitrifiers exist on all of the emplace specimens. 
Numbers and species of thiobacilli associated with various samples (except "chunks") were obtained by using species-isolation methods that differentiate between $T$. neapolitanus and the more acid loving $T$. thiooxidans. The results showed that there were a greater abundance of the $T$. thiooxidans (on average $10^{4} / \mathrm{cm}^{2}$ ) than T. neapolitanus (ranged from nondetectable to $10^{2}$ ) associated with these samples. These data were important because those microorganisms are most often associated with MID.

For the "chunks" a more general method, using enrichment methods, was employed to indicate the presence or absence of $T$. thiooxidans. Using this method the presence of viable T. thiooxidans was confirmed on all three Site 1 samples as well as the YM Type $\mathrm{H}$ emplaced specimens from Sites 2 and 3 . This means that the Type $\mathrm{H}$ specimens from all three sample locations were colonized by thiobacilli.

In addition to examination of retrieved "chunks" swabs were made of each of the emplaced specimens. Results from swabs samples were positive for the presence of both T. thiooxidans and T. neapolitanus. These data confirm those from the chunks and suggests that not all viable thiobacilli cells on the chunks remain active after collection.

\section{Third Visit}

At the time of the third visit high moisture conditions (dense mist) inside the tower prevented obtaining photographs of the sample sites. However, conditions appeared to be similar to those seen in the previous visit. As noted before, the rebar spacer at Site 1 continued to be easily discernable. Measurements at the spacer taken during this visit showed that an estimated $6 \mathrm{~mm}$ of the surface at Site 1 has either been removed or is soft enough to be easily scrapped away (an increase of $2 \mathrm{~cm}$ over the previous visit). At Site 2 nearly $4 \mathrm{~mm}$ of surface material has been lost while at Site 3 only a $2 \mathrm{~mm}$ loss was evident.

Again a close study of the emplaced cement specimens at all sites showed that their exposed faces (both original and new) were covered by the characteristic, thin layer of accumulated material. Examination of this layer again showed it to be slimy in nature. The surface $\mathrm{pH}$ (determined by $\mathrm{pH}$ sensitive paper tape) at all three sampling sites remained at $\sim 5$. However, laboratory analysis of wall scrapping material found these values to be 5.7 at Site $1 ; 6.9$ and 7.0 respectively at Sites 2 and 3 (Table 3).

Cement samples from the third sampling were sent to MSU for SEM examination at the time of collection. These included samples ("chunks") of all the test specimens emplaced at the three sites in the tower. Also, chunks were retrieved from specimens placed at Site $2 \mathrm{a}$ (cat walk location). Only the chunks were 
examined this time since previous work (previous SEM report) had shown that the debris obtained from samples scraped from the wall did not provide a suitable frame of reference (i.e. it was not possible to determine the original orientation of the sample) for distinguishing the portion of the sample's surface that was originally part of the exposed wall surface. Therefore, it was not possible to ensure that surface particles were prepared and examined by SEM. Given the initial evidence of microbial activity, as indicated by the slime covering, and based on past experience, pieces of the recovered emplaced specimens were subjected to SEM examination. The initial SEM effort with these samples did not produce quality data and so the samples were returned for additional examination.

The second examination of the samples by SEM provided much better data. Evidence of microbial activity was found on most of the recovered specimens (ASTM, calcium aluminate [CA], YM Type $\mathrm{H}$, YM Type $\mathrm{K}, \mathrm{ASTM}-\mathrm{HgCl}_{2}$ ) obtained at each of the locations (Figures 37 through 49). Specimens showed the presence of hyphal strands (Figure 37) and individual cocci (characteristic of nitrifying bacteria as well as other types; can be seen in Figures 40 and 42) and rod shaped bacteria (characteristic of thiobacilli as well as others; well defined in Figures 39, 40, 41, 43, 44, and 49). Figure 43 (Type $H$ specimen at Site 3 ) shows rod bacteria actively dividing while in Figure 47 (Type $\mathrm{H}$ specimen at Site 2a) rod bacteria are seen in "chain" formations. Except for the Type $\mathrm{H}$ sample from Site 2, all of the YM samples were shown to have biofilm and a bacterial presence (Figures 41, 43, 44,47 , and 48). The occurrence of bacteria was not uniform for all the sampling sites. All the samples from Sites 1 and $2 a$ had a confirmed presence of biofilm and microorganisms on the examined surfaces (Figures 37 through 40 and 45 through 48). It was noted that Type $\mathrm{H}$ and $\mathrm{K}$ specimens at Site 1 had areas that were densely populated (Figures 38 and 39). At Site 2 the presence of biofilm and bacteria were only detected on the ASTM, Type $\mathrm{K}$ and ASTM- $\mathrm{HgCl}_{2}$ specimens (Figure 41). Activity at Site 3 was found on the ASTM, Type $\mathrm{H}$ and $\mathrm{K}$ samples (Figures 42, 43, and 44).

Once again it was possible by direct observation to confirm the presence of bacteria on samples residing inside of the tower wall. These data together with the those from SEM examinations obtained from earlier samples, present solid evidence that under conditions yet undefined, bacteria will rapidly colonize fresh concrete surfaces (within 11 months) and maintain a presence for an extended period of time (at least 18 months). These SEM images also identify biofilm as one of the key components of an inoculated surface.

The observations from this investigation were most interesting. Of great interest was the presence of both biofilm and large numbers of bacteria on the YM Type $\mathrm{H}$ and $\mathrm{K}$ specimens from all three wall and cat walk locations (Figures 45,47 and 49). These specimens consistently appear to have a uniform covering of bacteria 
and biofilm. Also, based on the SEM examination, it appears that there is more profound bacteria activity at Sites 1 and $2 a$ than at the other two wall sites.

As before, selective media were used to confirm that the presence of bacteria, documented by SEM, could have been viable thiobacilli and nitrifying bacteria. Efforts to isolate these particular bacteria from the various samples was successful (Table 3). Results for the wall scrapings are given in cells/g and cells $/ \mathrm{cm}^{2}$ while the other results are presented as cells/g of material. Duplicate samples processed at two different laboratories confirm the presence of three species of thiobacilli and their numbers at the three sites. T. neapolitanus, T. intermedius and the more acid loving $T$. thiooxidans were isolated from the wall scraping samples. In contrast to data from the second sampling period, there were larger numbers of $T$. neapolitanus $\left(\sim 10^{4}\right.$ to $10^{5}$ cells $\left./ \mathrm{g}\right)$ that $T$. thiooxidans $\left(\sim 10^{3}\right.$ cells $\left./ \mathrm{g}\right)$. Previously, T. neapolitanus ranged from nondetectable to $10^{2}$ at the wall sites with $10^{3}$ to $10^{5}$ cells of $T$. thiooxidans. The occurrence of $T$. intermedius was not determined at that time but the current data showed that $T$. thiooxidans were less abundant than $T$. intermedius.

An intersite comparison of the numbers of thiobacilli showed a noticeable difference of $T$. thiooxidans numbers between the three wall sites. At Site 1 the numbers of this microorganism were nearly the same $\left(10^{5} \mathrm{cell} / \mathrm{s} / \mathrm{g}\right)$ as those of the other two thiobacilli species. However, these numbers decreased at least two order of magnitude at Site 2 and three orders at Site 3 (Table 3) The presence of the other two species did not appear to correlate with site location. As pointed out earlier, physical measurements of wall deterioration at each site showed the occurrence of deterioration to be in the order Site $1>$ Site $2>$ Site 3 . The bacteria occurrence data also correlated well with the $\mathrm{pH}$ of the wall material taken at each site. Those $\mathrm{pHs}$ were 5.7 at Site 1 increasing to 7.0 at Site 3. The lower $\mathrm{pH}$ is indicative of $T$. thiooxidans activity linked to concrete degradation. Because $T$. thiooxidans is thought to be the most aggressive MID microorganism, data on its occurrence and activity could have a bearing on the severity of wall deterioration.

The quantities of nitrifying bacteria at each of the wall sites appeared unaffected by chemical conditions at the locations. They averaged $10^{5} \mathrm{cells} / \mathrm{g}$ (Table 3 ) which indicates that they are well established. These data were of interest because as pointed out previously these microorganisms prefer locations with $\mathrm{pHs}$ in excess of 7. Habitation in specialized niches appears to be one explanation for the anomaly of finding them at lower $\mathrm{pH}$. It was found that high numbers of heterotrophic microorganisms $\left(\sim 10^{8} / \mathrm{g}\right)$ were colonizing the walls at each site. The numbers of these microorganisms are similar to quantities of bacteria found in agricultural soils. Their contribution to MID could be through the production of biofilm which would provide an integrated habitat for all three species of bacteria. 
The $\mathrm{pH}$ determination on $\mathrm{CA}$ and YM Type $\mathrm{K}$ "chunks" retrieved from the emplaced specimens showed that they were much more alkaline than the surrounding wall material $(\mathrm{pH} \geq 10)$ (Table 3 ). This was expected since they were newer, less aged materials. Those composed of the CA formulation were at least a $\mathrm{pH}$ unit higher than the YM Type $\mathrm{K}$ specimens. Species specific enumeration on these samples indicated that most did not support thiobacilli bacteria (Table 3). The exceptions the YM Type H specimen at Site 1 from which $T$. neapolitans, thiooxidans and intermedius were found and the YM Type $\mathrm{K}$ sample at Site 1 supporting T. thiooxidans and intermedius. Also, T. intermedius was found on the Type $\mathrm{K}$ specimen at Site 2. However, no thiobacilli were found on the other samples including the Site 3 specimens. These results were similar to those of the previous sampling (Table 2). On the other hand, nitrifying bacteria in the range of $10^{3}$ to $10^{5}$ were found on all the chunk samples. Heterotrophic bacteria in the range of $10^{6}$ to $10^{7}$ were found on all YM Type $\mathrm{K}$ specimens (the two types of ASTM and YM Type $H$ samples were not analyzed) with the larger number being at Sites 1 and 2.

Analyses of "Swab" samples taken from the emplaced samples were conducted for the enumeration of T. neaploitanus and thiooxidans as well as nitrifying bacteria (Table 3). Samples were collected from both "old" and "new" exposed surfaces. As was explained in the section on sampling, swab samples were taken from the face of each of the emplaced specimens. It was pointed out that during the previous sampling (September/October, 1994) a portion of the face (1/2) of the ASTM control, YM Type $\mathrm{H}$, and $\mathrm{ASTMHgCl}$ at each site had been removed. Because of that, these specimens had both an old (original) surface and a new surface. Both of these surfaces were swabbed so a determination on microbial population could be made between the old and new habitats. Isolation data from these samples were much more definitive than those of the chunks. They showed that there was a greater abundance of thiobacilli than suggested by that analysis. Thiobacilli were found at all the sites with the order of abundance being Site $1>$ Site $2>$ Site 3. All the samples retrieved from Site 1, except the ASTM- $\mathrm{HgCl}_{8}$ o, had both species of thiobacilli. T. thiooxidans was inhabiting all the specimen surfaces at Site 2 except the YM Type $\mathrm{Ko}$ and the ASTM- $\mathrm{HgCl}_{8} \mathrm{o}$. This microorganism was only found on the ASTM and ASTM- $\mathrm{HgCl}_{8}$ surfaces at Site 3 . Overall, the numbers of $T$. thiooxidans was greater than those of $T$. intermedius. This was interesting since the elevated $\mathrm{pH}$ of the samples should have been more conducive for the growth of the alkaline tolerate T. intermedius. Again it seemed that the bacteria were protected from the alkaline environment due to specific niches. There appeared to be no correlation between microbial occurrence or numbers between the old and fresh surfaces. That means that the new surfaces became suitable for thiobacilli growth within at least six months (the period of time between the previous sampling and this one). In the case of these samples specimen surface $\mathrm{pH}$ had no correlation with bacterial numbers. This again confirms the need of understanding the significance of microniches. 
The numbers of nitrifying bacteria isolated from the swab samples were consistent with those of the chunks. Why there is a description between the thiobacilli data of the two sample sets is open to speculation. It is possible sample preservation could have played a part though this explanation is not entirely satisfactorily because of the success in recovering nitrifying bacteria. A more plausible answer is an apparent difficulty in dislodging the thiobacilli from surface of the chunk samples.

\section{Accelerated Laboratory Study}

Six sets of pictures (Figures 50 through 55) of the ASTM controls and the YM formulation specimens after 1,29, and 61 days of exposure to sterile medium (control) and lixiviant (treatment) are provided. Figures 50 through 53 show the immersed specimens in their contact cells on Days 1 and 29 while Figures 54 and 55 display the specimens after they had been removed from the contact cells on Day 61. Figures 50, 52, and 54 are of those specimens exposed to the sterile media while Figures 51,53 , and 55 show the specimens at various times during their exposure to the $T$. thiooxidans lixiviant. The specimens are arranged by formulation with the first being the ASTM cement followed by YM types $\mathrm{H}$ and $\mathrm{K}$ and the ASTM cement containing $\mathrm{Hg}$ (the red color of these specimens is the result of a food dye used for identification purposes).

A comparison of the control (Figure 52) and treatment (Figure 53) show that by Day 29 there were obvious physical effects caused by the lixiviant. The lixiviant treated specimens had begun to loose their sharply defined features as compared to the controls. Characteristically, the ASTM specimen had become very light in color (attributed to loss of cement paste with consequential exposure of quartz sand). The surface of the YM specimens appeared to have been slightly effected (increased roughness) with some loss of material (small pieces laying on the bottom of the contact cell). There appeared to be little physical difference between the Type $\mathrm{H}$ and $\mathrm{K}$ specimens. The white covering seen on the surface of the ASTM formulations exposed to media was due to precipitation of salts.

By Day 61 all the specimens in contact with the lixiviant showed significant signs of deterioration. The effect on the ASTM formulation was as expected (i.e. extensive disintegration; Figures 55a and 55d). The YM samples were not as disintegrated though spalling had occurred and the loss of cement matrix and aggregate were apparent (Figures 55b and 55c). It was also noted that the embedded aggregate in these specimens was beginning to stand proud. Finally, all formulations exposed to the sterile medium, and in particular the YM specimens, showed no visual evidence of degradation (Figure 54).

Effluents from the test cells were collected weekly. These liquids were stored prior to ICP analysis for $\mathrm{Ca}, \mathrm{Fe}, \mathrm{Al}$, and $\mathrm{Si}$ content. All these data were first 
normalized (i.e. $\mathrm{ppm}$ element $\mathrm{x}$ collected volume $=$ total $\mathrm{mg}$ element per collection period) then a total, corrected value (element content in unexposed mineral salts medium was subtracted from the corresponding treatment and control) of the quantity of leached elements was calculated. The final values are found in Table 4.

In general, as seen in Table 4 leaching of all the elements was significantly increased, in comparison to that of the sterile media, when the specimen formulations were exposed to the $T$. thiooxidans lixiviant. The element removed in the greatest quantity by both treatments was $\mathrm{Ca}$. In the presence of the thiobacilli treatment both ASTM formulations lost in excess of $530 \mathrm{mg}$ Ca while for the YM specimens this amount was nearer $330 \mathrm{mg}$. Data from the sterile media controls showed that the ASTM specimens lost slightly less Ca than the YM formulations (93 and $94 \mathrm{mg}$ verses 100 and $134 \mathrm{mg}$ ). Past experience has shown that the increased loss of $\mathrm{Ca}$ due to thiobacilli lixiviant exposure is evidence of cement matrix dissolution. Therefore, it appears that the greater loss of $\mathrm{Ca}$ by the ASTM specimens correlates with the significantly greater loss of mass.

There was no loss of $\mathrm{Fe}$ from any specimen exposed to the sterile medium and for all practical purposes the same was true for Al. When exposed to thiobacilli lixiviant, loss from the ATSM formulations was nearly the same, 11 and $14 \mathrm{mg}$ respectively. However, a difference was noted between the YM specimens with more $\mathrm{Fe}$ loss associated with Type $\mathrm{H}$. Again the same was true for Al losses. As with $\mathrm{Ca}, \mathrm{Si}$ was leached from all the specimens by the sterile medium and thiobacilli lixiviant. As expected there was a significantly increased loss of Si due to exposure to thiobacilli lixiviant. Loss of Si from the ASTM formulations was comparable ( 49 and $40 \mathrm{mg}$ ) while that of the Type $H$ formulation was about twice the Type $K$ ( 41 verses $23 \mathrm{mg}$ ).

A further refinement of the leach data was made by subtracting the value for the control treatment from that of the corresponding thiobacilli data. This made it possible to isolate the effect of the thiobacilli activity. Using these data, the individual cumulative leach curves for each element, based on specimen type, were plotted. They are displayed in Figures 36 through 39. Because actual concentrations of each element in the original formulated specimen were not known, percent loss could not be calculated. Therefore, all data are presented in absolute quantities (mg). It can be seen from these figures that the trends for element loss, depending on treatment and specimen, follow those previously described. From these data it appears that there was still active leaching of $\mathrm{Al}$, $\mathrm{Fe}$, and $\mathrm{Si}$ when the study was terminated (Figure 56, 58, and 59). However, the rate of $\mathrm{Ca}$ leaching decreased some 15 days before termination (Figure 57 ).

\section{Discussion}


This project was initiated in FY-1994. During the intervening time period a field evaluation site at a natural laboratory has been established and initial laboratory testing has been completed. To date, project results have been presented in six interim reports.

Data produced by this project support the growing awareness that, in spite of precautions, biotic factors could effect the integrity of cementateous repository materials. For example, before the cooling tower used for the field study was constructed, ECNZ conducted several studies to select appropriate construction materials. Data from these studies was used to estimate structural effects due to known environmental conditions. The testing program included: (1) Using a corrosion test rig to expose concrete test specimens to condensate from an Ohaaki geothermal, steam bore hole; (2) Laboratory test studies which exposed concrete prisms and mortar bars containing various cement types, cement contents, admixture types and pozzolan to chemically aggressive solutions; and (3) Construction of a concrete test wall to assess various construction practices. Evaluation of test results lead to the conclusion that the inclusion of a pozzolan material into the cement mixture would significantly reduce sulphate-induced expansion and swelling associated with acid attack. The pozzolan specified for the concrete mix was a naturally occurring pumicite with a specific surface greater than $600 \mathrm{~m}^{2} / \mathrm{Kg}$. The high specific surface was found to reduce expansion by reacting with more free lime so that less was available for reaction with sulphate solutions. Pozzolans were also believed to reduce expansion by acting as poreclogging materials, thus reducing the permeability of the concrete. A final mixture of $375 \mathrm{Kg} / \mathrm{m}^{3}$ cement with $75 \mathrm{Kg} / \mathrm{m}^{3}$ of ground pumicite was used for tower construction.

The reason for precaution was due to the dual use of the tower. It was designed so that non-condenstable gases could be introduced into the tower through venting into the steam generated during the process of cooling hot condensate water. Gas injection into the steam plume can be at a maximum rate of $40 \mathrm{t} / \mathrm{h}$. The composition of this gas stream is predominately $\mathrm{CO}_{2}$ (by a factor of $10^{2}$ ). Concentration of $\mathrm{H}_{2} \mathrm{~S}$ and $\mathrm{NH}_{3}$ in the stream were not available for this report. However, it is estimated that the concentrations of $\mathrm{H}_{2} \mathrm{~S}$ and $\mathrm{NH}_{3}$ from the evaporated condensate water could be 0.5 to $1.5 \mathrm{mg} / \mathrm{L}$ in a $300-400 \mathrm{t} / \mathrm{h}$ steam plume. Whether these gas contact the tower wall is not known. The injection system was designed to minimize any contact. At the point of injection the temperature of the gas stream is near $140 \mathrm{C}$. It is assumed that because of the thermal lift of the gases $(12 \mathrm{~m} / \mathrm{s})$ they form a singular column with little or no mixing with the surrounding steam plume.

In spite of the above "engineered" precautions, MID has challenged the integrity of the Ohaaki concrete and if left untreated could challenge the structural integrity of the tower. BSI has now confirmed what ECNZ suspected. To date a total of 
176 samples have been collected and analyzed for the presence of MID microorganisms. Results from examination of those samples has clearly demonstrated that the tower concrete have been inhabited, in abundance, by a variety of microorganisms known to promote MID of concrete. Several species of thiobacilli together with nitrifying and heterotrophic bacteria and fungi, were isolated from the samples. The numbers of microorganisms within each of these populations are dynamic.

This project has progressed to the point that some first approximations of the involvement of MID at various tower locations can be made. Data are now showing that there is a gradation of MID effects at the three sampling sites within the tower. This is fortunate since additional investigations can use these three environments for a side by side comparison. This will aid in the understanding of MID initiation and persistence. Also, other information that will help will be background data obtained from the chemical/physical examination of the environment at the sites. This will include data on temperature regimes and the concentrations of key elements such as reduced sulfur and nitrogen.

In general, data have been obtained that show several species of thiobacilli ( $T$. intermedius, T. neapolitanus, T. thiooxidans, and T. ferrooxidans), together with nitrifying and heterotrophic bacteria and fungi, inhabit the concrete environment of the tower. These data are providing an interesting commentary on the coexistence of the various species of microorganisms that appears to be at odds with the text book example of how MID of concrete is established and promoted. Based on microbial physiology, the cohabitation of a concrete surface by $T$. thiooxidans and $T$. ferroxidans with nitrifying bacteria should not occur. The two thiobacilli require a surface $\mathrm{pH}$ of 2 or less to exist while the nitrifiers must be in surroundings ranging between $\mathrm{pH} 6$ and 8.5 to live. In addition, it was not understood how the other thiobacilli ( $T$. intermedius and $T$. neapolitanus), which require an environment with an elevated $\mathrm{pH}$, are able to survive under conditions thought suitable only for acidophilic species. Clearly, the presence of such a variety of microorganisms indicates that there are multiple, distinctly different microhabitats present on the concrete surface. It is likely that these individual niches are shielded from detrimental influences by protective biofilms. This supports the hypothesis that observed deterioration of the tower concrete is a biological response to a MID conducive environment.

As can be seen, this study is laying the ground work for understanding the initiation of MID and its continuation on existing and fresh concrete surfaces. First, as already pointed out, the work is providing data on the existing MID activity at the Ohaaki cooling tower. Ongoing production of baseline data will aid in understanding the cause and progression of MID. Next, and perhaps more important to the YMSCP, are the data clearly showing that the MID consortium of thiobacilli and nitrifying bacteria can be established on fresh concrete and that the 
concrete formulations colonized include those proposed for use at the Yucca Mountain site. Habitation on YM samples occurred within 11 months. These data point out that the process of MID initiation on fresh YM concrete formations occurred faster that was expected.

As expected, data at this time indicate that thiobacilli are among the active contributors of MID at Ohaaki. It is suspected that they are being supported by a source of reduced sulfur originating from $\mathrm{H}_{2} \mathrm{~S}$ emissions into the tower atmosphere. On the other hand, the importance of the nitrifying bacteria as well as the source of reduced nitrogen can only be hypothesized. Earlier it was thought that the occurrence of these bacteria at the cat walk level of the tower might only be the result of contamination due to the presence nitrifiers in downward flowing condensate. As for the source of reduced nitrogen used by these bacteria it was speculated be produced by cyanobacteria established in the upper, sun lit areas of the tower. These organisms are known to fix free atmospheric $\mathrm{N}_{2}$ by reducing it to ammonia.

The above hypothesis is interesting, but its explanation for the source of reduced nitrogen it is not supported by literature on biological nitrogen fixation. While a substantial population of cyanobacteria is capable of fixing copious quantities of $\mathrm{N}_{2}$ it appears that the system is very tight and allows for little or no leakage of the reduced nitrogen. The product ammonia is retained by the nitrogen fixing cell through the formation of glutamine. One consequence of this reaction is that ammonia is only rarely released by healthy cells (Smith, 1983). It appears that a further investigation will be necessary before the source of nitrogen driving the activity of nitrifying bacteria can be established.

Additional data supporting evidence that MID can effect the YM concrete formulation has come from laboratory work. Using accelerated methods it has been shown that changes in appearance of treated material, together with the loss of primary elements ( $\mathrm{Ca}, \mathrm{Al}, \mathrm{Si}, \mathrm{Fe}$ ), can be correlated with exposure to the $T$. thiooxidans lixiviant. Further, there is evidence that these changes lead to the dissolution of the cement matrix and subsequent deterioration of the tested cementatious specimens.

It was found that uniform leaching of elements over time resulted in the eventual exhaustion of available $\mathrm{Ca}$. Interestingly, there was less $\mathrm{Al}$ and $\mathrm{Si}$ lost from the YM Type $\mathrm{K}$ specimen compared to Type $\mathrm{H}$ sample. It is not known whether this was due to the integrity of the $\mathrm{K}$ specimen or if it was a consequence of the specimen formulation (less content of these elements). Also the accelerated study showed that the presence of $\mathrm{HgCl}_{2}$ in a specimen did little to retard the degradation process. This indicated that if secondary microbial activity was occurring and did supplement the action of the lixiviant, the antimicrobial action of the $\mathrm{Hg}$ was not effective. 
Data obtained from both the field and laboratory work present a compelling case for continuation of the natural laboratory work. To confirm the results of the accelerated study, specimens of the same formulations evaluated in that test have been emplaced into the tower wall. Now that it is known that the YM

formulations can be damaged by MID it is essential that the fate of this material, under a naturally occurring MID environment, be routinely monitored. The work described in this project should make it possible to determine the most effective means of investigating and identifying the cause and effects of MID. The aim of this project is to produce information that will ultimately allow data on microbial mediated reactions to be integrated into the existing YM abiotic geochemical modeling frame work. Such data will include surface reactions promoted by MID and what affects the rate of these reactions. From this effort bounding conditions will be determined and used to predict the long-term consequences of MID in repository setting.

\section{Conclusions}

Results from this study are confirming that the Ohaaki cooling tower is an excellent choice for examining the development of MID of concrete under natural conditions. Data obtained from SEM micrographs, and selective as well as general isolation methods show that there is a consortium of MID promoting thiobacilli and nitrifying bacteria actively growing at three sampling sites established in the tower. These data show that bacterial species found in the wall consortium have also established themselves on the emplaced, concrete specimens. Of particular importance to the YMSCP is the consistent colonization, under natural conditions, of the YM Type $\mathrm{H}$ and $\mathrm{K}$ concrete specimens. There have been conclusive data obtained which document that these surfaces were inhabited by MID microorganisms within 11 months of exposure. These data not only demonstrated that active MID biota existed on the tower wall but that it was possible for these microbes to rapidly inoculate fresh, unweathered concrete surfaces. This means that the process of MID initiation on exposed, fresh YM concrete formations occurred faster that was previously expected.

Continued study of the consortium of bacteria that inhabit the wall and the subsequent colonization of the fresh surfaces provided on the emplaced specimens will help answer questions surrounding the natural development MID. For example, there have been conclusive data obtained which document that fresh surfaces were inhabited by MID microorganisms within 11 months of exposure. These data not only document that active MID biota existed on the tower wall but that it was possible for these microbes to rapidly inoculate fresh, unweathered concrete surfaces. This means that the process of MID initiation on exposed, fresh YM concrete formations occurred faster that was previously expected. Such information should have a direct bearing on developing a consciences opinion on whether the effects of MID will be of any long-term consequence at Yucca Mountain. 
In spite of these accomplishments, after 18 months the ground work for understanding the initiation of MID and its continuation on existing and fresh concrete surfaces is still developing. Ongoing production of baseline data can only provide one part of the data required to provide an understanding of the cause and progression of MID. Other pieces of the MID puzzle will come from gaining an understanding of the favorable MID environment provided by the tower. This includes obtaining a better understanding of the cycling of energetic compounds (reduced nitrogen and sulfur but in particular sulfur) at the tower and in exterior environs. It will also be necessary to be able to understand more fully the action of the microhabitats that provide the niches that must be present to protect microorganisms and allow them to exist under a harsh environment.

Data from past field activities together with those from accelerated laboratory testing studies, confirming that $\mathrm{YM}$ type $\mathrm{H}$ and $\mathrm{K}$ formulations are susceptible to MID attack, are most disturbing. While a degradation rate has not been established for YM specimens, data from accelerated testing of a variety of other concrete formulations demonstrate the relevance of these results. Further, it has been suggested that the results after a 60 day accelerated test are an indicator of what will happen to concrete within two years after MID has been initiated and sustained by favorable conditions.

Data are confirming that there is a gradation of MID effects at the three sampling sites within the tower. This is fortunate since additional investigations of the three environments associated with these sites will provide comparable data which will help in the understanding of MID initiation and persistence. Part of the information that will help this process will be background data obtained from the chemical/physical examination of the environment at the sites. This will provide data on temperature regimes and the concentrations of key elements such as reduced sulfur and nitrogen. These data prove that conditions known to promote MID can be established on at least one YMP concrete formulation. The results, therefore, justify continued baseline observations of the effects of MID on the Ohaaki tower structure, developing an understanding of the environment conditions that initiate and promote MID, and continued study of the development and effects of MID on the emplaced specimens.

\section{Recommendations}

The ECNZ experience has direct application to the effort being put forth for the planning and evaluation phase of the YMP. It is advisable that the YMP planning program include a task to evaluate the possible impact of MID. This task should have several subtasks including, but not limited to: 1) A study to determine if concrete used in the YMP is susceptible to the effects of MID;2) Developing an understanding of what conditions promote and sustain the development of MID on massive concrete structures (i.e. types of bacteria, chemical compounds that act as accelerators for proliferation, conductive environments); 3) A determination of whether MID can occur in the environment created by Yucca Mountain 
construction; 4) Understanding what preventative steps should be taken during construction at Yucca Mountain; and 5) Conduct baseline studies at sites already experiencing the effects of MID for the purpose of gaining a better understanding of MID processes under actual environmental conditions.

Given the importance results of the work to date, the cooling tower study should be extended for an indefinite time period. Doing so will give us the opportunity to determine the rate of MID that occurs under the natural, conducive conditions provided by the tower environment. Further study will allow us to develop an understanding of the conditions that are conducive to MID initiation and promotion. While this subject relates to studies and funding levels that will be proposed for the next budget cycle it should be pointed out that preliminary work in this area has already been initiated. The NZ IGNS has been requested to begin work to investigatethe origin and quantities of reduced forms of sulfur and nitrogen at Ohaaki. While it is known that there are sufficient quantities of these compounds available to promote MID, quantities in ambient air and condensate as well as source term data are lacking. Additional baseline work will aid in developing an understanding of the composition and microbial availability of sulfur and nitrogen compounds inside the cooling tower environment. A partial list of tasks which will compliment the ongoing work and will serve as priorities for the program include:

1. Continue biannual sampling to determine microbial numbers and locations

2. Determine the quantities of nitrogen and sulfur species in water being fed into the cooling tower, i.e. water from the hot well, as well as water collected in the moat below the cooling tower. Determine the $\mathrm{pH}$ of all water samples.

3. Collect condensed water vapor (mist) inside the cooling tower which arises as a result of the evaporative cooling of the hot well water. Sampling locations should be near the center of the tower (underneath the gas disbursal unit) and near the three wall sampling sites. Samples should be collected at both the catwalk elevation and at the highest elevation that can be accessed. Analysis samples for species of nitrogen and sulfur and $\mathrm{pH}$.

4. Collect air samples at those locations described above and analyze for gaseous species of nitrogen and sulfur.

5. Collect condensate samples from the walls at the three wall sampling sites and analyze for species of nitrogen and sulfur. Determine the $\mathrm{pH}$ of these samples.

6. Determine the rate of flow of condensate water down the wall at the three wall sampling locations. 
7. Collect scrapings of wall surface material from each of the three sampling locations for nonbiological processing. Analysis for both soluble and total elements should include $\mathrm{Ca}, \mathrm{Al}, \mathrm{Fe}, \mathrm{Si}$, nitrogen and sulfur compounds.

If, after further investigation, a decision is made that biocide application in the tower renders it unacceptable for continued study then another location in this MID rich area will be utilized. For example other concrete structures such as silencers may be suitable. Such a structure would provide elevated temperatures which will simulate the YM facility which is expected to get up to $200 \mathrm{C}$.

There should be a study following the biological fate of sulfur at Ohaaki. Perhaps the most worthwhile way of doing that will be to investigate the sulfur cycling in near by thermal lakes which are rich with species of sulfur and have a variety of temperature gradients. Specation of sulfur and gases in selected lakes is being conducted by Dr. Christenson at the New Zealand IGNS and he has expressed an interest in cooperating with BSI so IGNS can include a biotic component in their studies. This would provide an opportunity to look for the presence of thermophilic thiobacilli (those thiobacilli which can live at temperatures in excess of $35 \mathrm{C}$ ) which could thrive at temperatures provided by the waste at YM. Such a study would be multi-year.

Another benefit of the lake work would be the opportunity of using them as natural, accelerated testing facilities. Such studies would be similar to that conducted by BSI under laboratory conditions during 1994. However, a lake would allow for the study to be conducted with native thiobacilli growing under natural conditions. In addition, the studies could be conducted under a range of temperatures due to the thermal gradient found in several lakes. Such a study would fit well into YMP plans to have concrete specimens placed in select NZ lakes. With the assistance of BSI, these planned efforts could be organized to produce bounding data. This would be accomplished by examining specimens before, during, and after their exposure to ascertain evidence of microbial growth (isolation and SEM) and resulting MID damage. Also, simultaneous chemical data, as previously described, could be retrieved by IGNS. They have extensive experience in collecting data from sulphur rich lakes.

There is also a need to initiate long-term, meaningful laboratory work that will document the rate of MID progression over time. Such work should be conducted in environmentally controlled chambers. These controlled conditions will provide an opportunity to carefully measure the initiation, propagation, and continuation of the MID process. In contrast to the accelerated studies conducted at the lake sites, these studies would be conducted under near natural conditions and will, therefore, have to be long-term in nature (perhaps one to two years). These instrumented studies will be used to examine activities on a microscale, i.e. $\mathrm{pH}$, temperature, cation and anion release, biofilm production, etc., and thus will 
provide a wealth of physical and chemical data which can be used to determine MID bounding conditions. Also, it will be possible to factor in the effects of a natural consortium of MID microorganisms, much like those found at the Ohaaki site. Precut, precisely measured (thickness), concrete slabs would be used. These specimens will be polished so that any deterioration will be easily detected. In addition they will be prescored so individual samples can be cleanly broken off for chemical and physical analysis as well as SEM examination. Specimens could also be provided to LLNL for them to conduct measurements to determine depth of activity penetration and AFI could be conducted.

There should be an in situ test carried out at the YM site. This can be done through the fabrication and instillation of MID promoting test cells These cells once attached directly to the tunnel (rock) and concrete surfaces, will maintain an environment conducive to MID development. Once the process is initiated it will be possible to observe first hand the affects of MID in an actual repository setting.

\section{Literature Cited}

ASTM, 1990. Standard Test Methods of Compressive Strength of Hydraulic Cement Mortar. ASTM C109-90. 1990 Annual Book of ASTM Standards.

Milde, K., W. Sand, W. Wolff, E. Bock. 1983. Thiobacilli of the corroded concrete walls of the Hamburg sewer system. J. Gen. Microb. 129:1327-1333.

Schmidt, E. L., L. W. Belser. 1982. Nitrifying Bacteria. in Methods of Soil Analysis, Part 2, Chemical and Microbiological Properties. Chapter 48,p. 10271042. Agronomy Monograph No. 9. ASA-SSSA, Madison, WI. 
Table 1. Types and numbers of microorganisms isolated from Ohaaki cooling tower:

First visit.

\begin{tabular}{|c|c|c|c|c|c|c|c|c|c|}
\hline Sample & $\begin{array}{l}\text { Thiobacillus } \\
\text { intermedius }\end{array}$ & $\begin{array}{l}\text { Thiobacillus } \\
\text { neapolitanus }\end{array}$ & $\begin{array}{l}\text { Thiobacillus } \\
\text { thiooxidans }\end{array}$ & $\begin{array}{l}\text { Thiobacillus } \\
\text { ferrooxidans }\end{array}$ & $\begin{array}{l}\text { sulfate } \\
\text { reducers }\end{array}$ & $\begin{array}{l}\text { ammonin } \\
\text { oxidizers }\end{array}$ & $\begin{array}{l}\text { nitrite } \\
\text { oxidizers }\end{array}$ & chemoorganotrophs & fungl \\
\hline $\begin{array}{l}\text { location } 1 \\
\text { cement core }\end{array}$ & b.d.ab & b.d.ab & b.d.ab+e & $\therefore$ & $\therefore$ & b.d.ab, na" & b.d.ab, net & $>10^{6}$ & $6 \times 10^{\circ}$ \\
\hline $\begin{array}{l}\text { location } 1 \\
\text { chiseled }\end{array}$ & b.d. & b.d. & b.d., - & + & - & b.d., b.d. & b.d., $4 \times 10^{4}$ & $1 \times 10^{4}$ & $1 \times 10^{4}$ \\
\hline $\begin{array}{l}\text { location } 1 \\
\text { surface }\end{array}$ & $6 \times 10^{7}$ & $6 \times 10^{8}$ & $1 \times 10^{3},+$ & - & - & $3 \times 10^{4}, 1 \times 10^{4}$ & $2 \times 10^{5},>3 \times 10^{5}$ & $>10^{\circ}$ & $5 \times 10^{7}$ \\
\hline $\begin{array}{l}\text { location } 2 \\
\text { cement core }\end{array}$ & b.d. & b.d. & b.d.,t & - & - & b.d., na & b.d., $\mathrm{na}$ & $3 \times 10^{3}$ & b.d. \\
\hline $\begin{array}{l}\text { location } 2 \\
\text { chiscled }\end{array}$ & b.d. & b.d. & b.d., + & - & + & b.d., $\mathrm{na}$ & b.d., $\mathrm{na}$ & $3 \times 10^{5}$ & $1 \times 10^{5}$ \\
\hline $\begin{array}{l}\text { location } 2 \\
\text { biofilm }\end{array}$ & $4 \times 10^{3}$ & $4 \times 10^{3}$ & $2 \times 10^{4},+$ & - & - & $7 \times 10^{4}, 5 \times 10^{4}$ & $2 \times 10^{6},>3 \times 10^{5}$ & $2 \times 10^{7}$ & $2 \times 10^{7}$ \\
\hline $\begin{array}{l}\text { location } 3 \\
\text { cement core }\end{array}$ & b.d. & b.d. & b.d.. - & + & - & b.d., na & b.d., $\mathrm{ma}$ & $6 \times 10^{3}$ & $1 \times 10^{3}$ \\
\hline $\begin{array}{l}\text { location } 3 \\
\text { chiseled }\end{array}$ & b.d. & $8,6 \times 10^{1}$ & $2 \times 10^{\prime},-$ & - & - & $2 \times 10^{\prime}, \mathrm{na}$ & b.d., $\mathrm{ne}$ & $1 \times 10^{\prime}$ & $1 \times 10^{8}$ \\
\hline $\begin{array}{l}\text { location } 3 \\
\text { biofllm }\end{array}$ & $>2 \times 10^{6}$ & $2 \times 10^{8}$ & $4 \times 10^{5},+$ & - & - & $4 \times 10^{9}, 1 \times 10^{5}$ & $2 \times 10^{6},>4 \times 10^{5}$ & $4 \times 10^{7}$ & $4 \times 10^{7}$ \\
\hline $\begin{array}{l}\text { location le } \\
\text { suppont of catwalk }\end{array}$ & $5 \times 10^{3}$ & $3 \times 10^{2}$ & $5 \times 10^{2}, n a^{6}$ & na & - & b.d., ne & b.d, $\mathrm{ma}$ & $1 \times 10^{6}$ & $1 \times 10^{5}$ \\
\hline $\begin{array}{l}\text { location } 2 a \\
\text { support of catwalk }\end{array}$ & b.d. & b.d. & b.d, $\mathrm{na}$ & na & - & b.d., $\mathrm{na}$ & b.d, na & $1 \times 10^{4}$ & $2 \times 10^{4}$ \\
\hline moat cement crust & $9 \times 10^{3}$ & $9 \times 10^{5}$ & $5 \times 10^{3},+$ & + & . & $5 \times 10^{\circ}, \mathrm{nz}$ & $>2 \times 10^{6}, \mathrm{na}$ & $>10^{\circ}$ & $>10^{\circ}$ \\
\hline $\begin{array}{l}\text { moat cement } \\
\text { chiseled chip }\end{array}$ & b.d. & b.d. & b.d., - & - & - & $4 \times 10^{4}$, b.d. & $>2 \times 10^{\circ}, 5 \times 10^{1}$ & $1 \times 10^{4}$ & $1 \times 10^{2}$ \\
\hline
\end{tabular}

2. Results from the laboratory of Dr. Wolfgang Sands

b. Results presented as number of cells per gram sample, bd = below detection limit

c. Results from the laboratory of Dr. Robert Rogers at INEL, + indicates presence, - indicates absence of specific microbes

d. Sample not analyzed

e. Results from the laboratory of Dr. Robert Rogers at MSU 
Table 2: Types and numbers of microorganisms isolated from Ohaaki cooling tower: Second visit.

\begin{tabular}{|c|c|c|c|}
\hline Sample Type & \multicolumn{3}{|c|}{ Microbial Numbers } \\
\hline Wall Scraping \# cells $/ \mathrm{cm}^{2}$ & T. neapolitanus & T. thiooxidans & ammonia oxidizers \\
\hline Site 1-A & $\mathrm{nd}^{\mathrm{a}}$ & $2.5 \times 10^{4}$ & $7.9 \times 10^{5}$ \\
\hline Site 1-B & $7 \times 10^{2}$ & $4.0 \times 10^{4}$ & $1.7 \times 10^{6}$ \\
\hline Site 2-A & nd & $1.7 \times 10^{5}$ & $5.4 \times 10^{7}$ \\
\hline Site 2-B & $3.8 \times 10^{1}$ & $1.7 \times 10^{3}$ & $5.4 \times 10^{7}$ \\
\hline Site 3-A & $1.6 \times 10^{1}$ & $1.2 \times 10^{4}$ & $2.2 \times 10^{6}$ \\
\hline Site 3-B & $1.2 \times 10^{2}$ & $1.6 \times 10^{3}$ & $1.3 \times 10^{5}$ \\
\hline \multicolumn{4}{|l|}{ Chunks \# cells/g } \\
\hline Site 1 ASTM & & + & $\geq 2.4 \times 10^{6}$ \\
\hline Site 1 ASTM $\mathrm{HgCl}_{2}$ & & + & $3.5 \times 10^{5}$ \\
\hline Site 1 YM H & & + & $\geq 2.4 \times 10^{6}$ \\
\hline Site 2 ASTM & & - & $1.4 \times 10^{3}$ \\
\hline Site $2 \mathrm{ASTM} \mathrm{HgCl}_{2}$ & & - & $2.3 \times 10^{2}$ \\
\hline Site $2 \mathrm{YM} \mathrm{H}$ & & + & $2.4 \times 10^{5}$ \\
\hline Site 3 ASTM & & - & $2.2 \times 10^{3}$ \\
\hline Site 3 ASTM $\mathrm{HgCl}_{2}$ & & - & $2.3 \times 10^{2}$ \\
\hline Site 3 YM H & & + & $1.7 \times 10^{4}$ \\
\hline \multicolumn{4}{|l|}{ Swabs \# cells/swab } \\
\hline Site 1 - 1 & $t^{b}$ & $t^{b}$ & $\geq 2.4 \times 10^{4}$ \\
\hline Site $1-2$ & $t^{\circ}$ & $t^{b}$ & $\geq 2.4 \times 10^{4}$ \\
\hline Site 1 - 3 & $t^{b}$ & $t^{b}$ & $\geq 2.4 \times 10^{4}$ \\
\hline Site 1 - 4 & $t^{b}$ & $t^{b}$ & $3.5 \times 10^{3}$ \\
\hline Site 1 - 5 & $+t^{b}$ & $t^{b}$ & $1.7 \times 10^{3}$ \\
\hline Site 2 - 1 & $t^{b}$ & $t^{b}$ & $\geq 2.4 \times 10^{4}$ \\
\hline Site 2 - 2 & $t^{b}$ & $t^{b}$ & $\geq 2.4 \times 10^{4}$ \\
\hline Site 2 - 3 & $t^{b}$ & $t^{b}$ & $2.4 \times 10^{3}$ \\
\hline Site $2-4$ & $t^{b}$ & $t^{b}$ & $2.4 \times 10^{9}$ \\
\hline Site 2.5 & $+b$ & $t^{b}$ & $\geq 2.4 \times 10^{4}$ \\
\hline Site $3 \cdot 1$ & $t^{b}$ & $t^{b}$ & $1.6 \times 10^{4}$ \\
\hline Site 3 - 2 & $t^{b}$ & $t^{b}$ & $\geq 2.4 \times 10^{4}$ \\
\hline Site $3-3$ & $t^{b}$ & $t^{b}$ & $2.4 \times 10^{3}$ \\
\hline Site 3.4 & $t^{b}$ & $t^{b}$ & $4.1 \times 10^{2}$ \\
\hline Site 3.5 & $t^{b}$ & $t^{b}$ & $\geq 2.4 \times 10^{4}$ \\
\hline
\end{tabular}

a. ND indicates microorganisms not detected b. required a 30 day period of enrichment 
Table 3. Types and numbers of microorganisms isolated from Ohaaki cooling tower: Third visit

\begin{tabular}{|c|c|c|c|c|c|c|}
\hline Sample Type & $\mathrm{pH}$ & & Microbial No. & & & \\
\hline $\begin{array}{l}\text { Wall Scraping } \\
\text { \# cells } / \mathrm{g}\left(\# \text { cells } / \mathrm{cm}^{2}\right)\end{array}$ & & T. neapolitanus & T. thiooxidans & T. intermedius & $\begin{array}{l}\text { Ammonia } \\
\text { Oxidizers }\end{array}$ & $\begin{array}{l}\text { Hetero - } \\
\text { trophs }\end{array}$ \\
\hline Sịte 1 & $5.7^{a}$ & $\begin{array}{l}3.3 \times 10^{5 b} \\
\left(3.2 \times 10^{5 b}\right) \\
\end{array}$ & $\begin{array}{l}n d^{b, c}, 2 \times 10^{5=} \\
\left(n d^{b}\right)^{2}\end{array}$ & $8 \times 10^{5}=$ & $\begin{array}{l}2 \times 10^{4} \\
6.2 \times 10^{5 b} \\
\end{array}$ & $6 \times 10^{7}$ \\
\hline Site 2 & 6.9 & $\begin{array}{l}1.1 \times 10^{4} \\
\left(1.4 \times 10^{4}\right)\end{array}$ & $\begin{array}{l}2.2 \times 10^{3} \\
\left(2.8 \times 10^{3}\right) \\
2 \times 10^{1}\end{array}$ & $4 \times 10^{6}$ & $\stackrel{\text { nd }}{1.8 \times 10^{5}}$ & $3 \times 10^{8}$ \\
\hline Site 3 & 7.0 & $\begin{array}{l}3.3 \times 10^{4} \\
\left(1.0 \times 10^{4}\right) \\
\end{array}$ & $\begin{array}{l}4.8 \times 10^{2} \\
\left(1.4 \times 10^{2}\right.\end{array}$ & $9 \times 10^{4}$ & $\begin{array}{l}2 \times 10^{5} \\
3.4 \times 10^{4}\end{array}$ & $1 \times 10^{8}$ \\
\hline \multicolumn{7}{|l|}{ Chunks \# cells/g } \\
\hline Site 1 ASTM & & $n d^{b}$ & & $\mathbf{n d}$ & $1.3 \times 10^{5 b}$ & \\
\hline Site 1 Cal Alum & $11.4^{4}$ & $n d^{b}$ & $\mathbf{n d}^{\mathrm{d}}, \mathbf{n d} \mathrm{d}^{\mathrm{b}}$ & $n d^{2}, n^{b}$ & $\stackrel{n d^{2}}{<7 \times 10^{3 b}}$ & nd" \\
\hline Site $1 \mathrm{YM} \mathrm{H}$ & & $1.9 \times 10^{4 b}$ & $1.2 \times 10^{5 b}$ & $8.3 \times 10^{3 b}$ & $2.9 \times 10^{4 b}$ & \\
\hline Site 1 YM K & 10.0 & $n d^{b}$ & $2 \times 10^{4}$ & $2 \times 10^{5}, \mathrm{nd}^{\mathrm{b}}$ & $\begin{array}{l}8 \times 10^{2} \mathrm{a} \\
3.2 \times 10^{3 \mathrm{~b}} \\
\end{array}$ & $4 \times 10^{7}=$ \\
\hline Site 1 ASTM $\mathrm{HgCl}_{2}$ & & $\mathrm{nd}^{\mathrm{b}}$ & $\mathbf{n d}^{\mathrm{b}}$ & $n d^{b}$ & $<2 \times 10^{3 \mathrm{~b}}$ & \\
\hline Site 2 ASTM & & $\mathbf{n d}^{\mathrm{b}}$ & $n d^{b}$ & $n d^{b}$ & $3.4 \times 10^{6 b}$ & \\
\hline Site 2 Cal Alum & 11.4 & $\mathbf{n d}^{\mathrm{b}}$ & $n d, n d^{b}$ & $\mathbf{n d}, \mathbf{n d} \mathbf{d}^{\mathrm{b}}$ & $\stackrel{\text { nd }}{\leq 7 \times 10^{2 b}}$ & nd \\
\hline Site 2 YM H & & $\mathbf{n d}^{\mathrm{b}}$ & $\mathbf{n d}$ & $n d^{b}$ & $1 \times 10^{4 b}$ & \\
\hline Site 2 YM K & 10.0 & $\mathrm{nd}^{\mathrm{b}}$ & $n d, n d^{b}$ & $2 \times 10^{a}, n d^{b}$ & $\begin{array}{l}\text { nd } \\
1 \times 10^{4 b}\end{array}$ & $2 \times 10^{7}$ \\
\hline Site 2 ASTM $\mathrm{HgCl}_{2}$ & & $\mathrm{nd}^{\mathrm{b}}$ & $n d^{b}$ & $n d^{b}$ & $9.9 \times 10^{4 \mathrm{~b}}$ & \\
\hline Site 3 ASTM & & nd $^{b}$ & $n d^{b}$ & $n d^{b}$ & $<2.8 \times 10^{30}$ & \\
\hline Site 3 Cal Alum & 11.0 & $n d^{b}$ & $n d, n d^{b}$ & $\mathbf{n d}, \mathbf{n d} \mathbf{b}^{\mathrm{b}}$ & ${ }_{\leq 1 \times 10^{3 b}}^{\text {nd }}$ & $2 \times 10^{6}$ \\
\hline Site 3 YM H & & $n d^{b}$ & $n d^{b}$ & $n d^{b}$ & $9.1 \times 10^{3 \mathrm{~b}}$ & \\
\hline Site 3 YM K & 10.4 & $\mathrm{nd}^{\mathrm{b}}$ & $n d, n d^{b}$ & $n d, n d^{b}$ & $\stackrel{\text { nd }}{<3 \times 10^{3}}$ & $2.6 \times 10^{6}$ \\
\hline Site 3 ASTM $\mathrm{HgCl}_{2}$ & & $n d^{b}$ & $n d^{b}$ & $n \mathbf{d}^{b}$ & $\leq 1.7 \times 10^{30}$ & \\
\hline Site 2a ASTM & & $\mathrm{nd}^{\mathrm{b}}$ & $9.9 \times 10^{5 b}$ & $\mathbf{n d} \mathbf{d}^{b}$ & $\leq 3.1 \times 10^{30}$ & \\
\hline Site 2a Cal Alum & & $\mathrm{nd}^{\mathrm{b}}$ & $1.2 \times 10^{6}$ & $n d^{b}$ & $<2.9 \times 10^{35}$ & \\
\hline Site $2 \mathrm{a}$ YM H & & $n d^{b}$ & $n d^{b}$ & $n d^{b}$ & $\leq 1.9 \times 10^{30}$ & \\
\hline Site 2a YM K & & $n d^{\mathrm{b}}$ & $n d^{b}$ & $n d^{b}$ & $<9.1 \times 10^{30}$ & \\
\hline Site 2a ASTM $\mathrm{HgCl}_{2}$ & & nd" & $6.4 \times 10^{2}$ & $n d^{\prime \prime}$ & $1.1 \times 10^{25}$ & \\
\hline \multicolumn{7}{|l|}{ Swabs \# cells/swab } \\
\hline Site 1 ASTM od & & $6.5 \times 10^{2 b}$ & $4.6 \times 10^{6 b}$ & & $7.9 \times 10^{3}$ & \\
\hline Site 1 ASTM n' & & $5.5 \times 10^{2}$ & $1.0 \times 10^{6}$ & & $6.6 \times 10^{2}$ & \\
\hline Site 1 Cal Alum o & & $2.2 \times 10^{2}$ & $4.0 \times 10^{5}$ & & $2 \times 10^{2}$ & \\
\hline Site $1 \mathrm{YM} \mathrm{H} \mathrm{o}$ & & $1.1 \times 10^{2}$ & $2.7 \times 10^{7}$ & & $2 \times 10^{2}$ & \\
\hline Site 1 YM H n & & $1.1 \times 10^{3}$ & $1.0 \times 10^{8}$ & & $4.9 \times 10^{3}$ & \\
\hline Site $1 \mathrm{YM} \mathrm{K} 0$ & & $1.4 \times 10^{3}$ & $1.6 \times 10^{8}$ & & $2 \times 10^{2}$ & \\
\hline Site $1 \mathrm{ASTMHgCl}$, $\mathrm{O}$ & & $4.8 \times 10^{2}$ & nd & & $1.1 \times 10^{3}$ & \\
\hline
\end{tabular}




\begin{tabular}{|c|c|c|c|}
\hline Site $1 \mathrm{ASTMHgCl}_{2} \mathrm{n}$ & $2.4 \times 10^{2}$ & $1.6 \times 10^{3}$ & $7 \times 10^{3}$ \\
\hline Site 2 ASTM o & nd & $1.6 \times 10^{7}$ & $2.8 \times 10^{4}$ \\
\hline Site 2 ASTM n & nd & $1.0 \times 10^{8}$ & $3.3 \times 10^{3}$ \\
\hline Site 2 Cal Alum o & nd & $1.0 \times 10^{6}$ & $7.8 \times 10^{2}$ \\
\hline Site $2 \mathrm{YM} \mathrm{H}_{\mathrm{O}}$ & $1.2 \times 10^{2}$ & $1.2 \times 10^{7}$ & $<2 \times 10^{2}$ \\
\hline Site 2 YM Hn & nd & $1.0 \times 10^{6}$ & $2 \times 10^{2}$ \\
\hline Site 2 YM K o & nd & nd & $<2 \times 10^{2}$ \\
\hline Site 2 ASTMHgCl, O & nd & nd & $2.3 \times 10^{3}$ \\
\hline Site $2 \mathrm{ASTMHgCl}_{2} \mathrm{n}$ & nd & $2.4 \times 10^{3}$ & $1.7 \times 10^{5}$ \\
\hline Site 3 ASTM o & nd & $6.5 \times 10^{5}$ & $2.3 \times 10^{3}$ \\
\hline Site 3 ASTM n & nd & $1.2 \times 10^{7}$ & $9.2 \times 10^{5}$ \\
\hline Site $3 \mathrm{Cal}$ Alum o & $7.0 \times 10^{\circ}$ & nd & $<2.0 \times 10^{2}$ \\
\hline Site 3 YM Ho & nd & nd & $<2.0 \times 10^{2}$ \\
\hline Site 3 YM H n & nd & nd & $1.7 \times 10^{3}$ \\
\hline Site 3 YM Ko & nd & nd & $<2.0 \times 10^{2}$ \\
\hline Site 3 ASTMHgCl, O & nd & $2.2 \times 10^{2}$ & $2.4 \times 10^{4}$ \\
\hline Site 3 ASTMHgCl, n & nd & $1.0 \times 10^{6}$ & $4.5 \times 10^{2}$ \\
\hline
\end{tabular}

a. Data from the Laboratory of Wolfgang Sand at the University of Hamburg, Germany

b. Data from the Laboratory of Robert Rogers

c. nd indicates microorganisms not detected

d. Original surface

e. Fresh surface exposed after chunk removal in September 1994 sampling. 
Table 4. Weight loss after 60 days of accelerated testing.

\begin{tabular}{|c|c|c|c|c|}
\hline TREATMENT & $\begin{array}{l}\text { SPECIMEN } \\
\text { FORMULATION }\end{array}$ & $\begin{array}{l}\text { INITIAL } \\
\text { WT (g) }\end{array}$ & $\begin{array}{l}\text { FINAL } \\
\text { WT (g) } \\
\end{array}$ & $\begin{array}{l}\text { WT LOSS } \\
\%\end{array}$ \\
\hline \multirow[t]{4}{*}{ T. thiooxidans } & ASTM Standard & 12.22 & 10.60 & 13.2 \\
\hline & YM Type H & 33.02 & 31.24 & 5.4 \\
\hline & YM Type K & 35.07 & 33.76 & 3.7 \\
\hline & ASTM $\mathrm{HgCl}_{2}$ & 12.47 & 8.24 & 33.9 \\
\hline \multirow{4}{*}{$\begin{array}{l}\text { Sterile } \\
\text { Medium }\end{array}$} & ASTM Standard & 12.48 & 12.45 & 0 \\
\hline & YM Type H & 32.80 & 33.44 & 0 \\
\hline & YM Type K & 35.08 & 35.71 & 0 \\
\hline & $\mathrm{ASTM} \mathrm{HgCl}_{2}$ & 12.72 & 12.56 & 0 \\
\hline
\end{tabular}




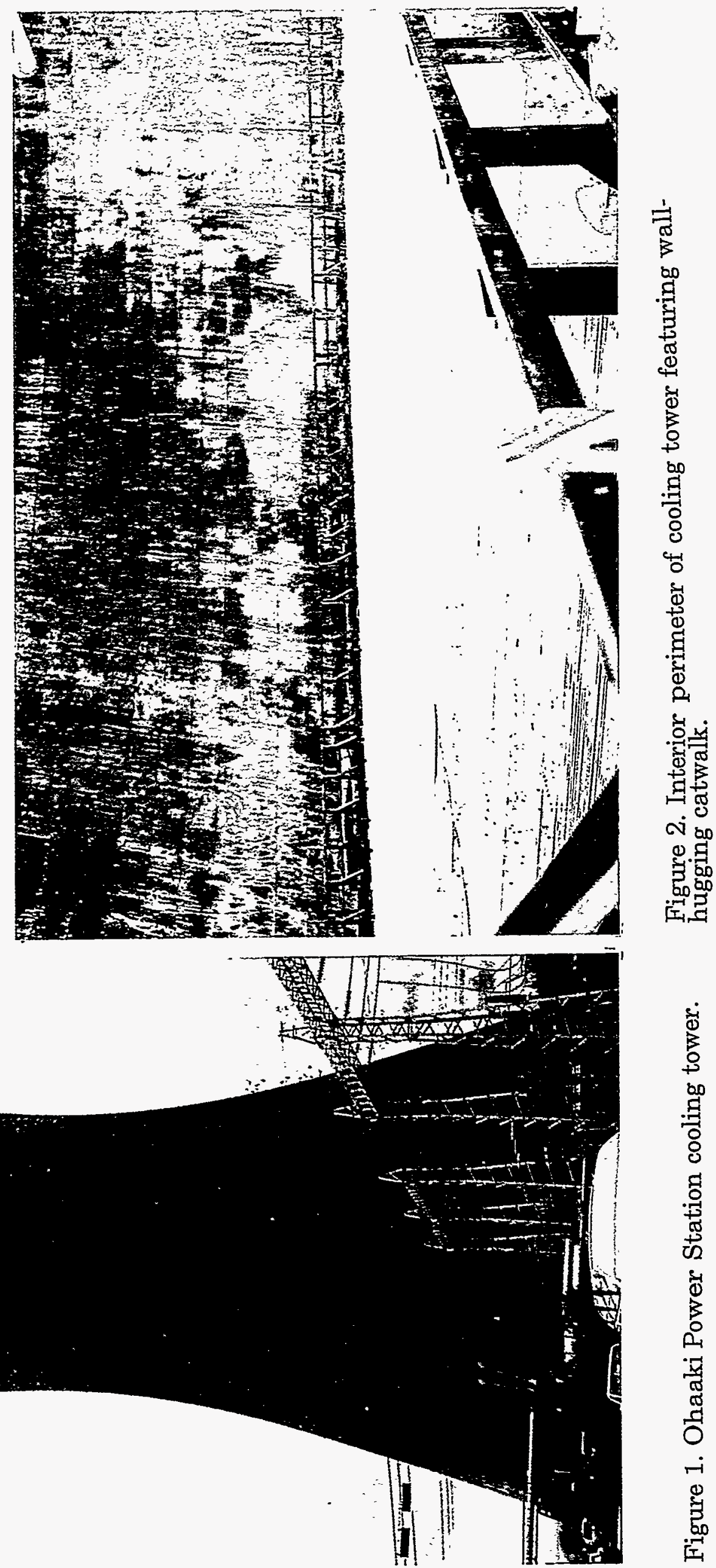




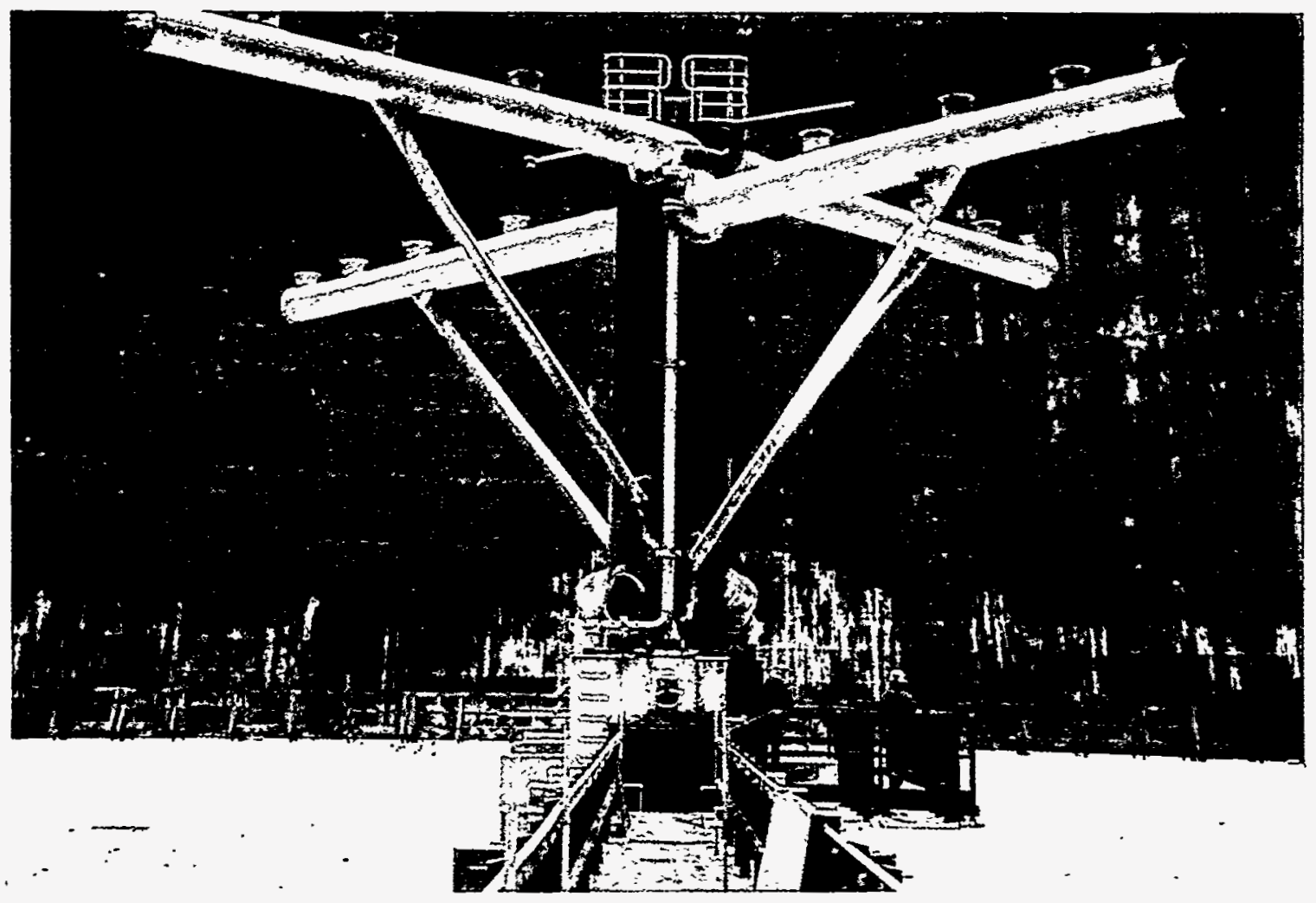

Figure 3. Interior of cooling tower featuring gas dispersion unit.

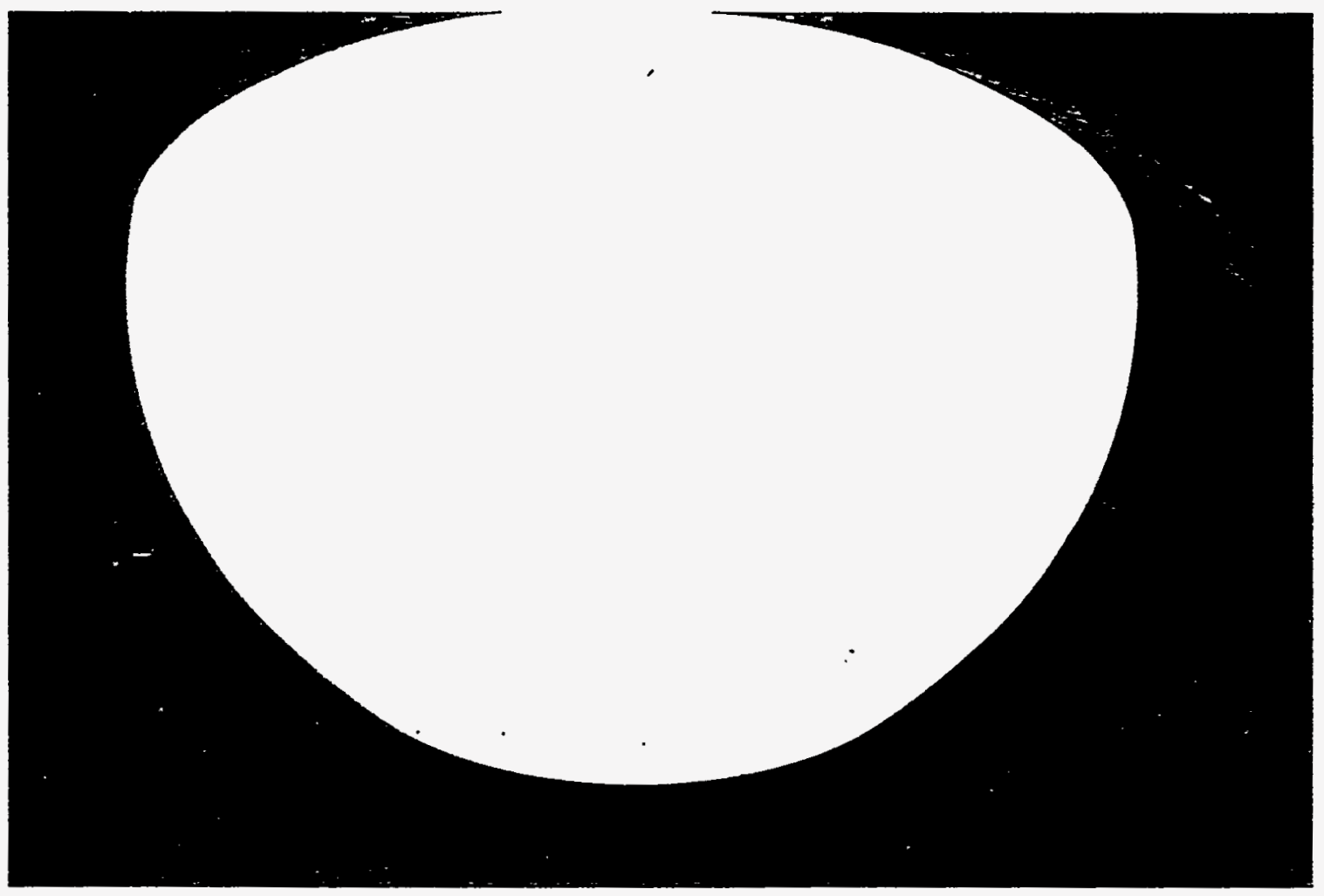

Figure 4. Interior of cooling tower by a wall looking skyward. 


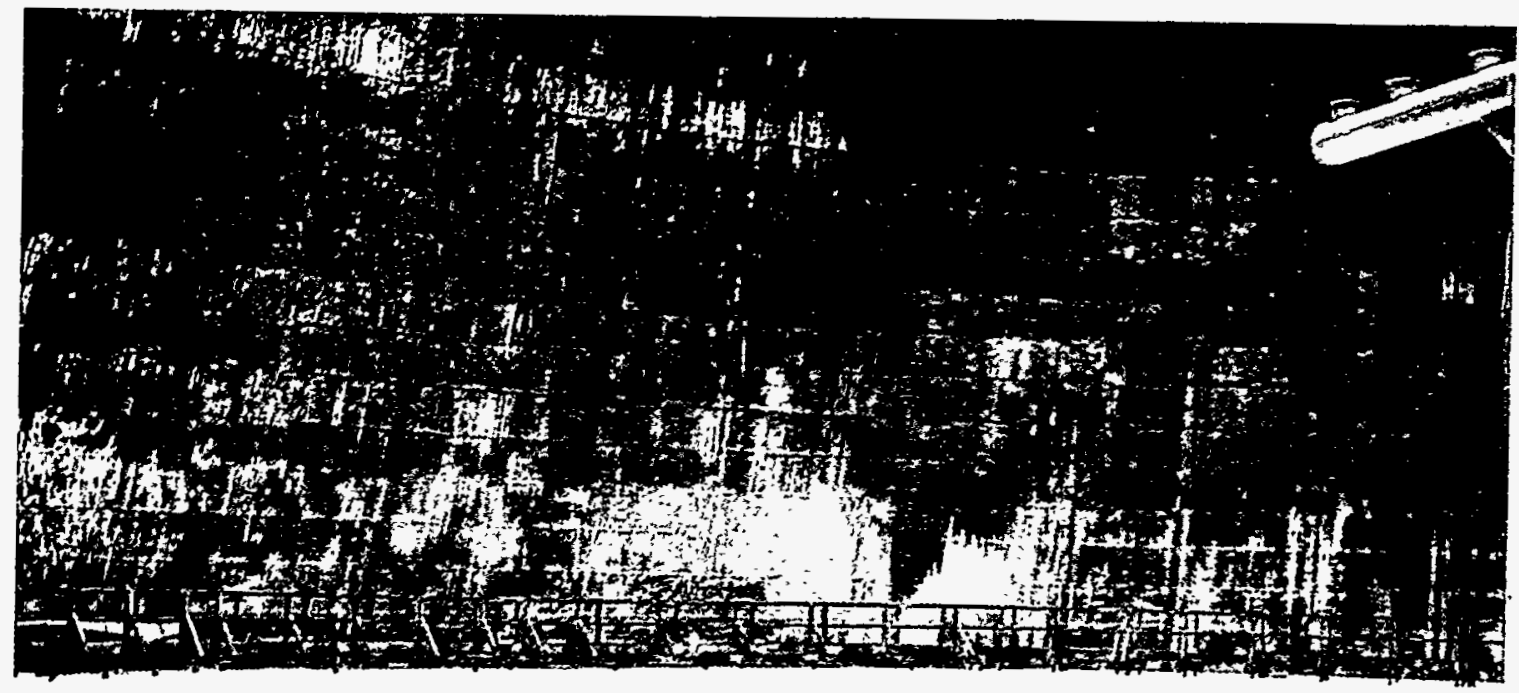

Figure 5. Interior of cooling tower featuring red stain on walls.

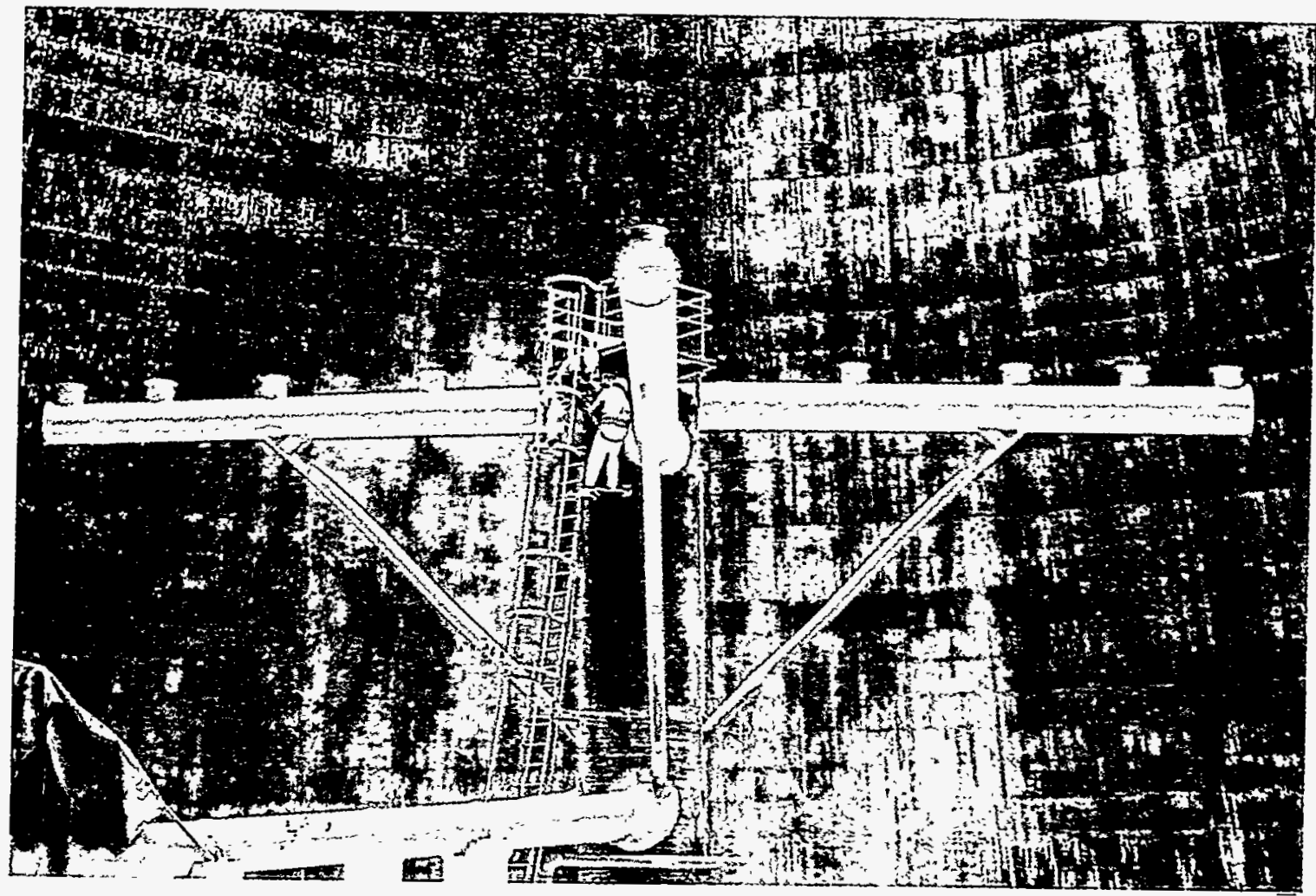

Figure 6. Interior of cooling tower with gas dispersion unit in foreground featuring green biofilm on upper walls. 


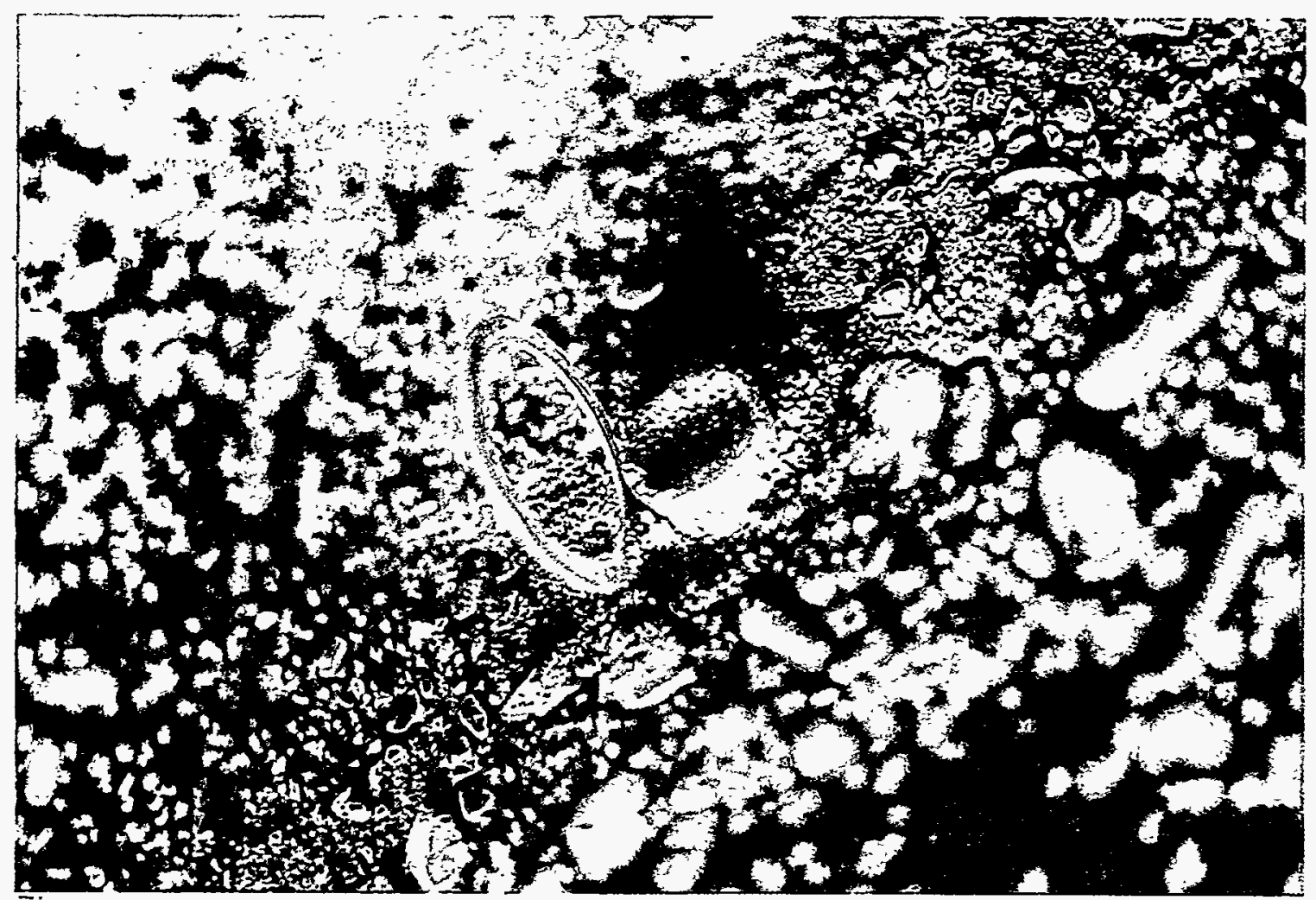

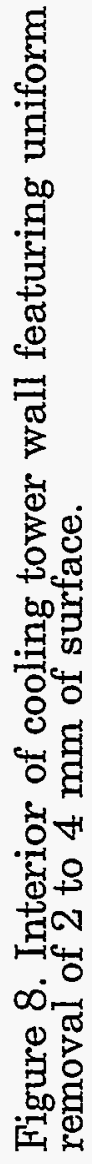

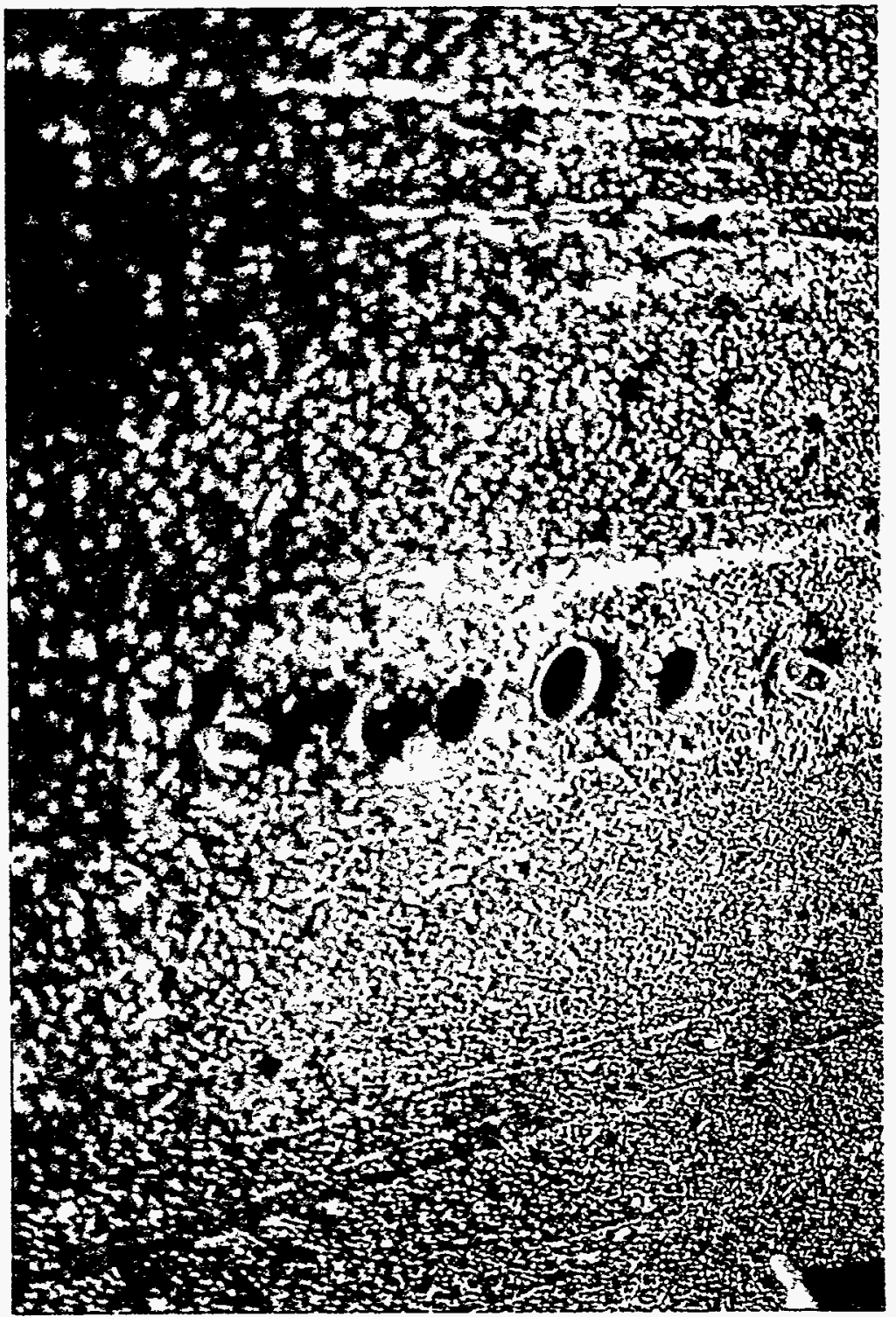

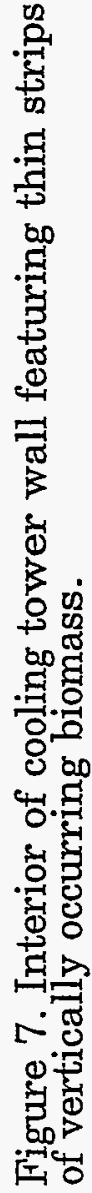




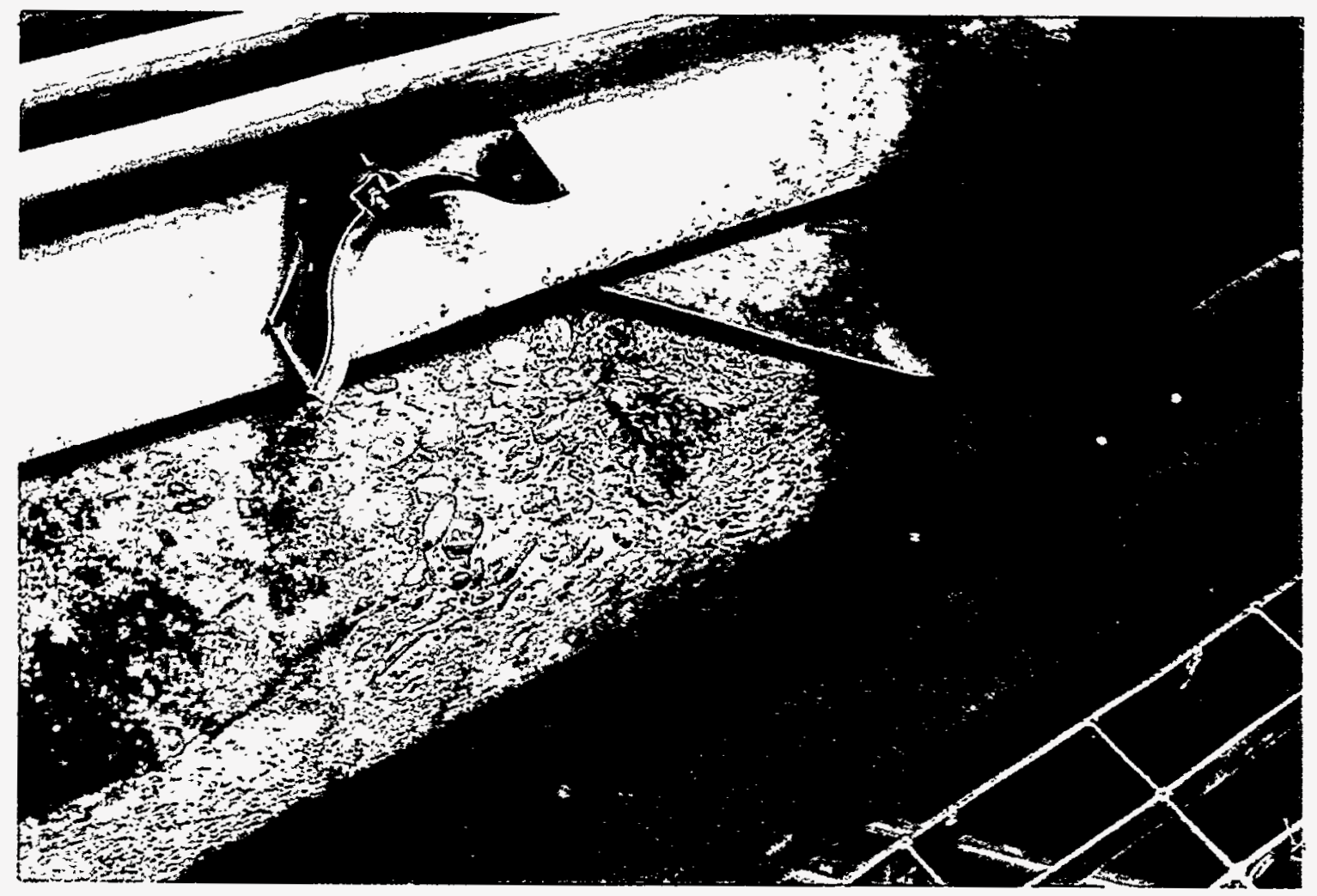
Figure 9. Interior of cooling tower featuring extensive loss of concrete $(2$ to $3 \mathrm{~cm})$
at catwaik location $1 \mathrm{a}$.

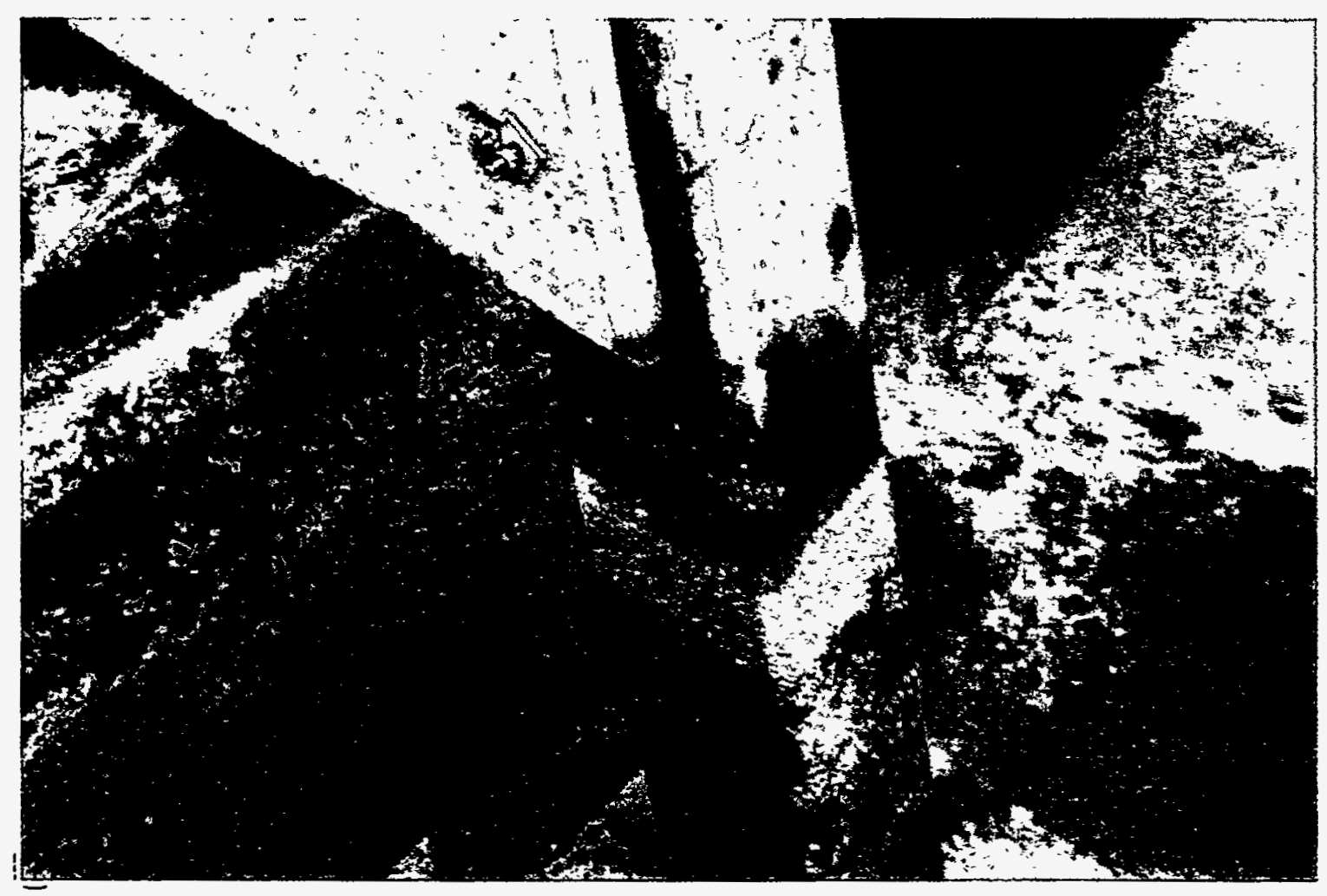

Figure 10. Cooling tower moat featuring extensive loss of concrete on exposed pillar. 


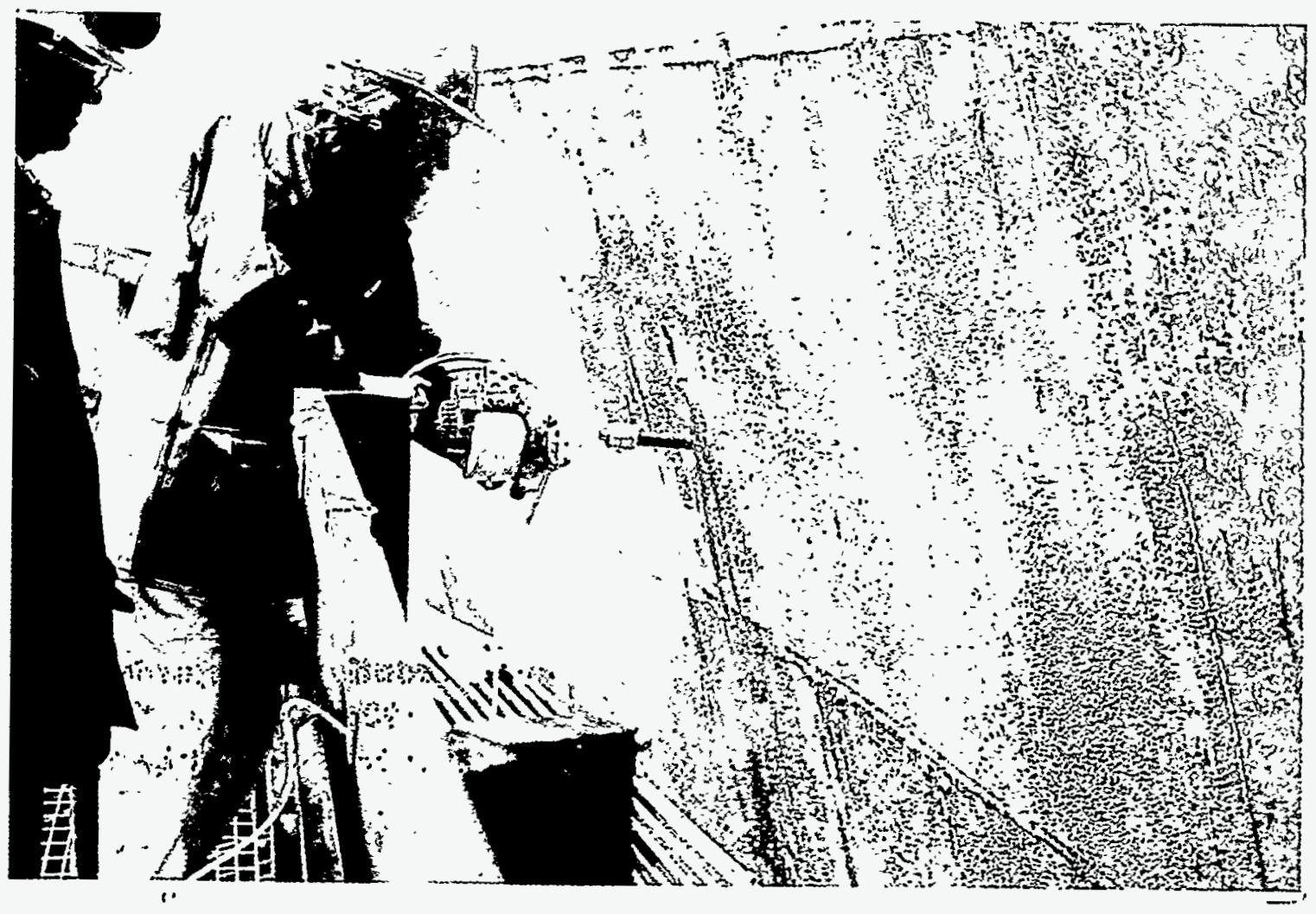

Figure 11. Obtaining core samples using hand-held, gas-powered core driller. 

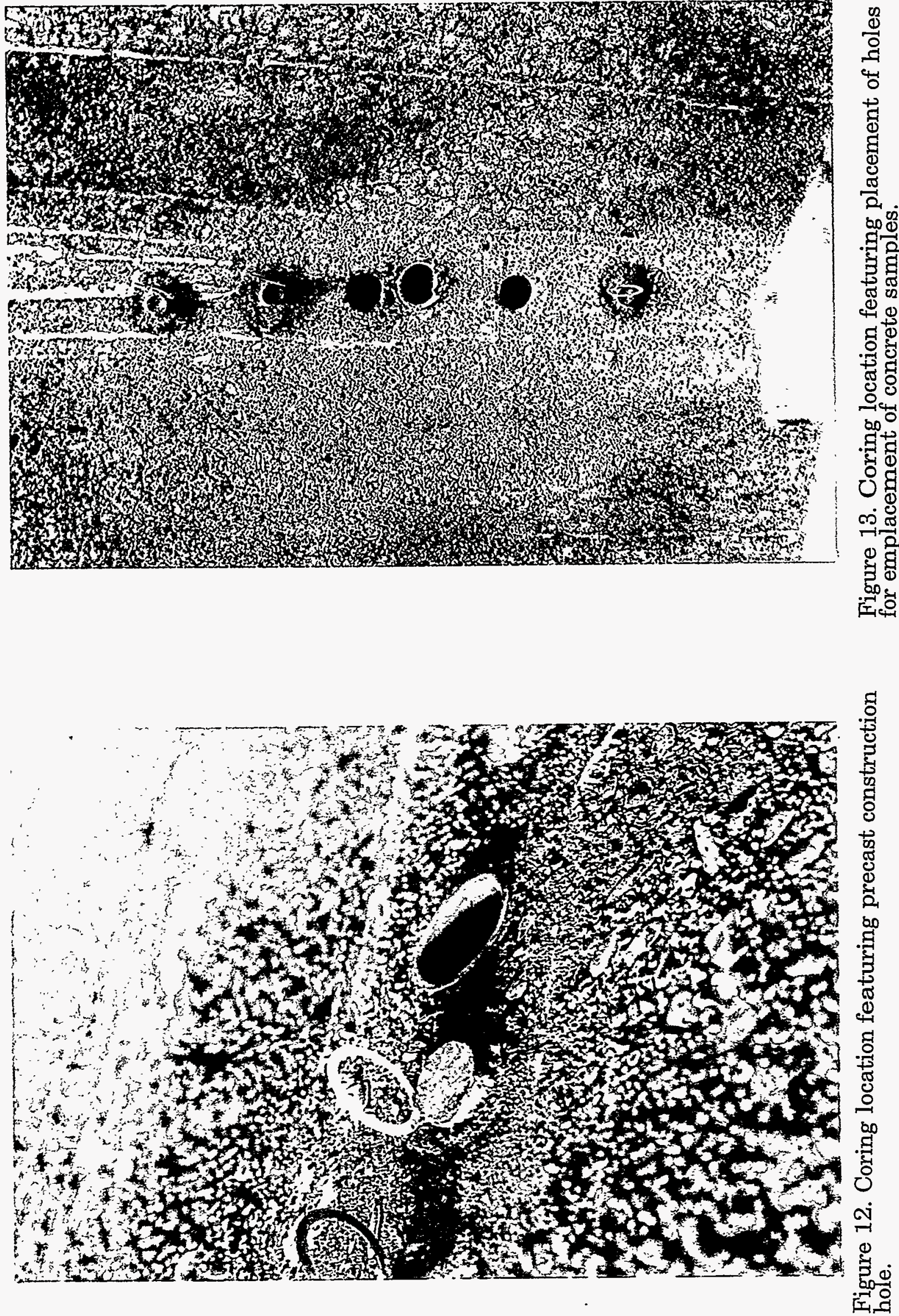

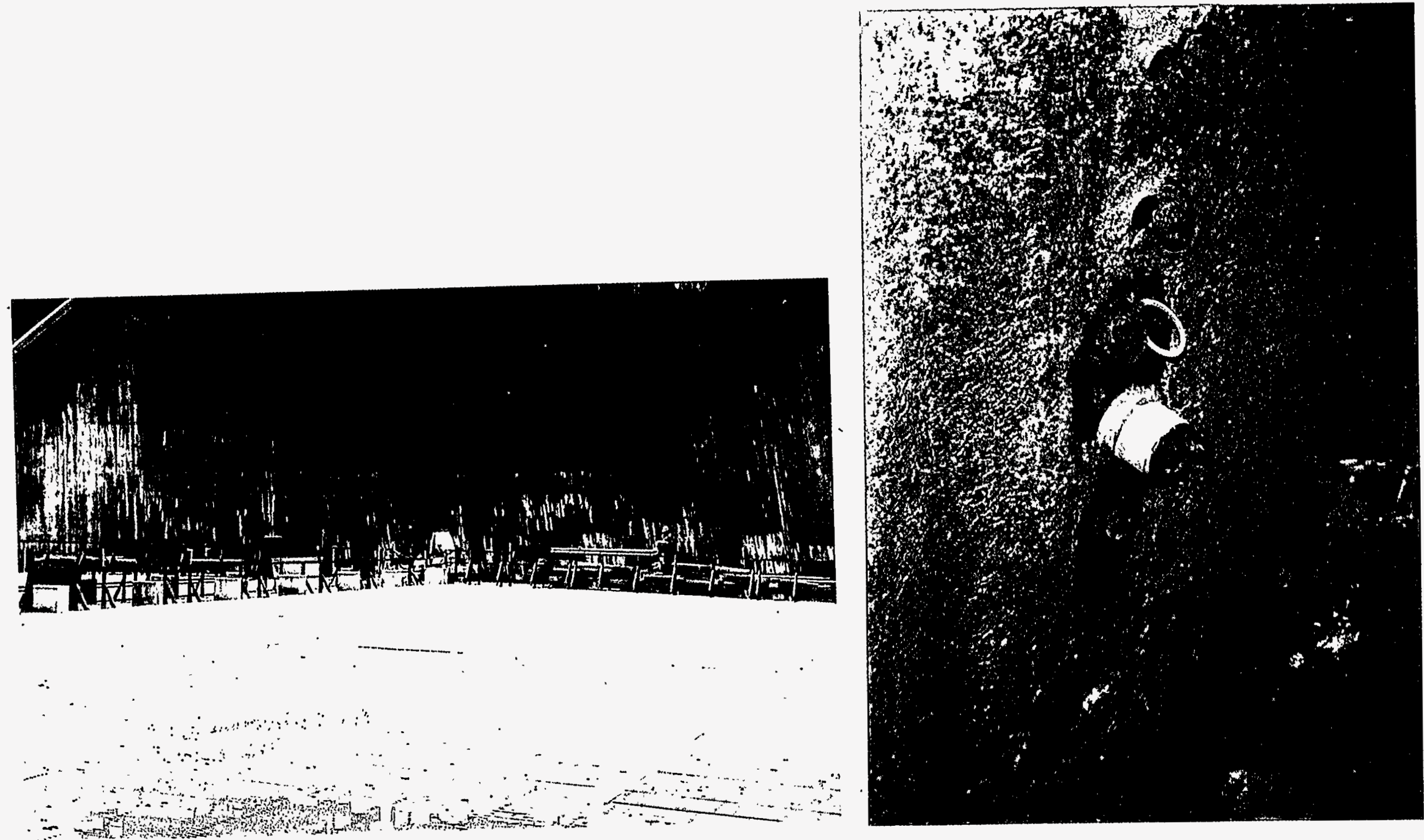

Figure 15. Wall location featuring placement of concrete

Figure 14. Interior of cooling tower featuring location of doored opening. samples and miniature temperature recording device. 


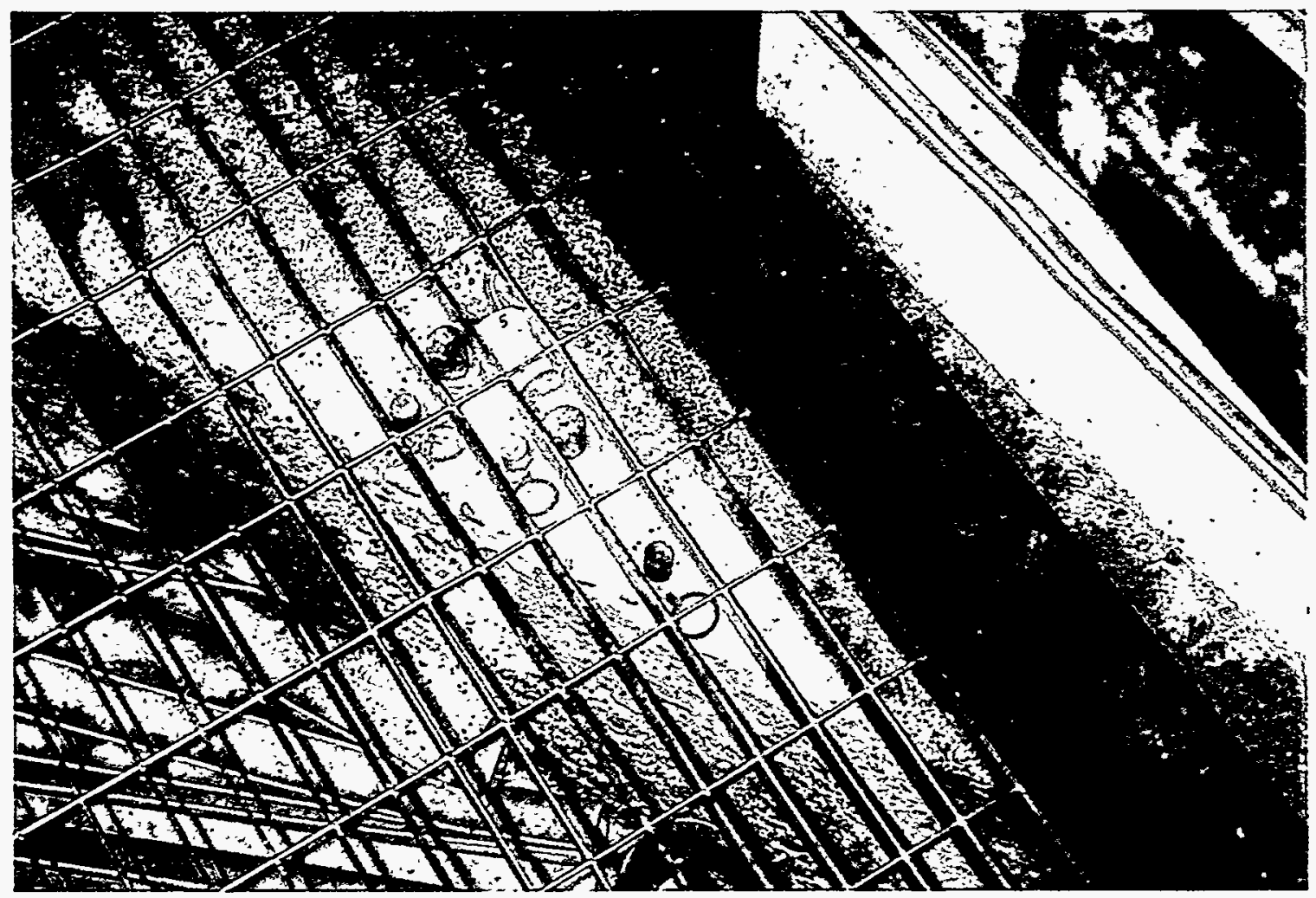

Figure 16. Catwalk location featuring placement of concrete samples and miniature temperature recording device. 


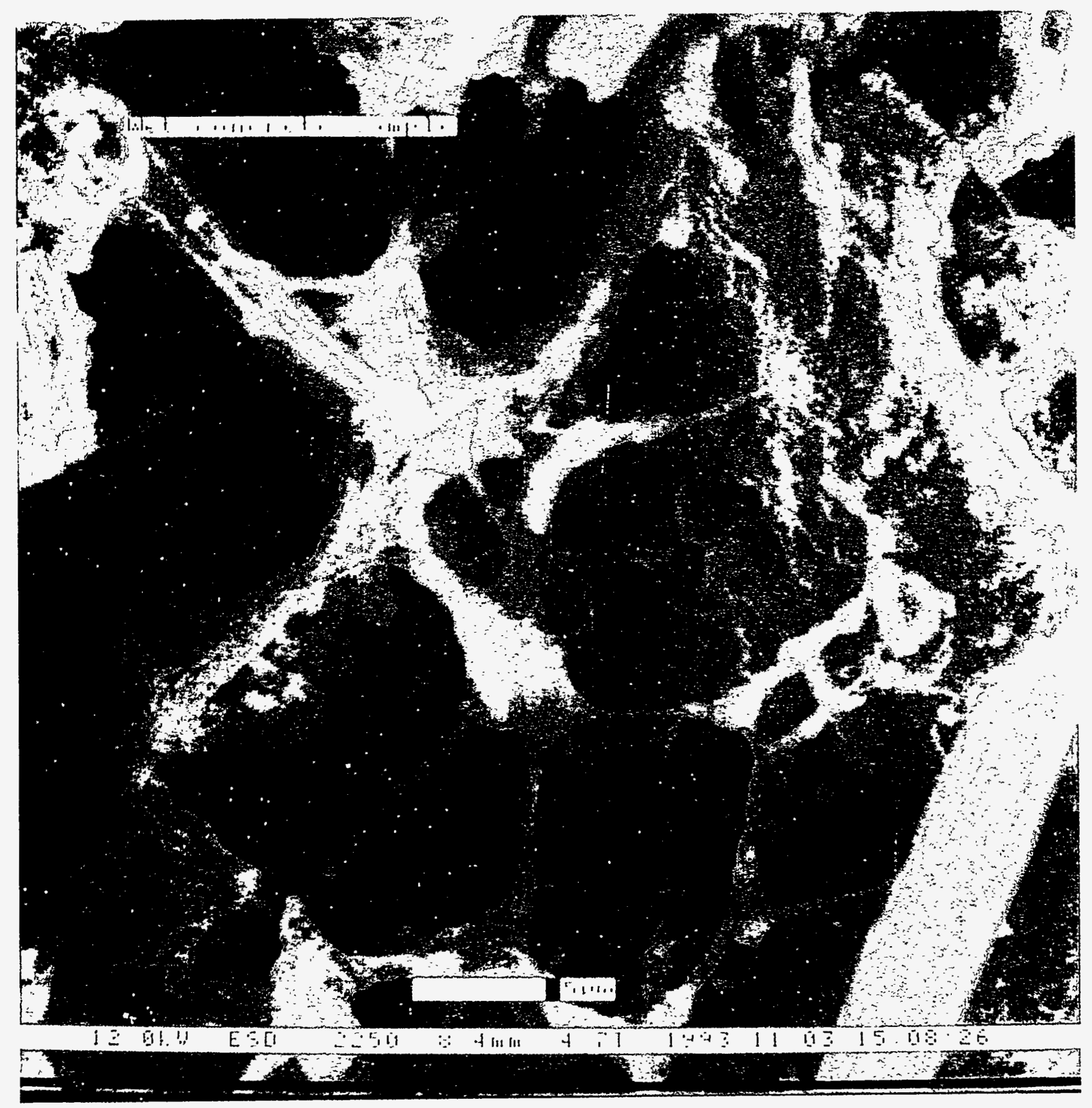

gure 17. ESEM image of crust from moat wall. Note appearance of "stringy" aorphus material thought to be biofilm. 


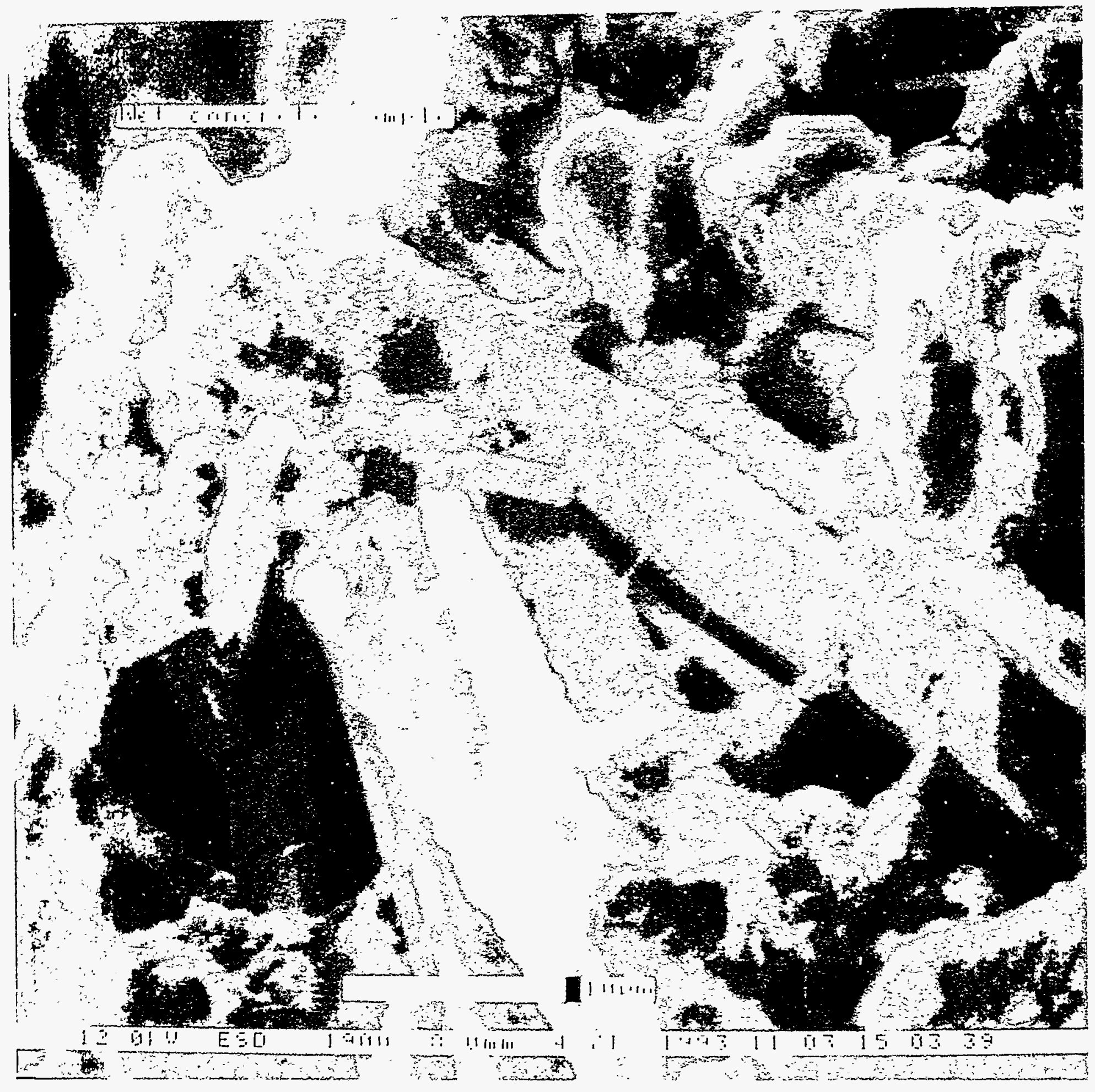

ure 18. ESEM image of crust from moat wall. Note appearance of amorphus erial, thought to be biofilm, coating surface. 


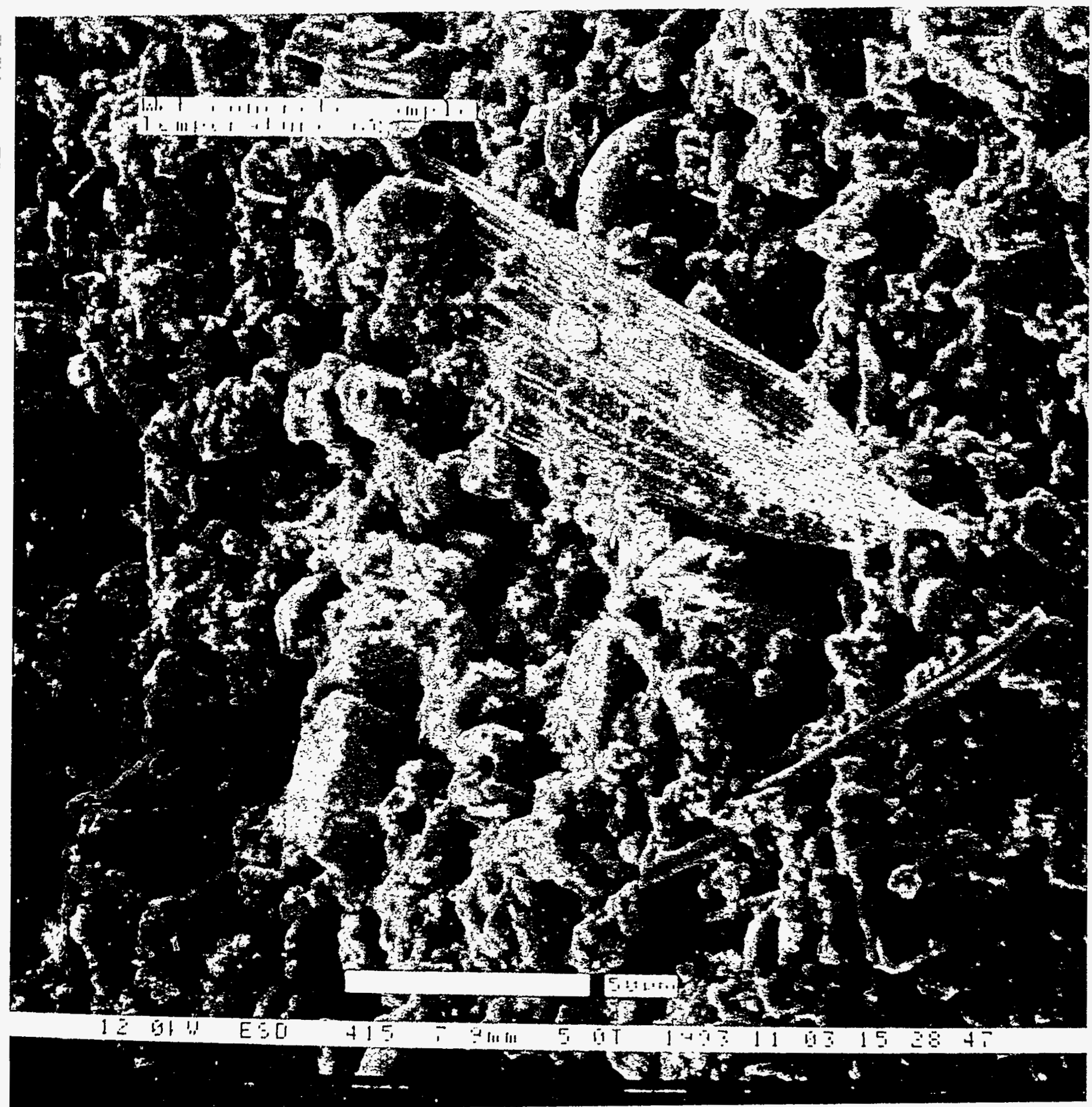

Figure 19. ESEM image of crust from moat wall. Note granular surface with what appears to be embedded algae fragment. 


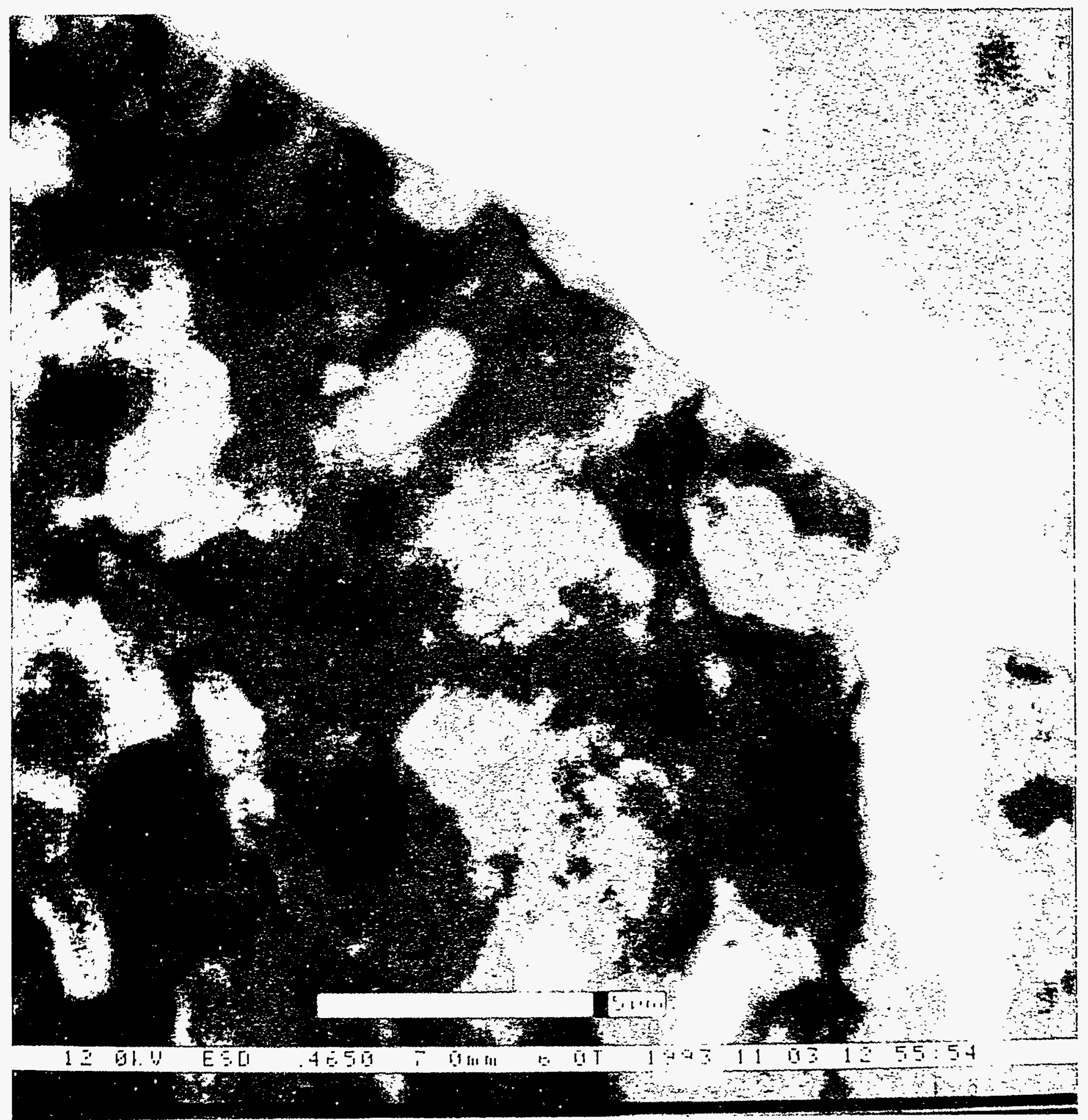

Figure 20. ESEM image of core from interior tower wall. Note amorphus coating containing rod shaped entities thought to be bacteria. 


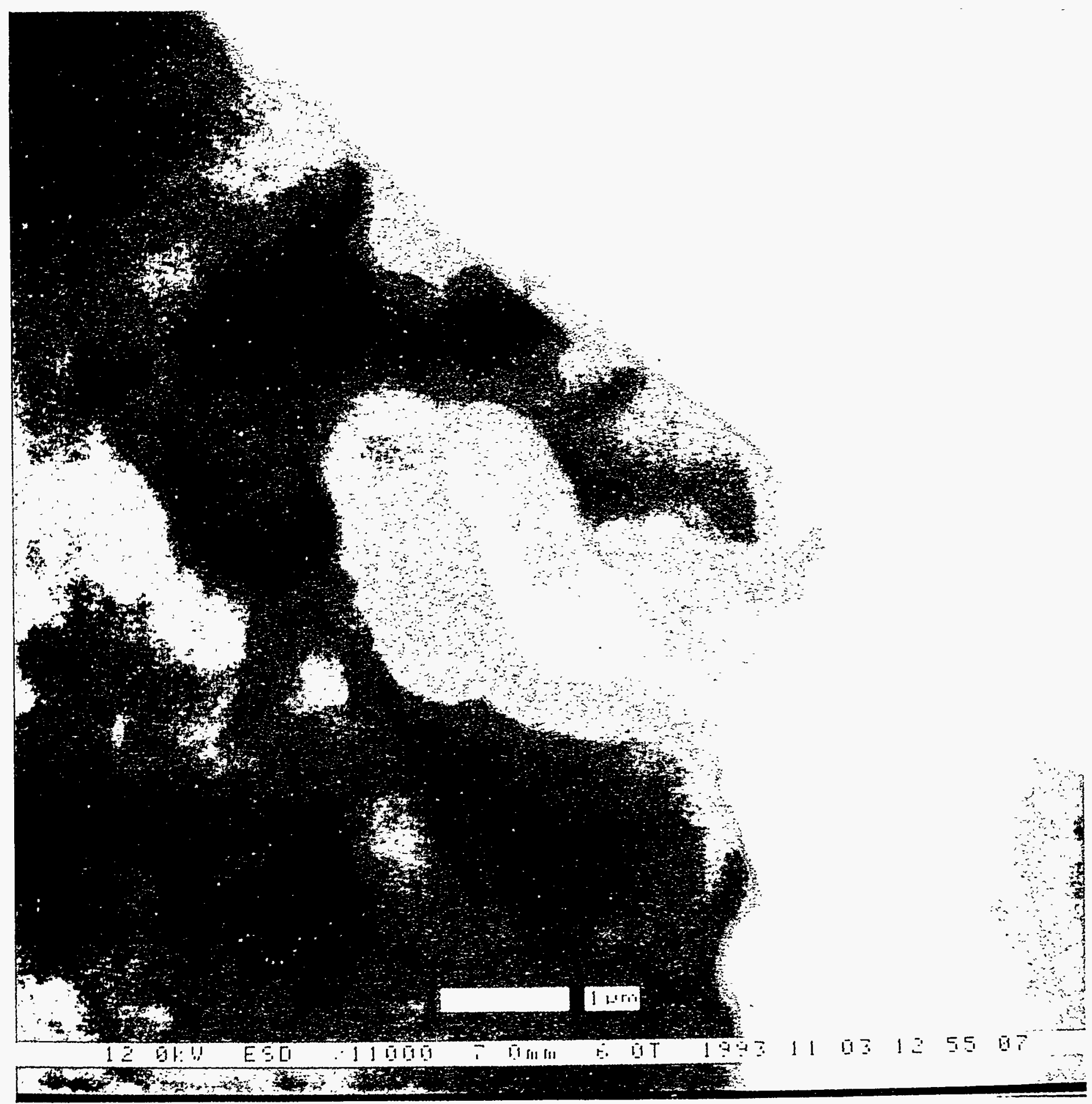

Figure 21. ESEM image of core from interior tower wall. Close up of area presented in Figure 20. 


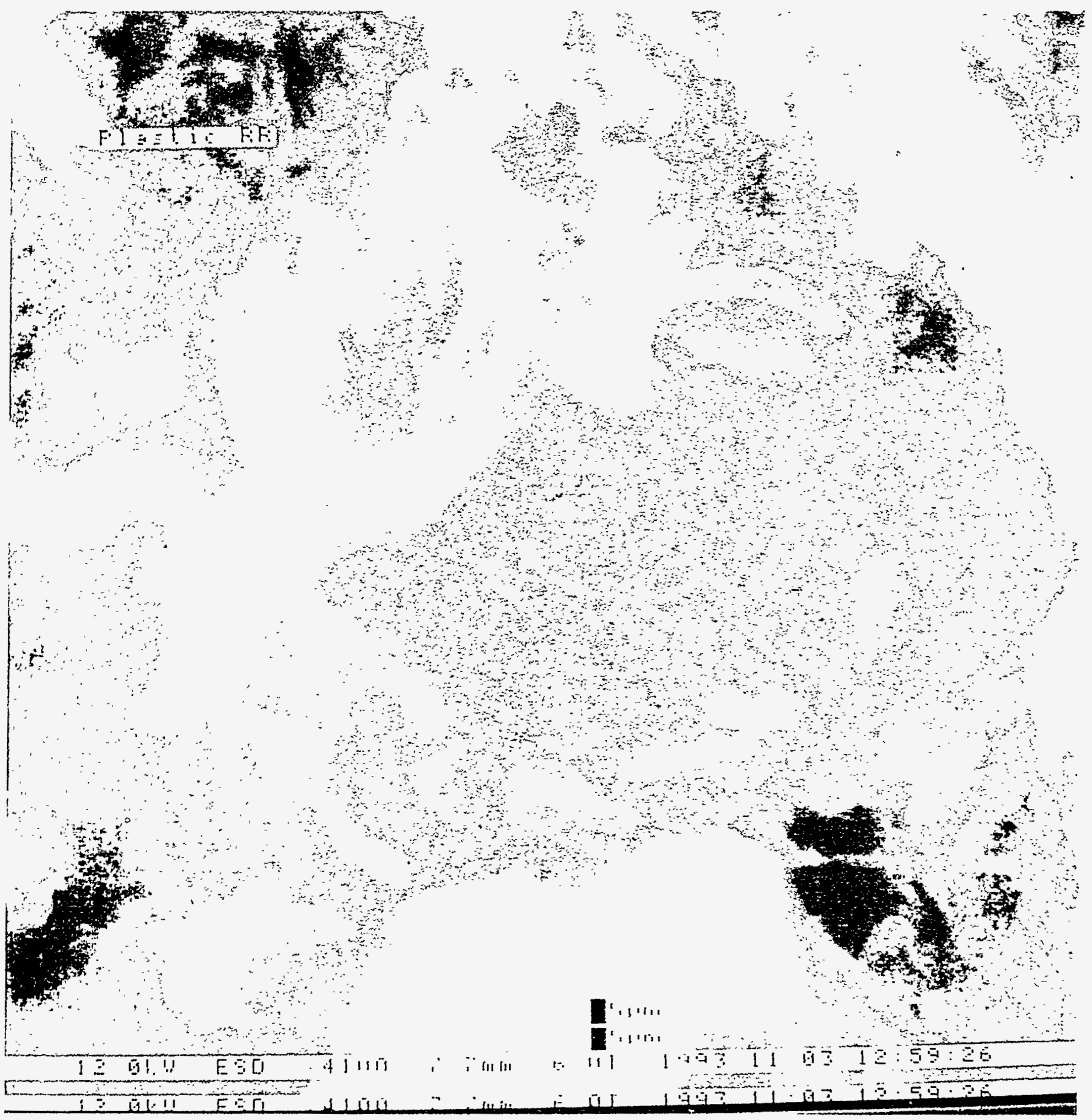

zure 22. ESEM image of core from interior tower wall. Note amorphus coating Itaining rod shaped entities thought to be bacteria. 


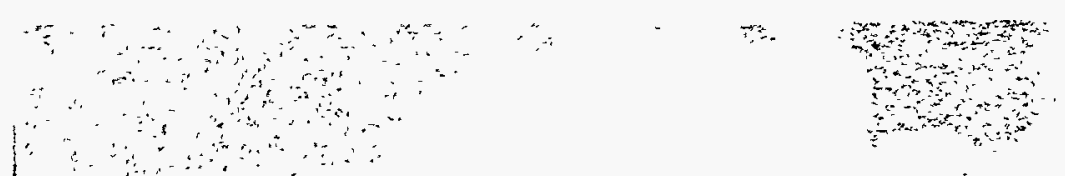

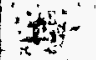

ond

$1+x$

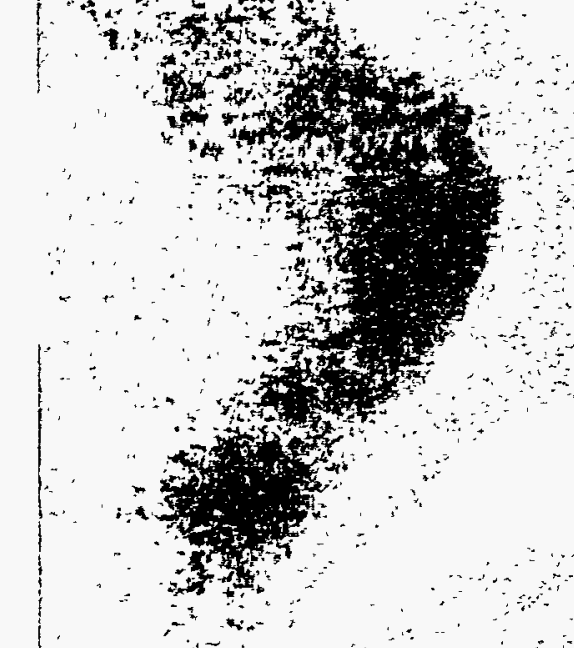

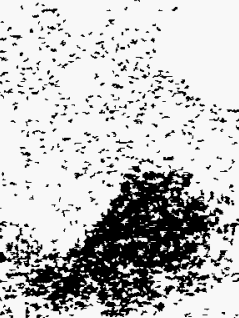
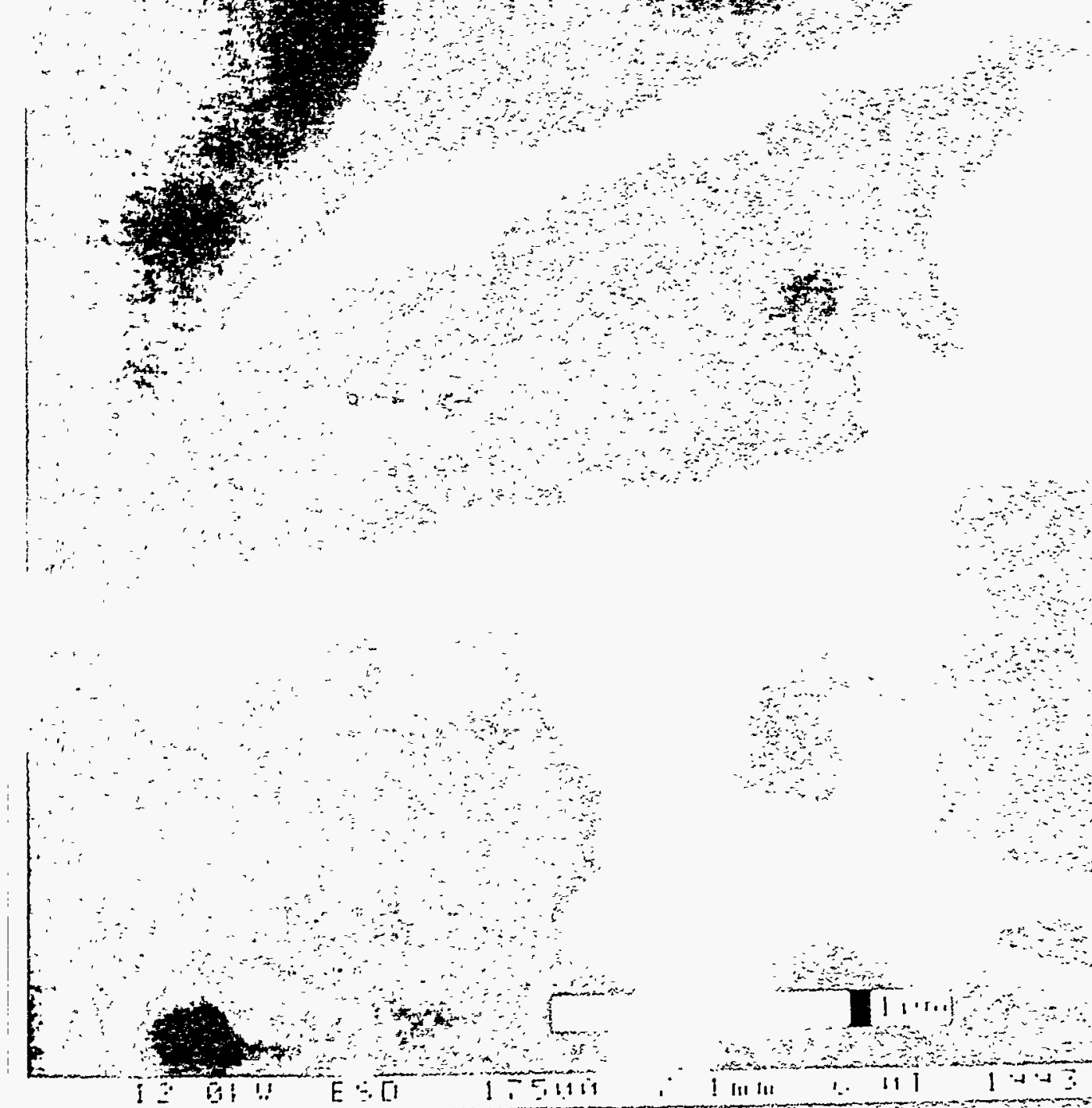


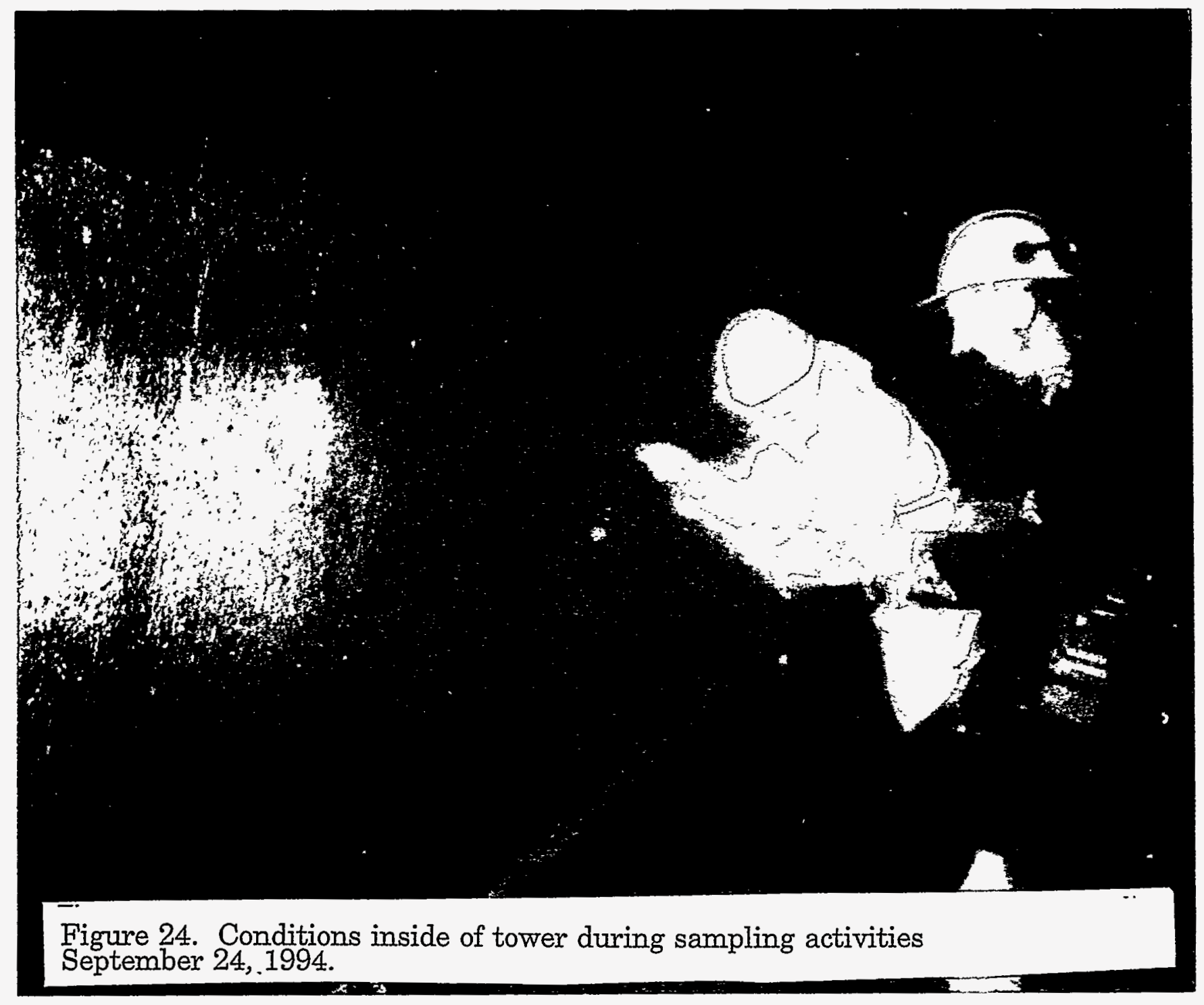




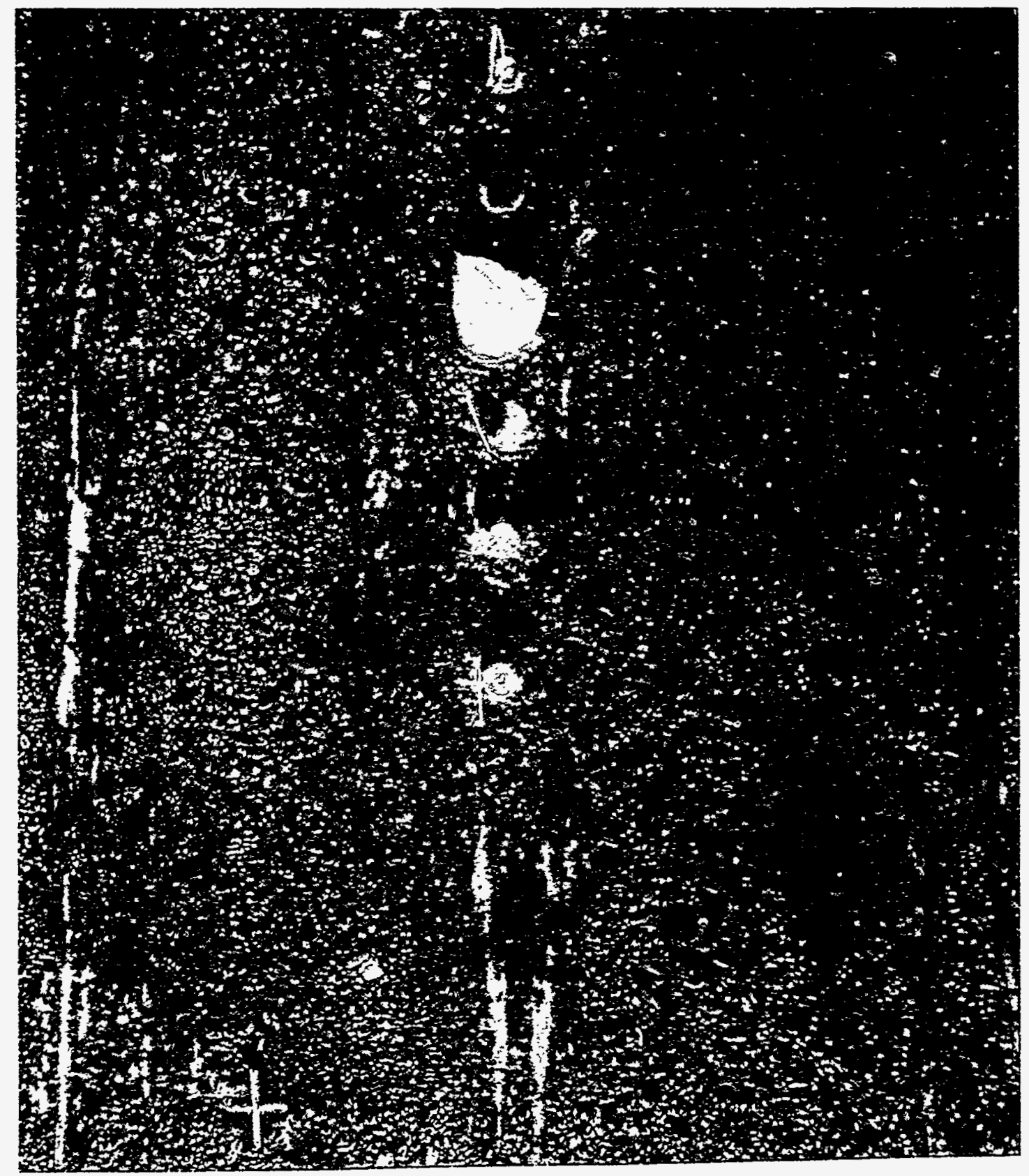

Figure 25. Wall at Site 1 showing emplaced specimens and X marker used to gauge wall degradation. 


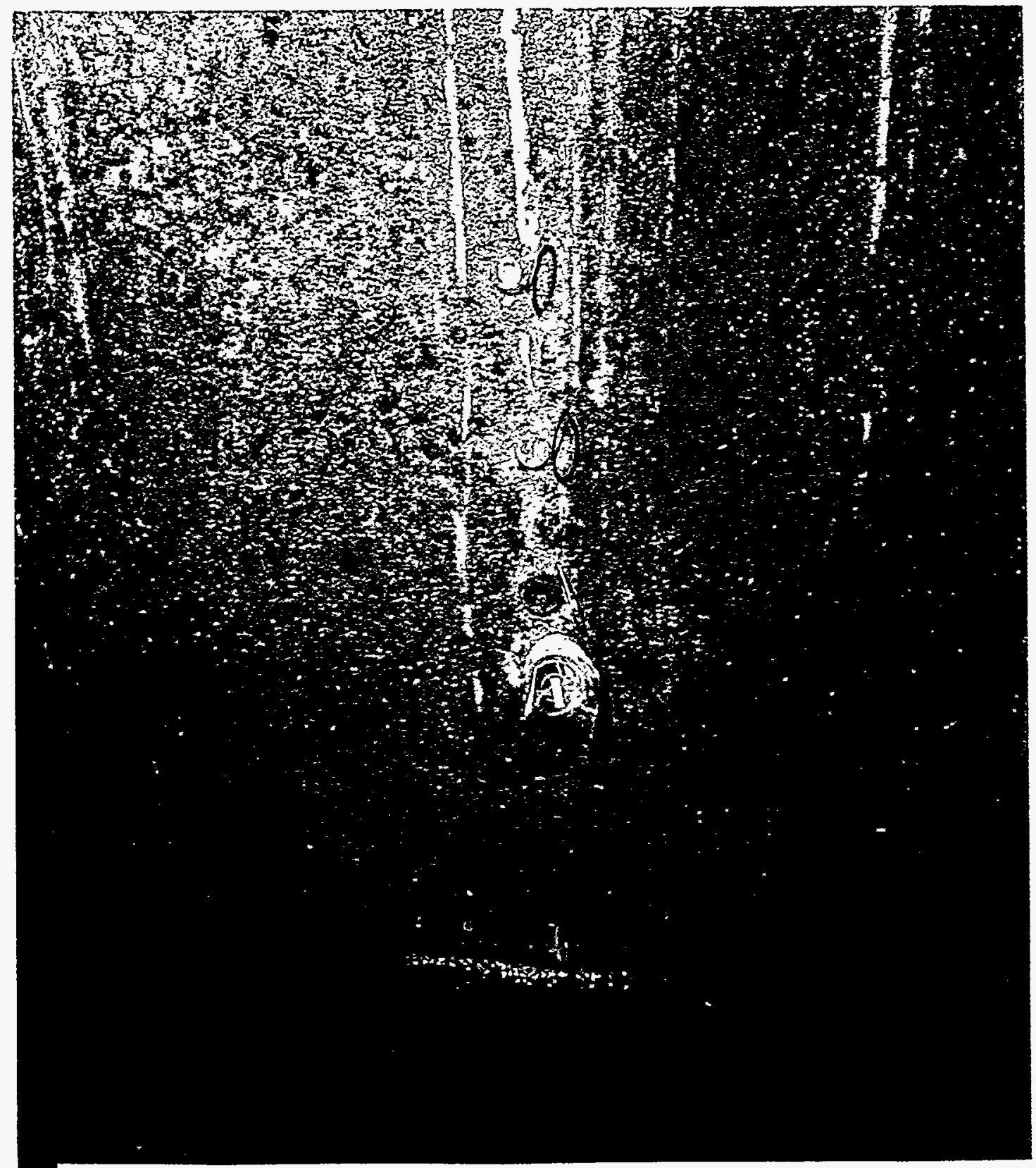

Figure 26. Wall at Site 2 showing emplaced specimens. 


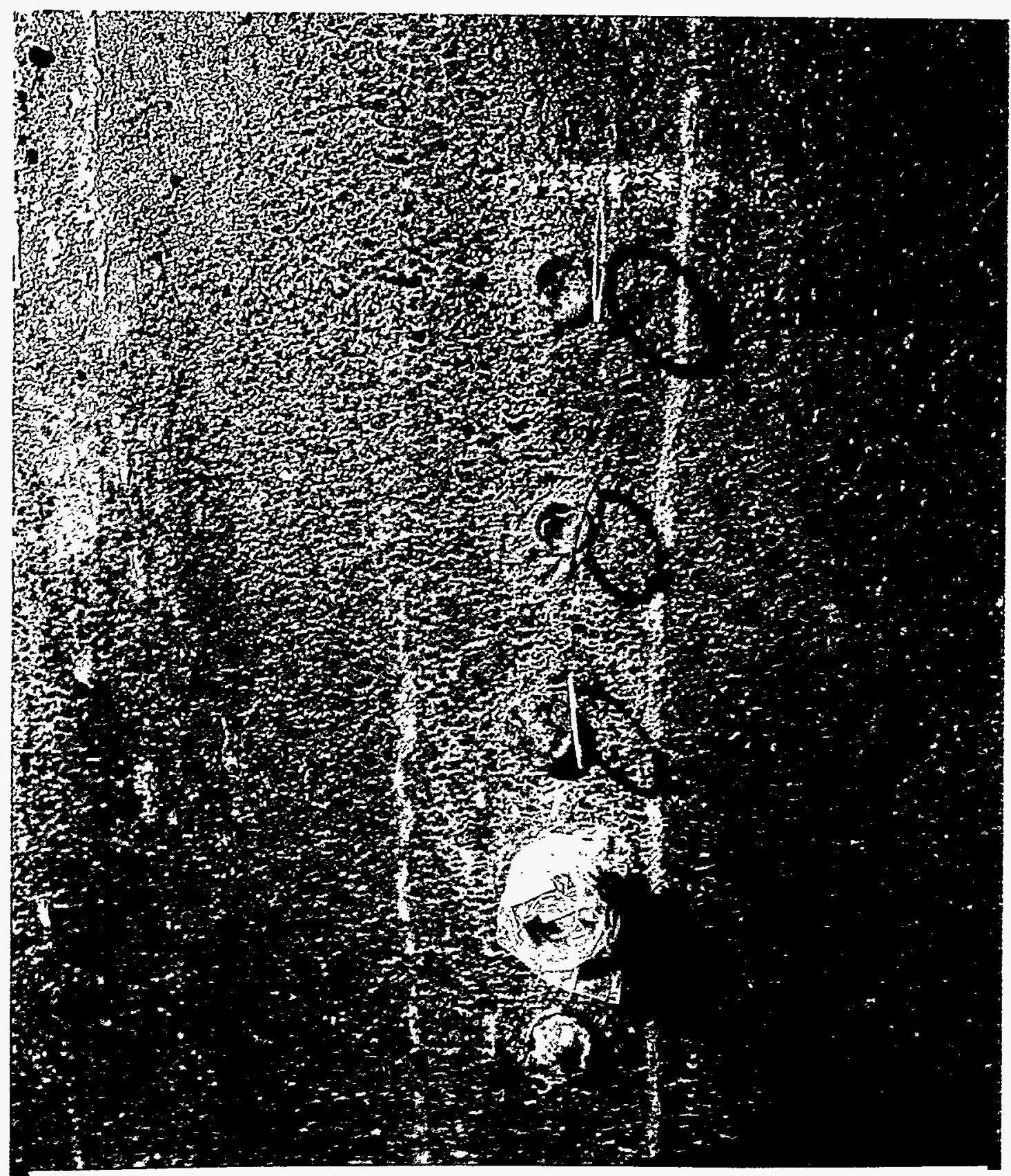

Figure 27. Wall at Site 3 showing emplaced specimens. 


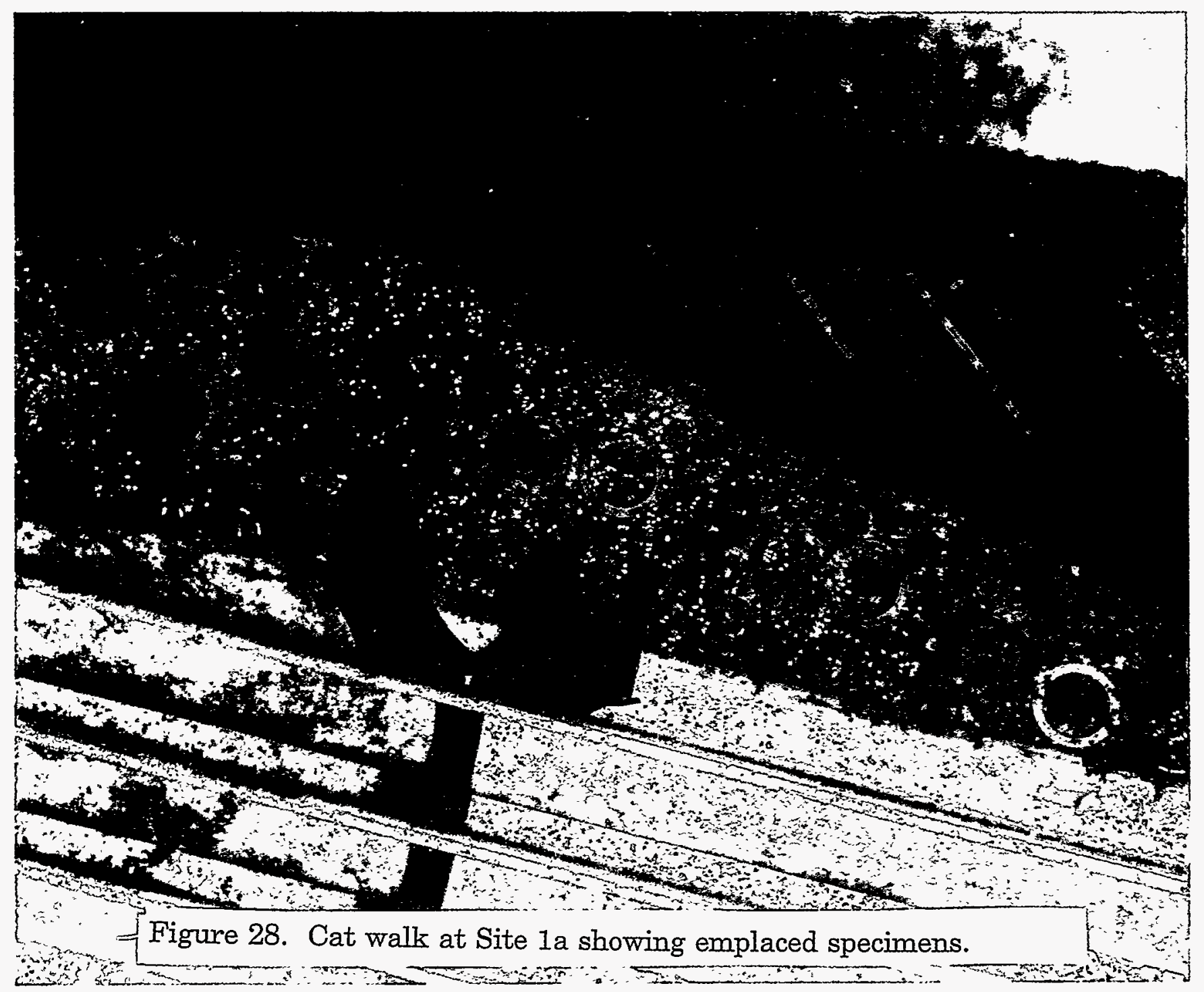




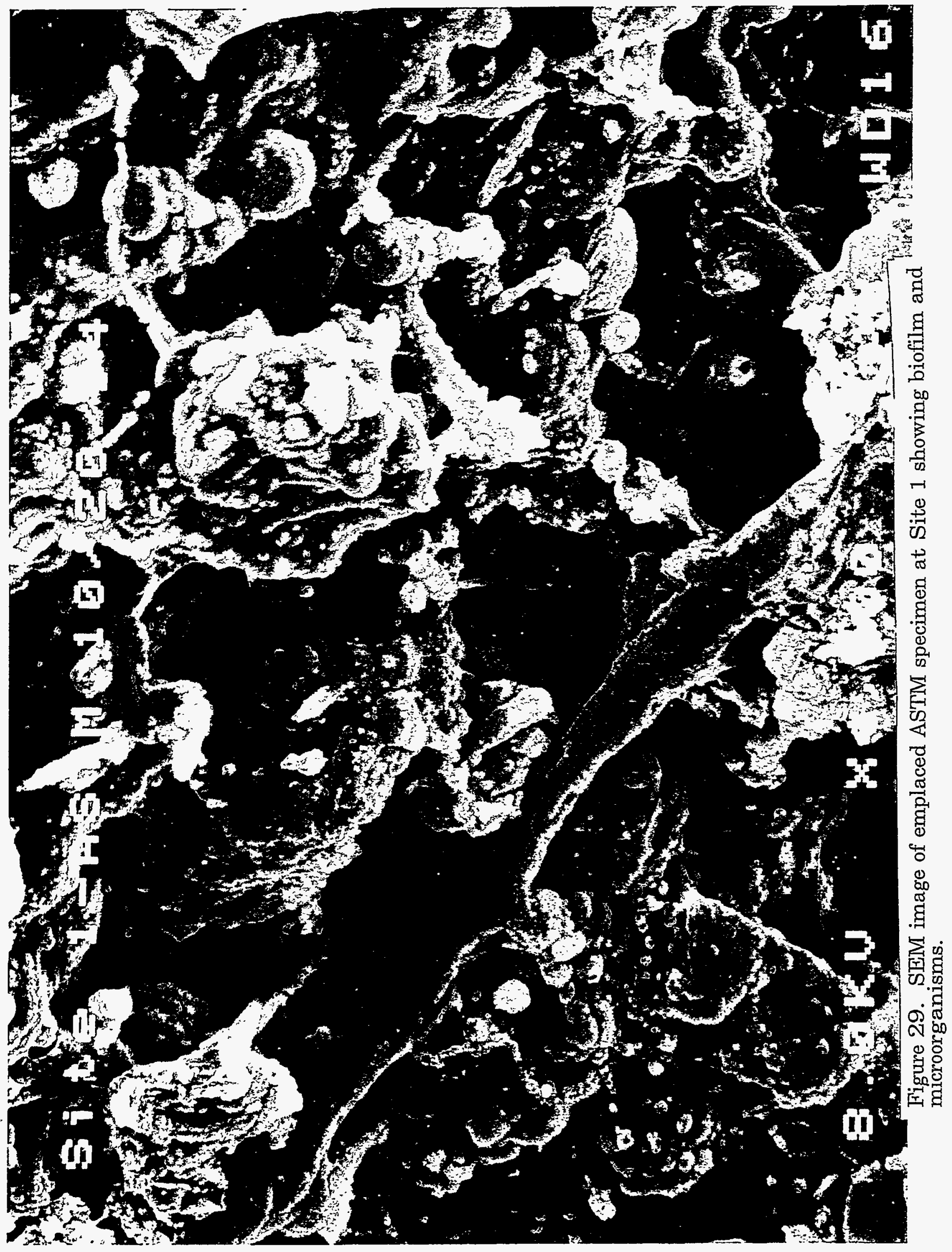




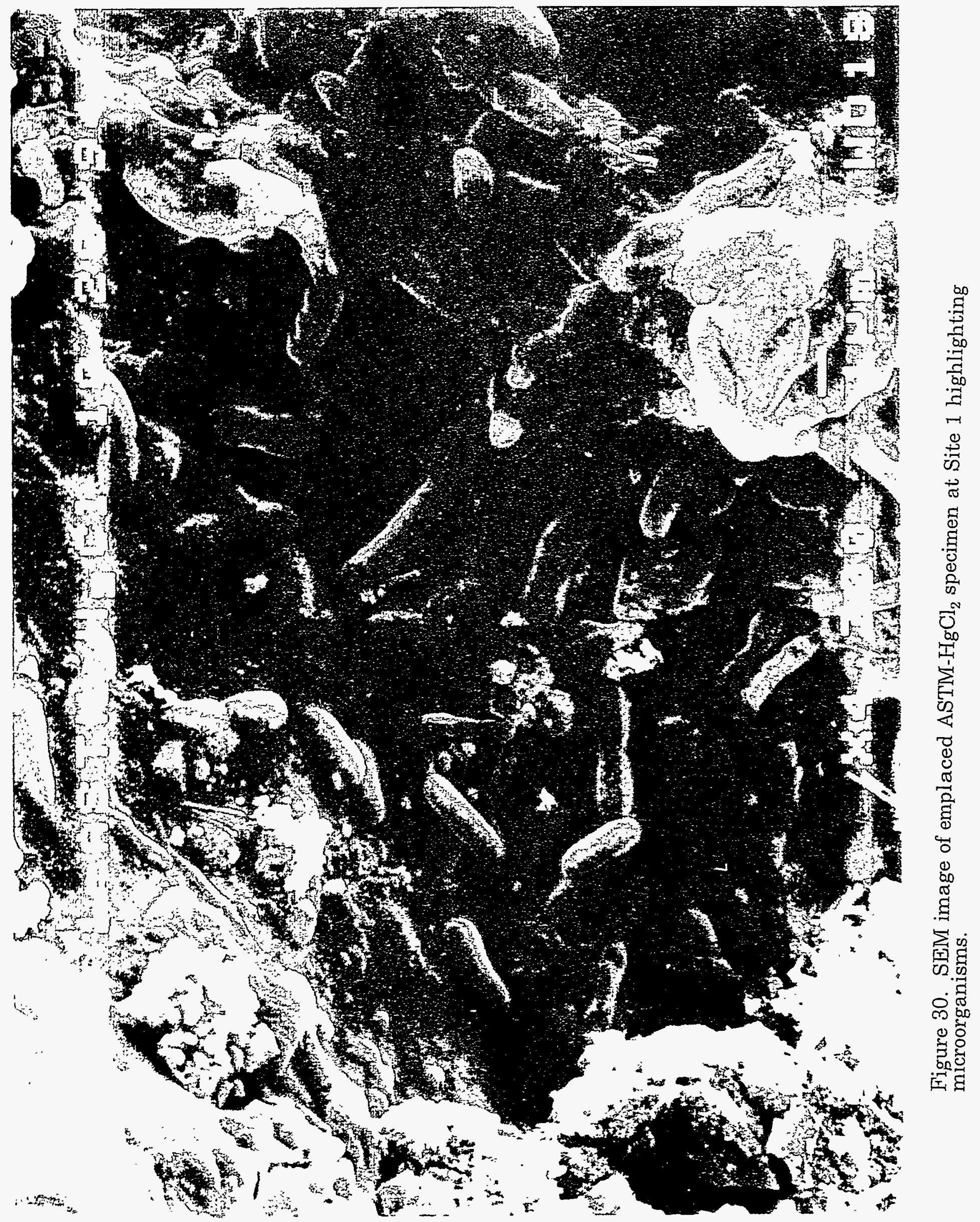




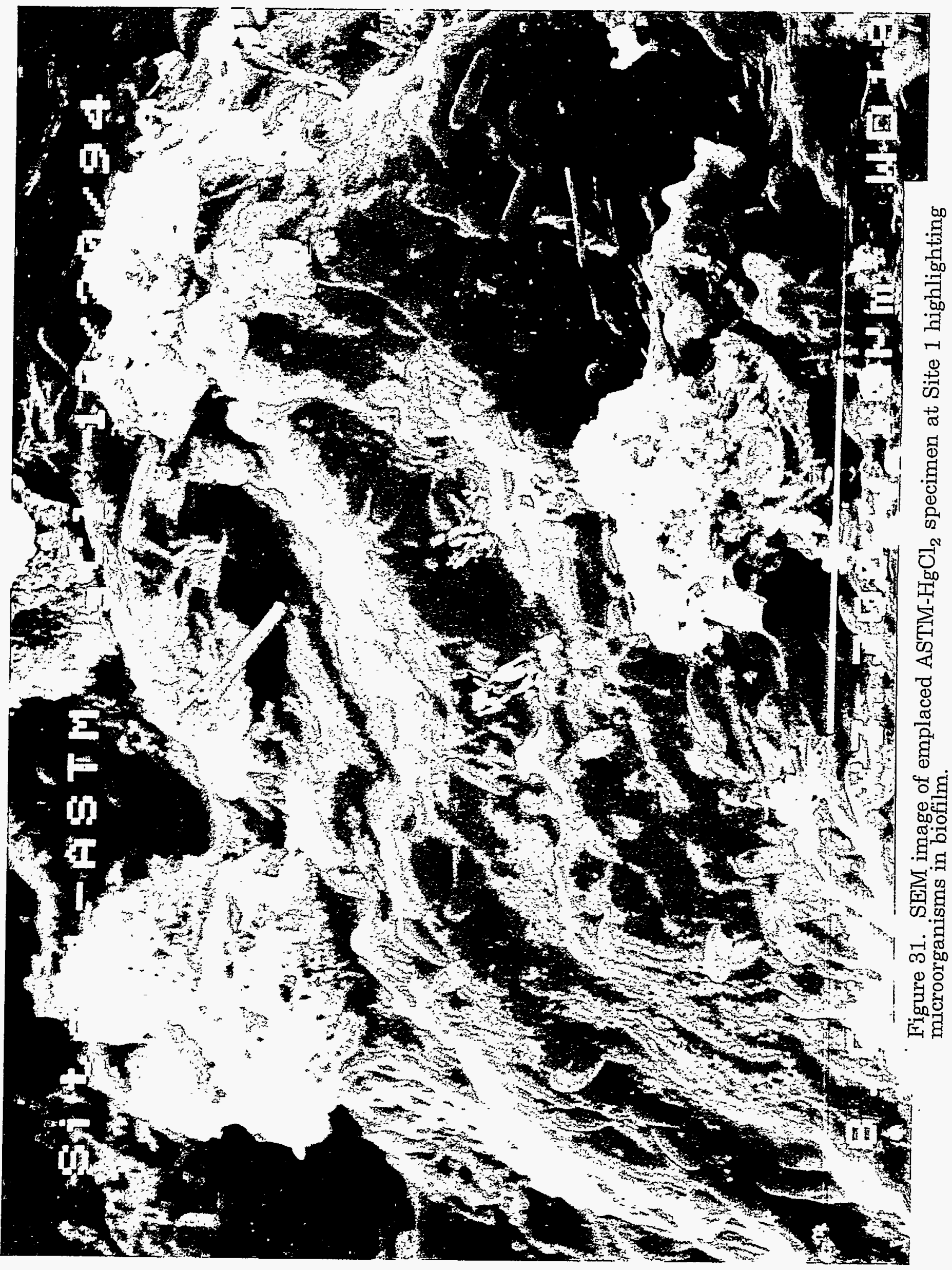




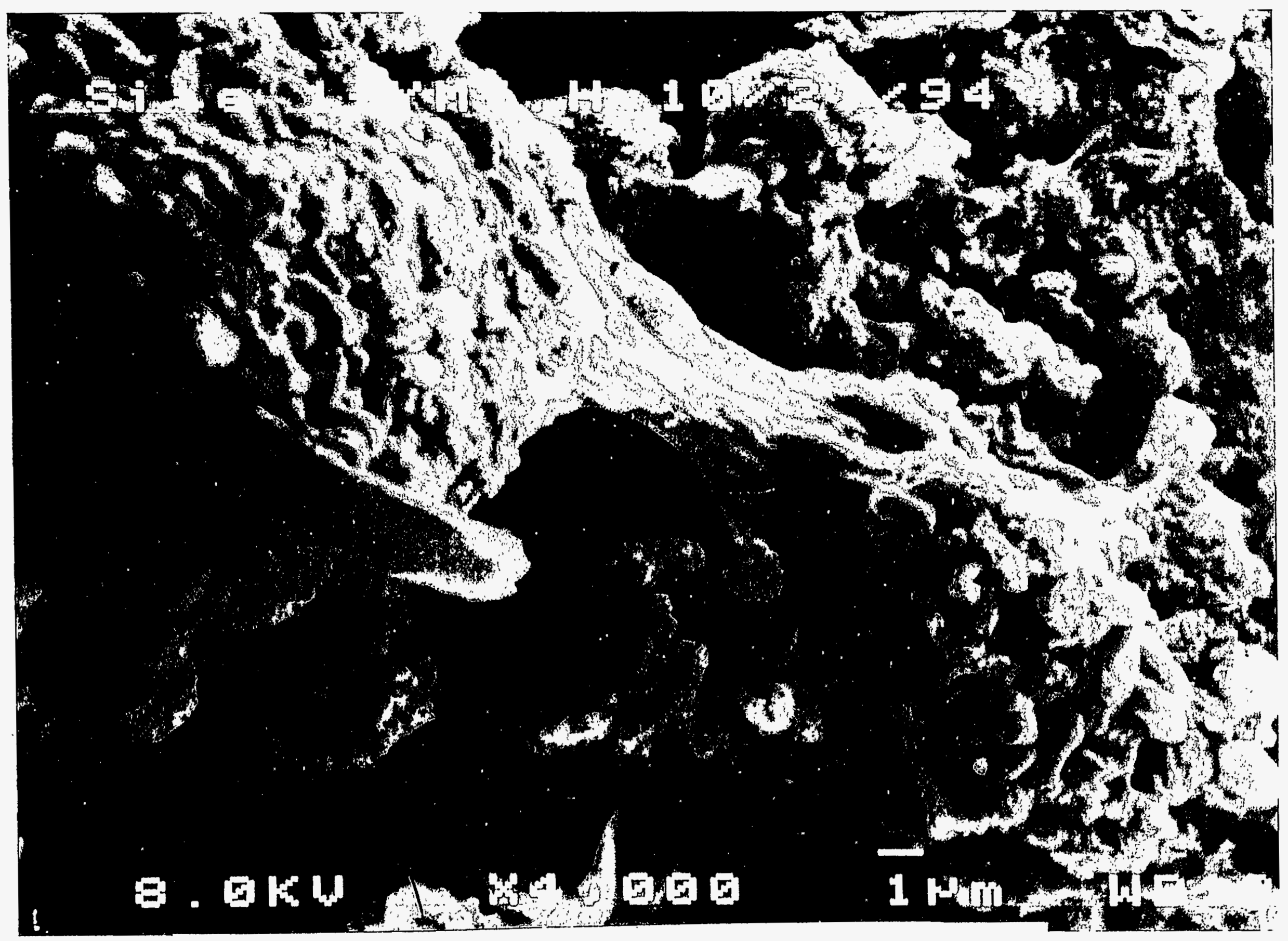

Figure 32. SEM image of emplaced YM Type $\mathrm{H}$ specimen at Site 1 highlighting microorganisms in biofilm. 


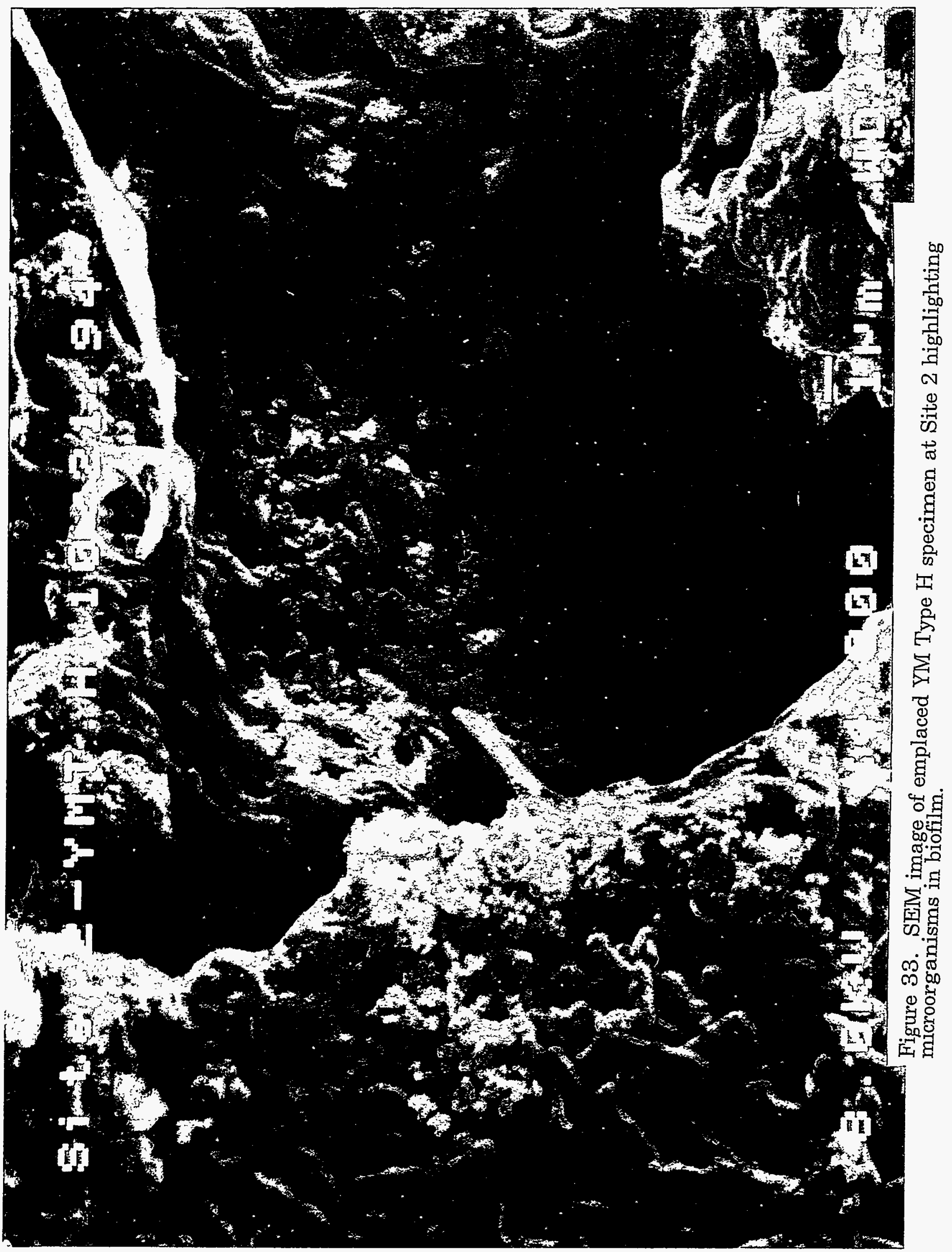




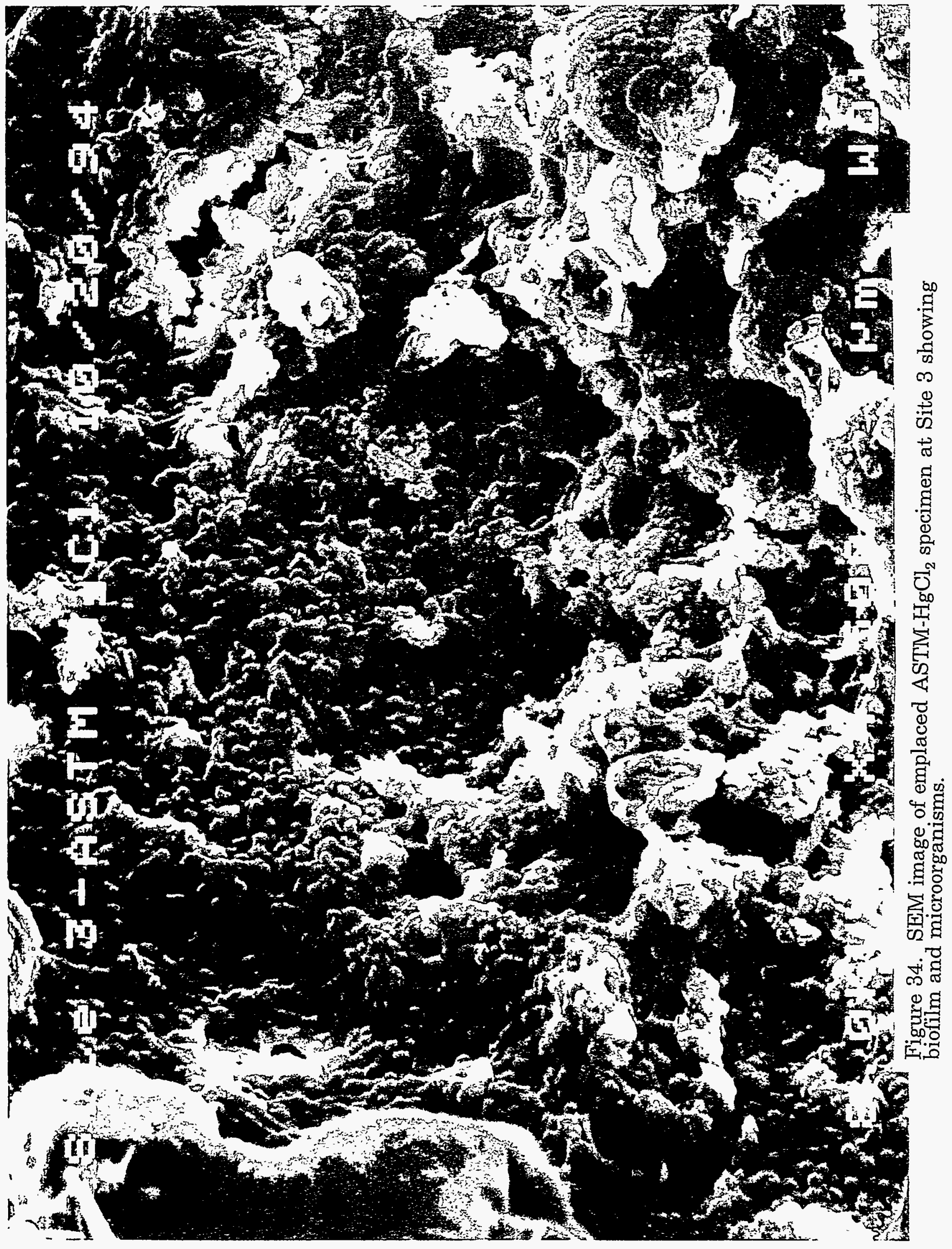




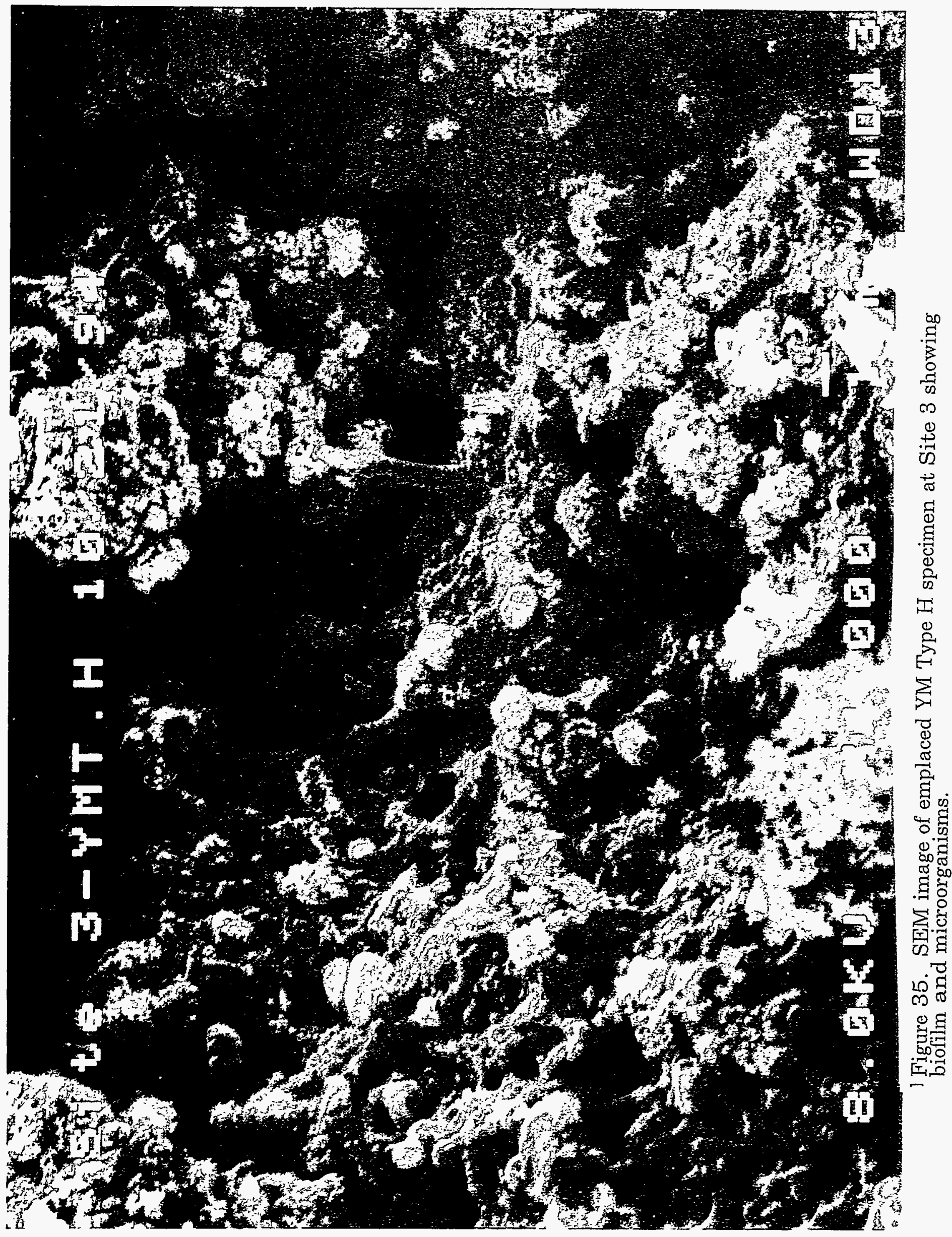




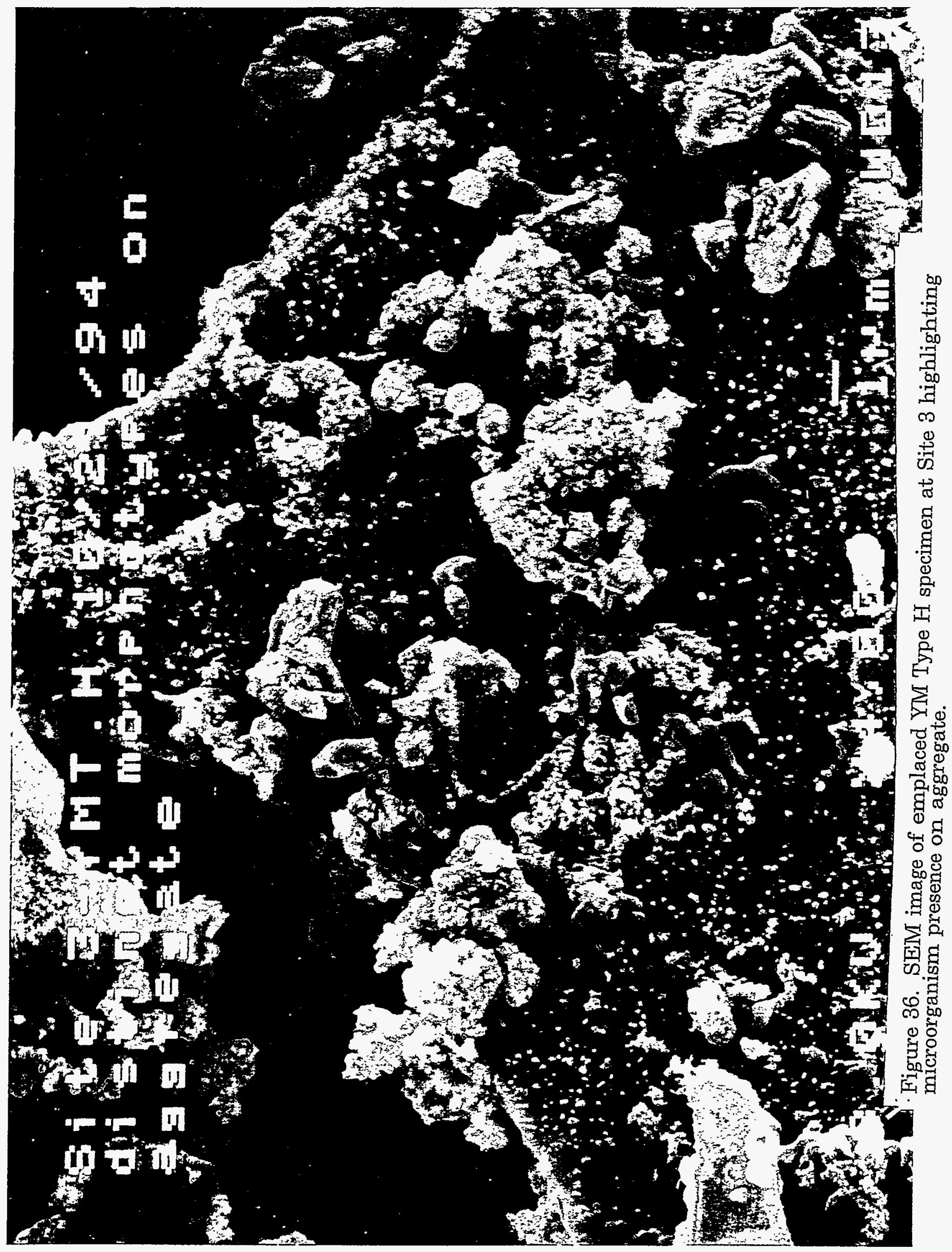




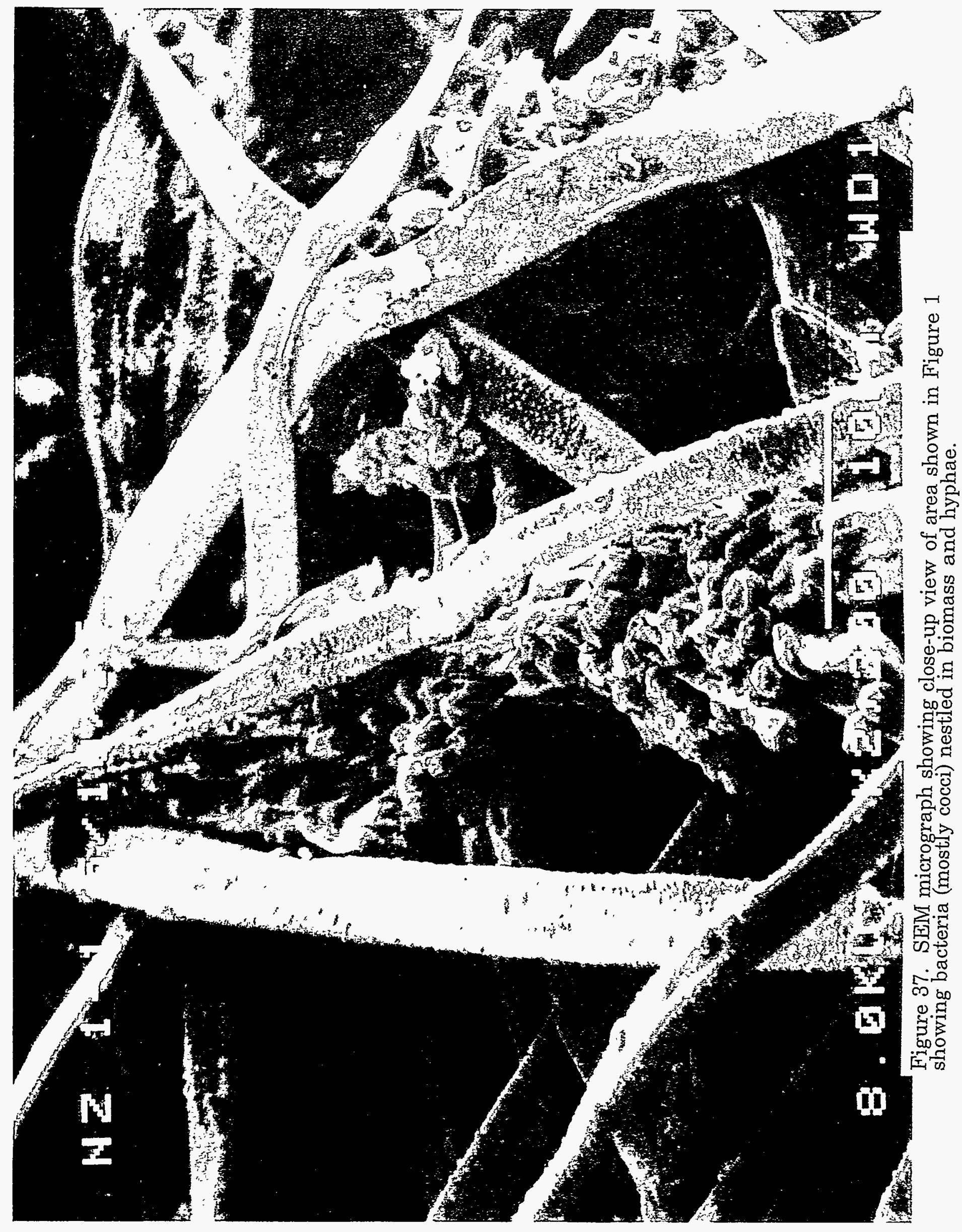




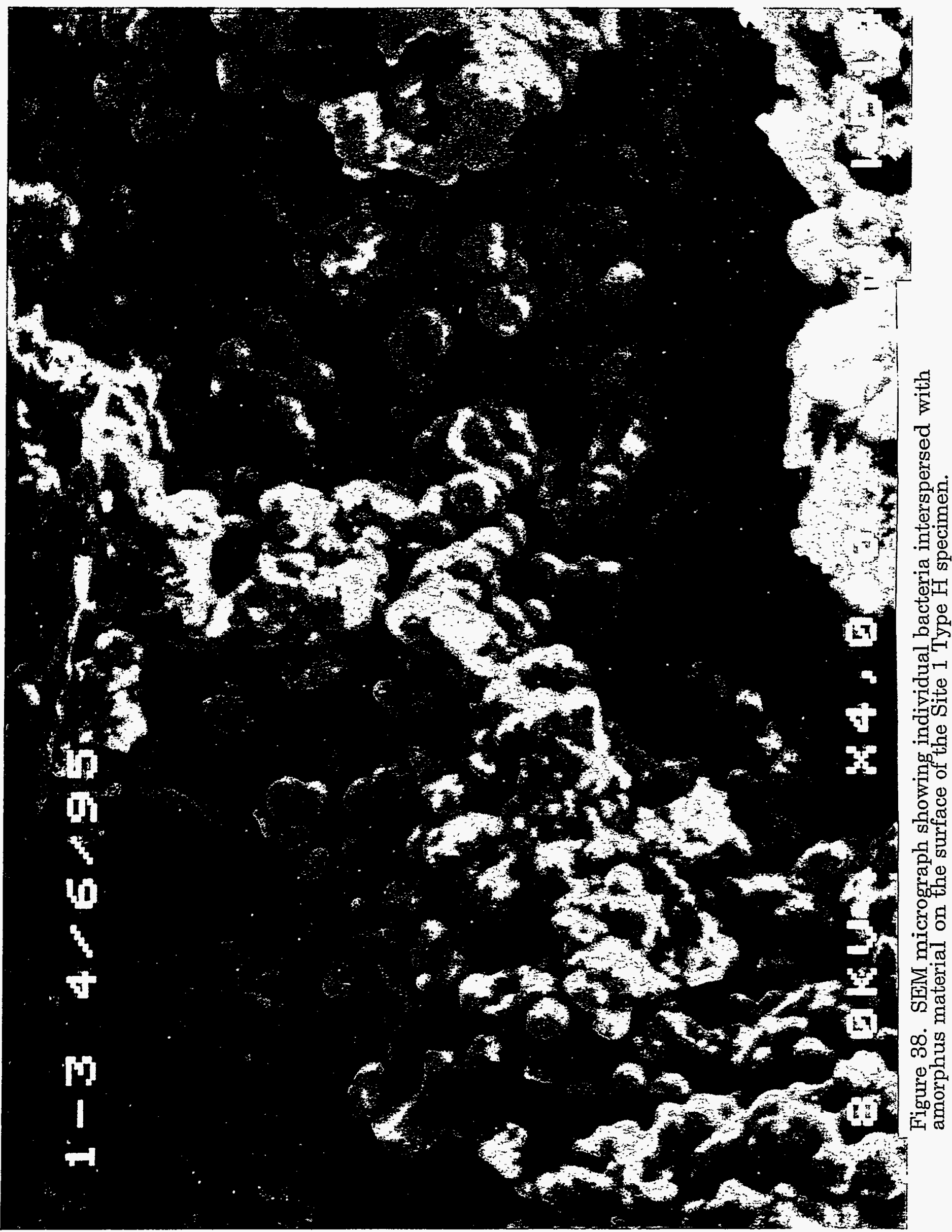




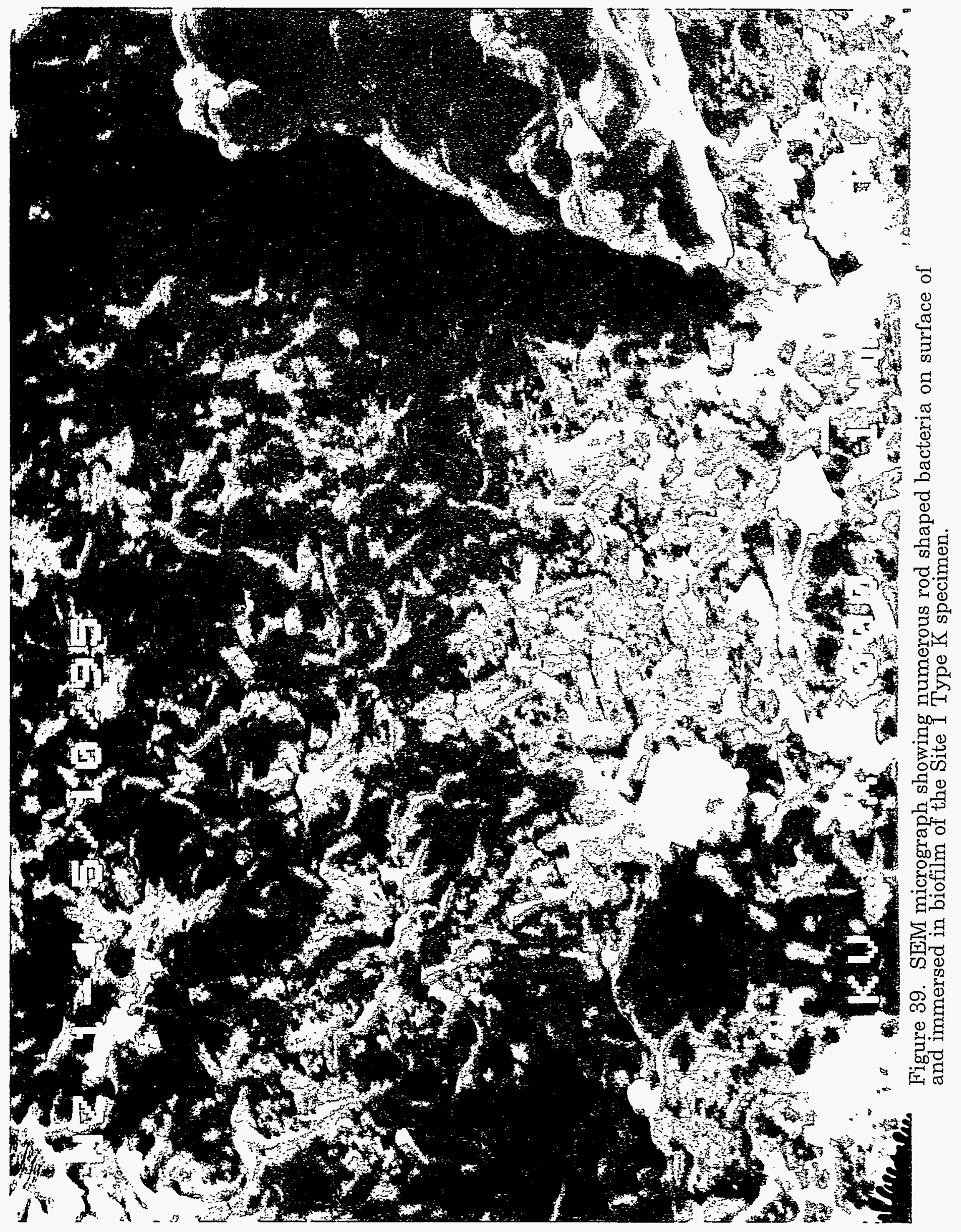




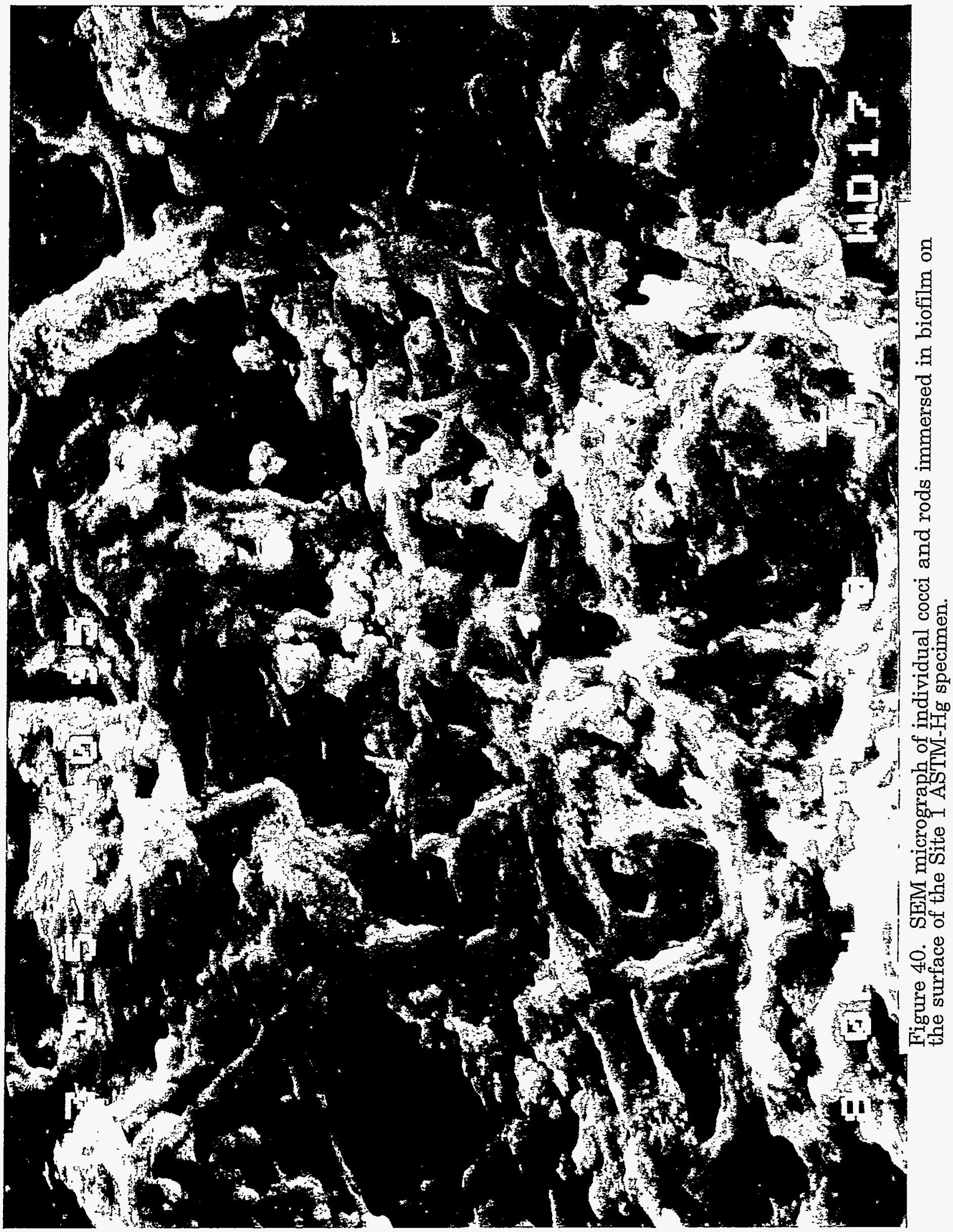




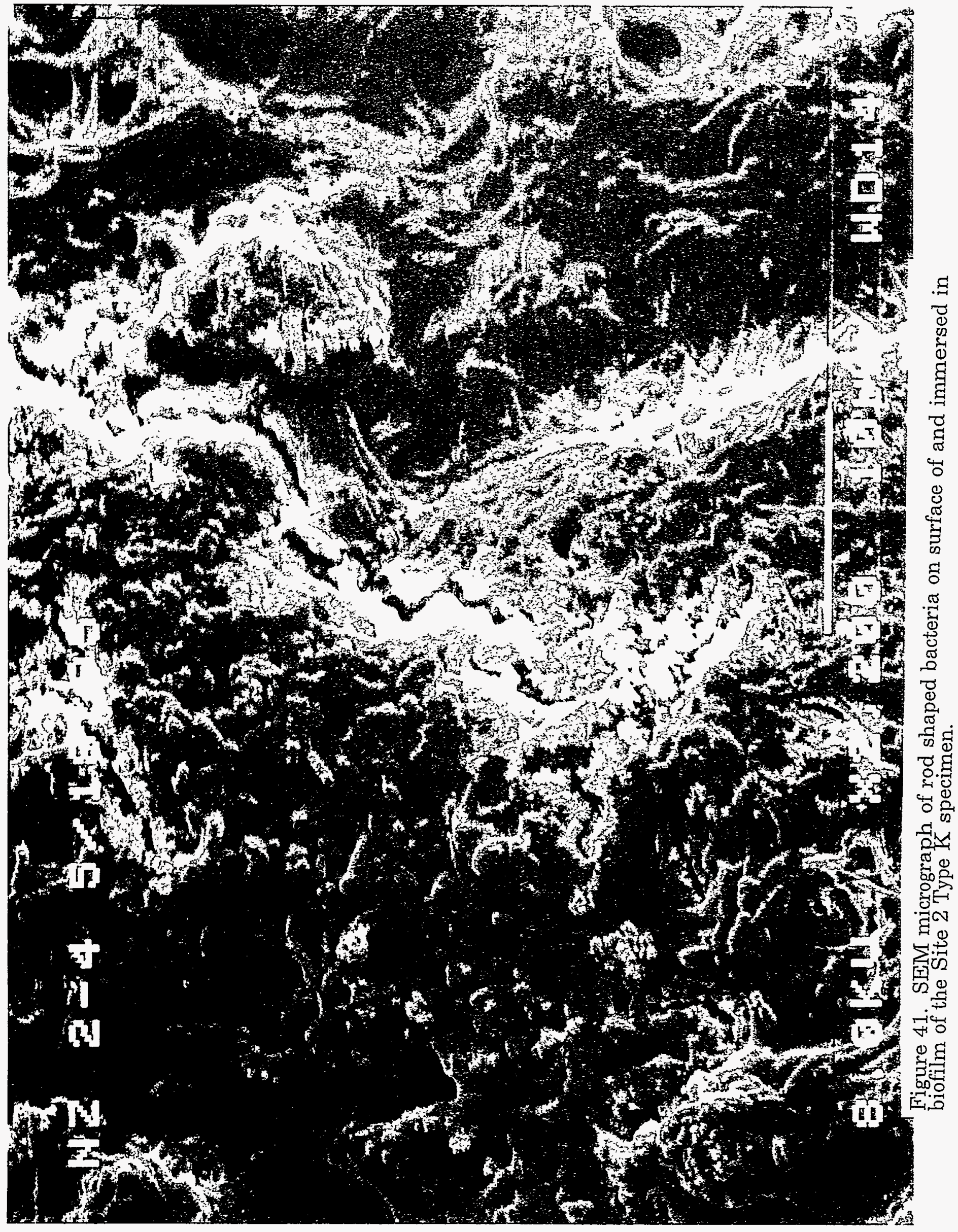




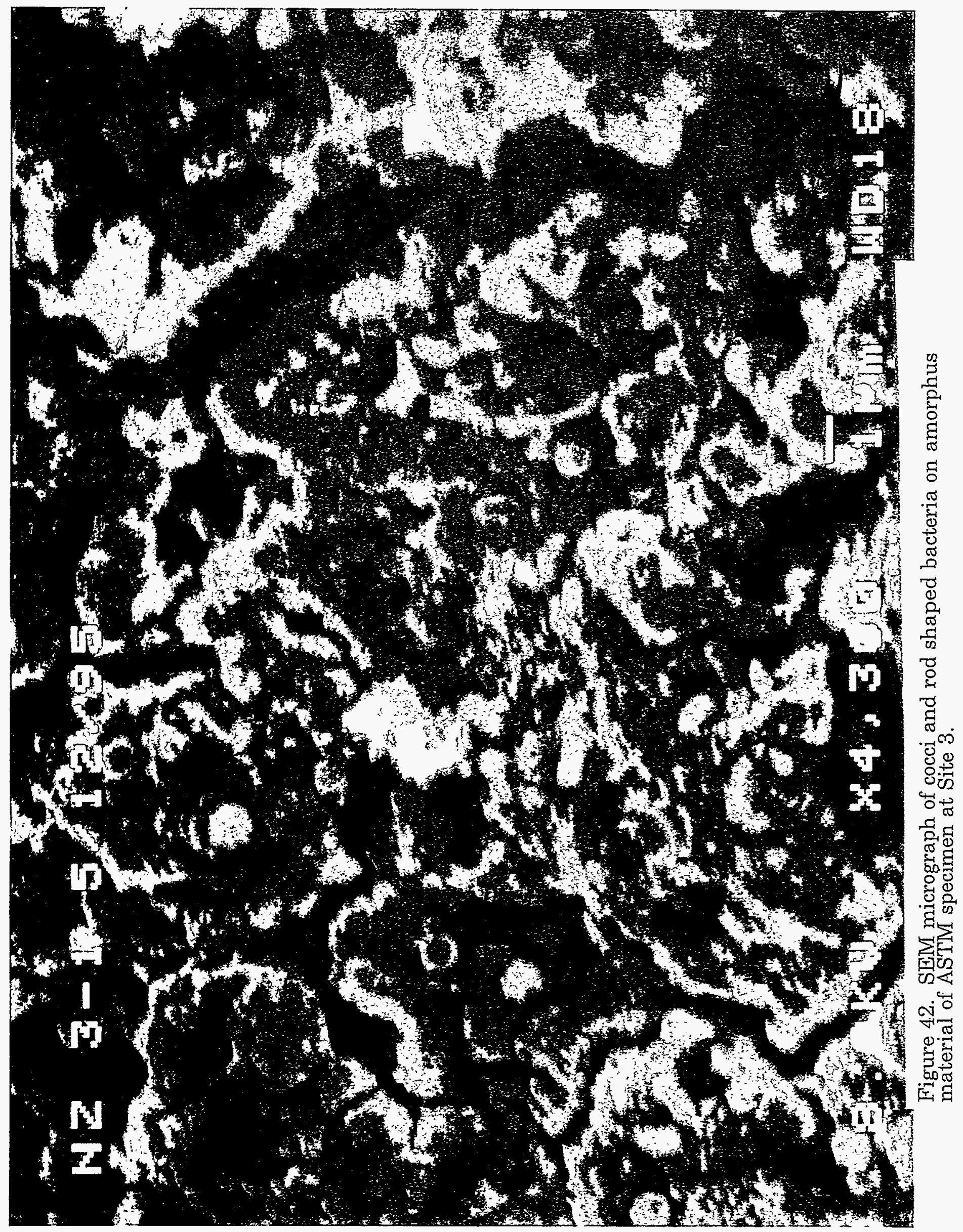




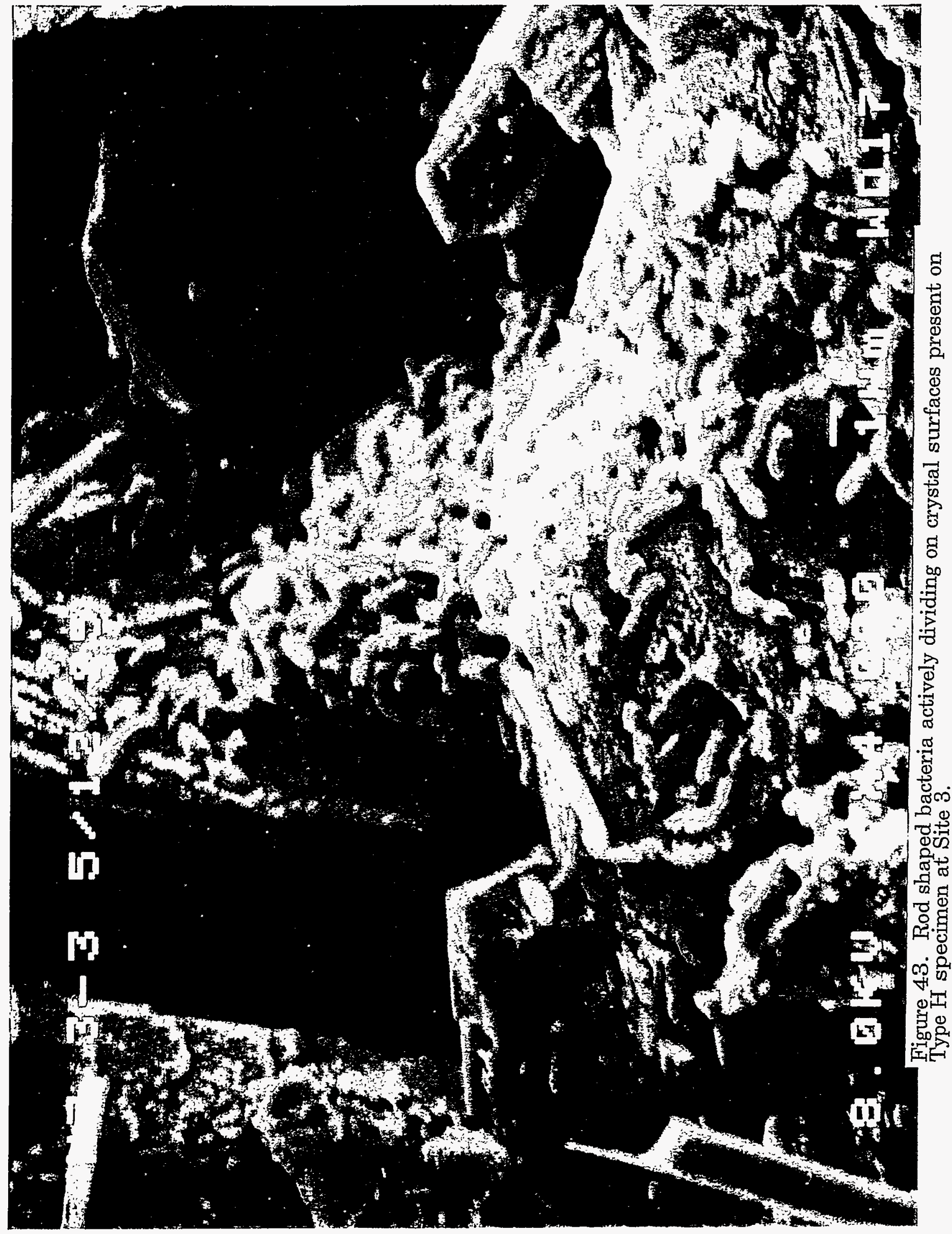




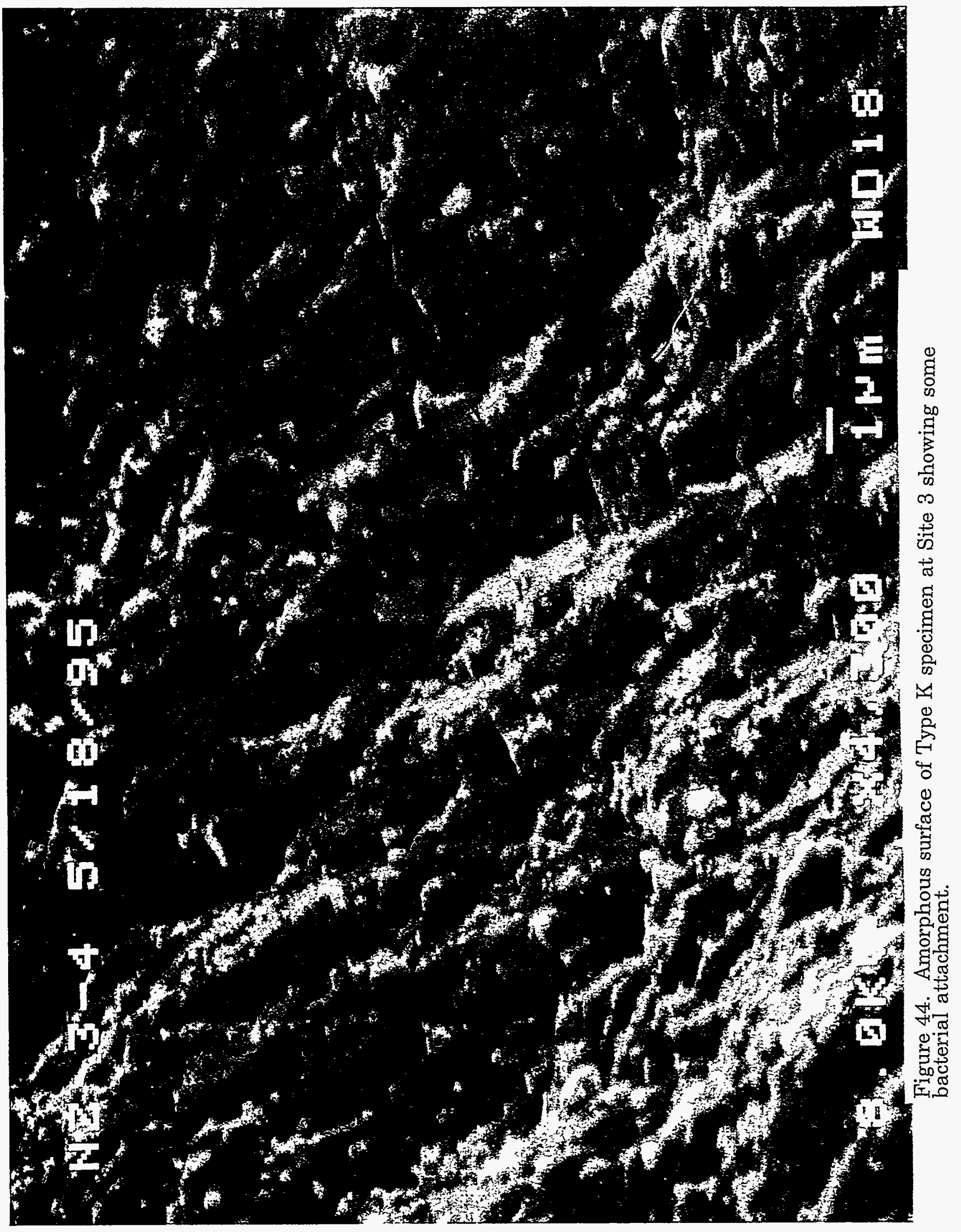




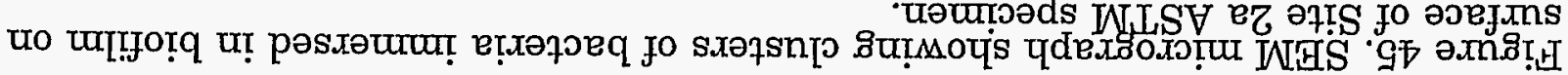

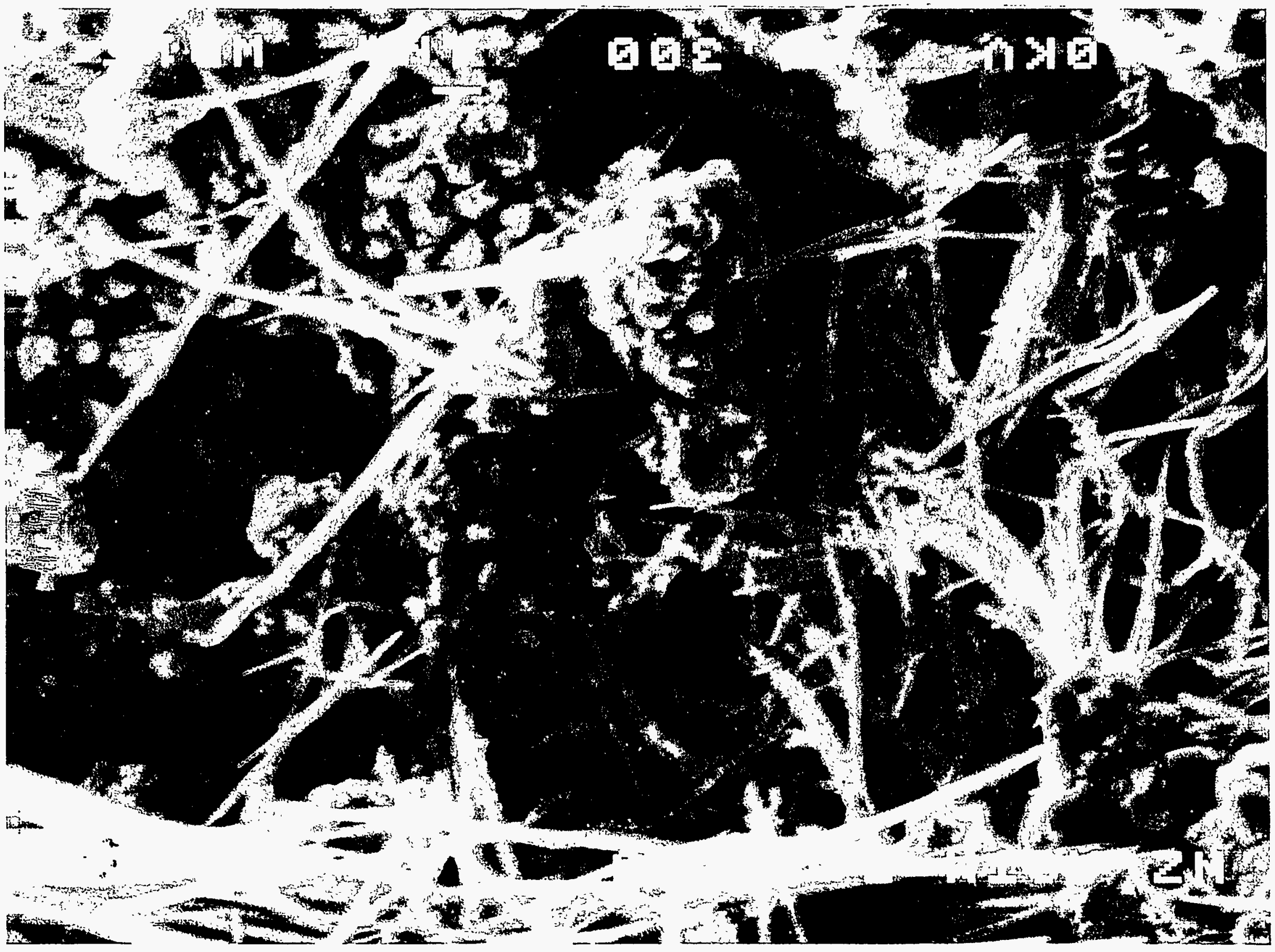




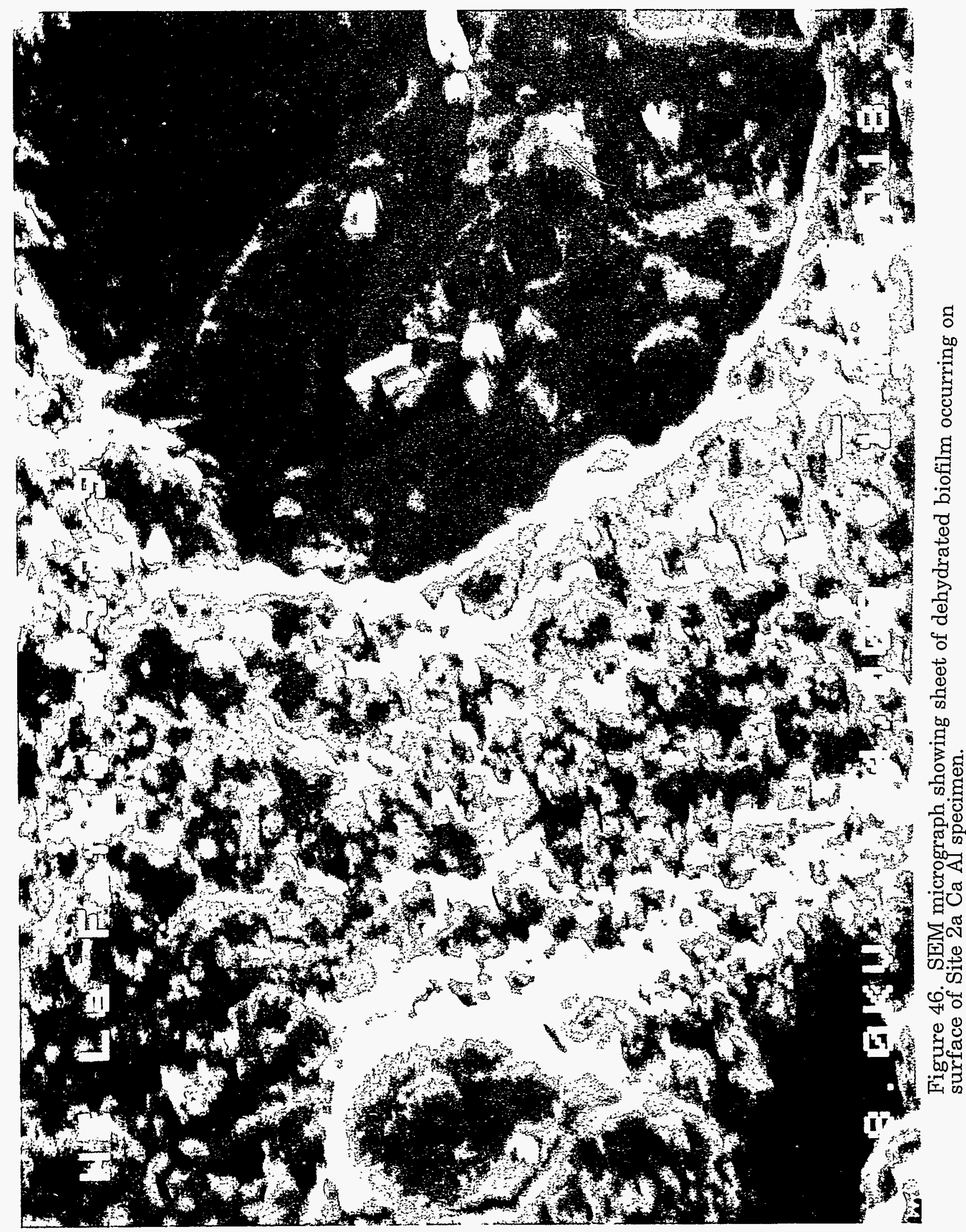




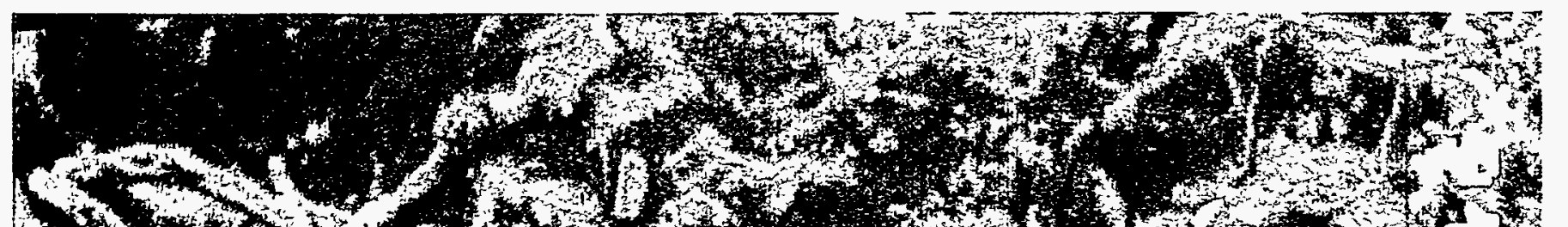

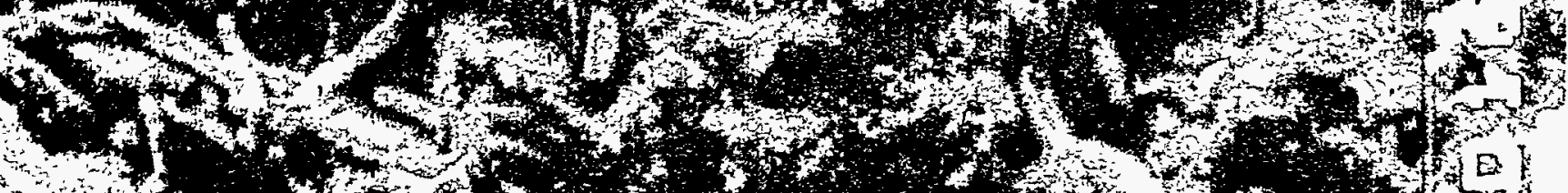

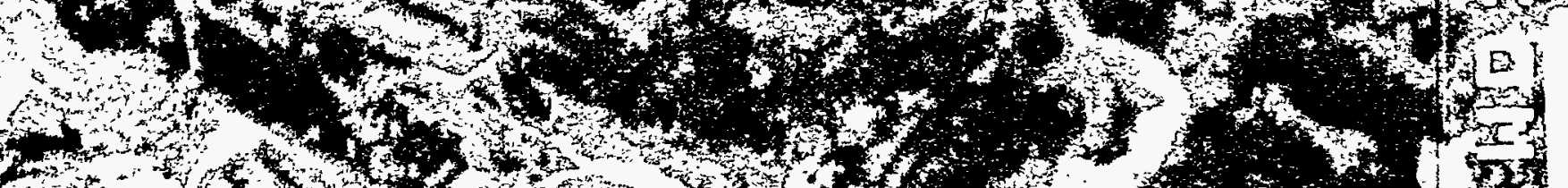

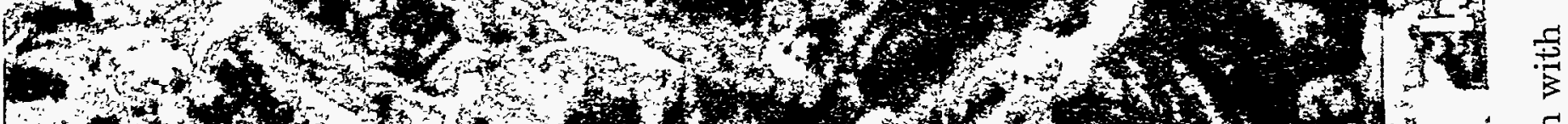

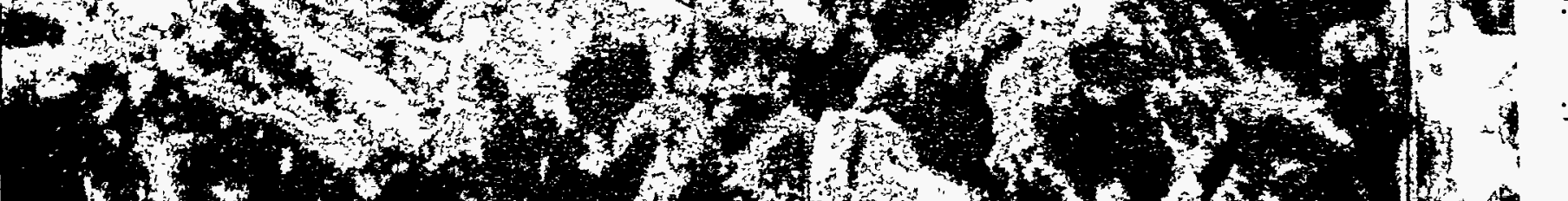

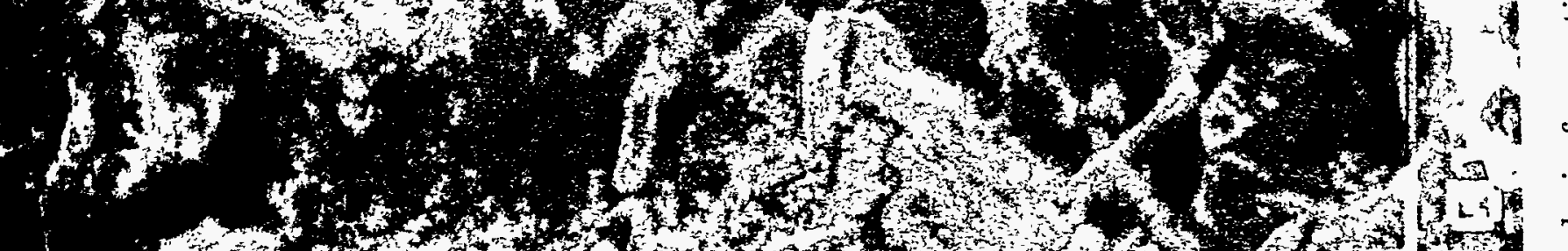

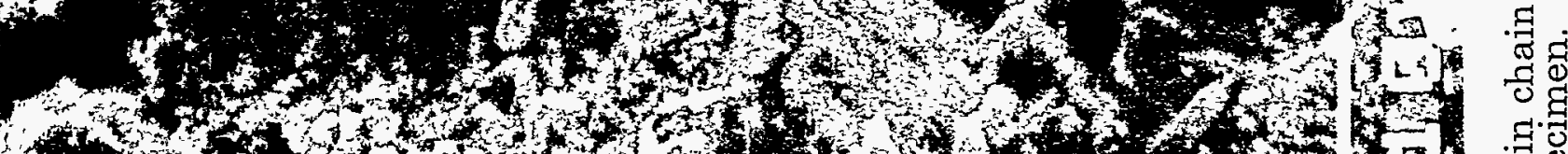

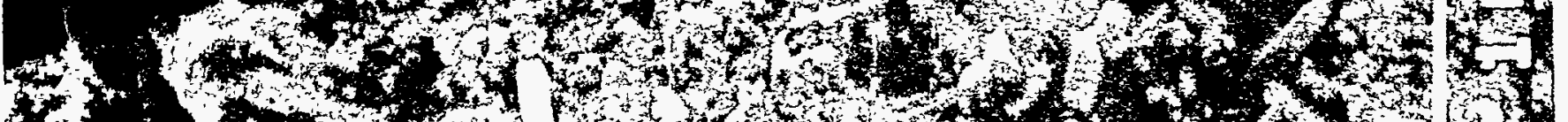

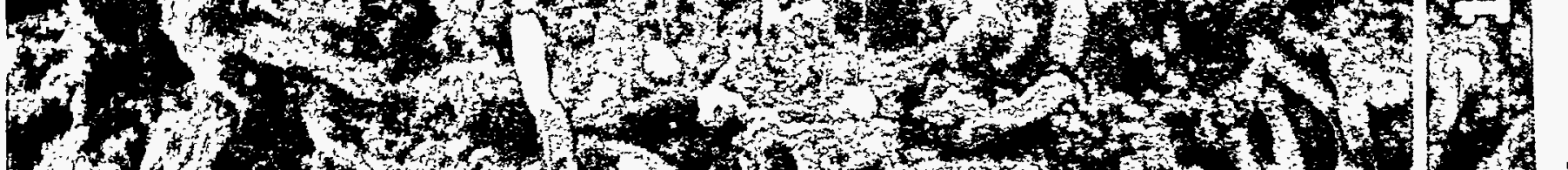
$34,616,0$ J

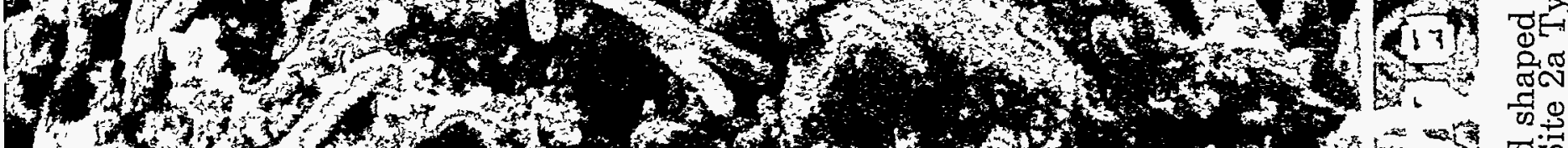

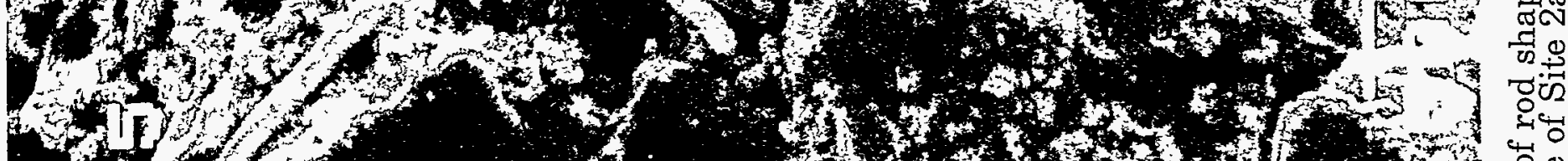

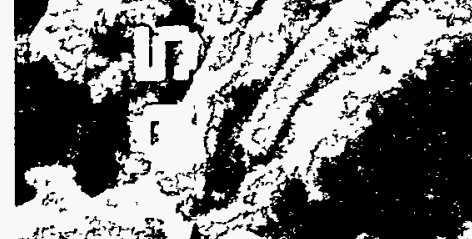

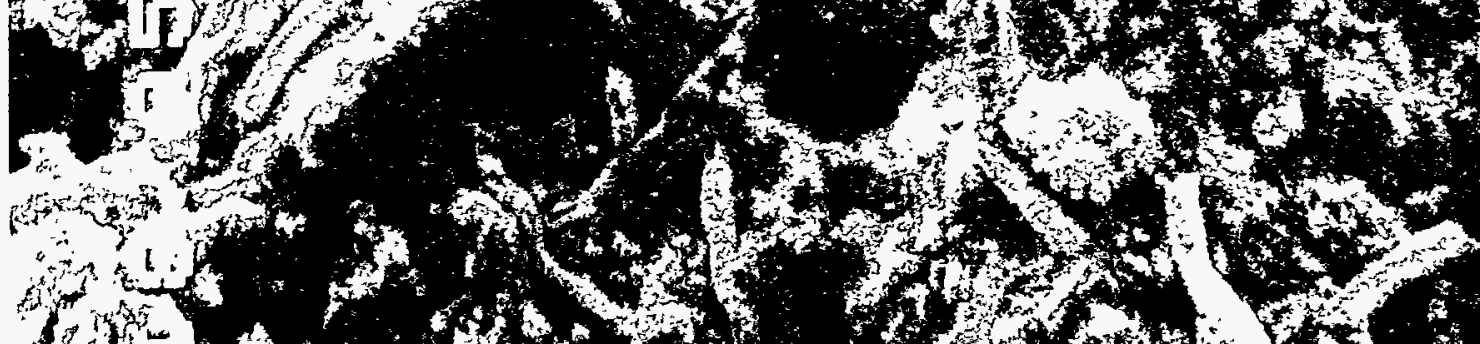

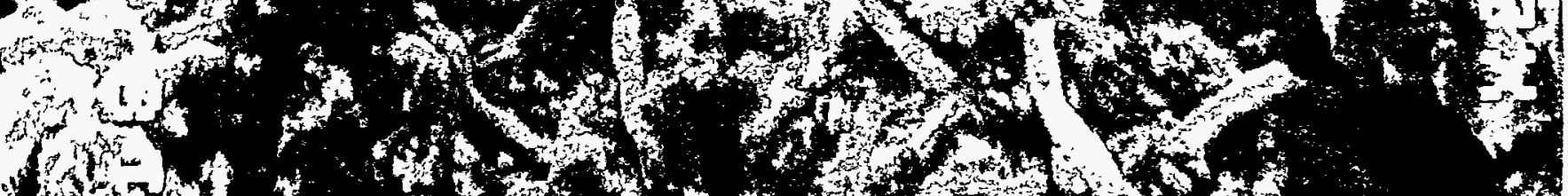

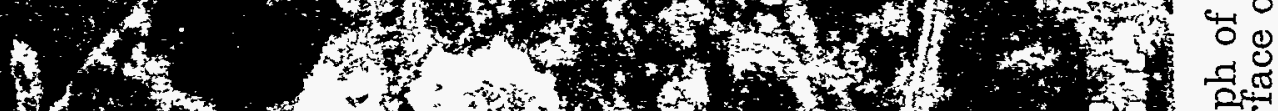

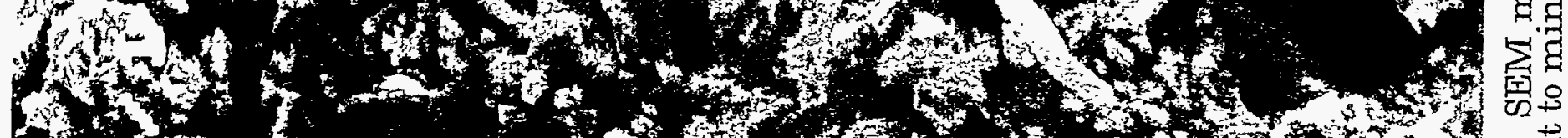

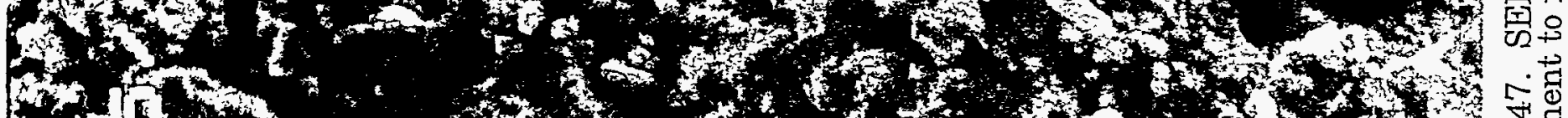

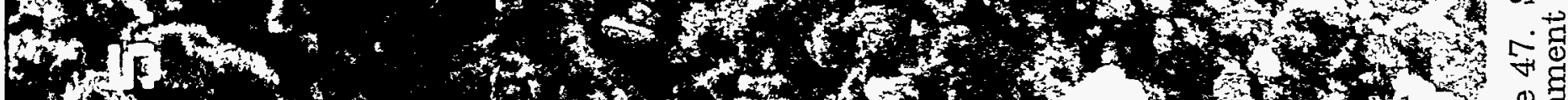

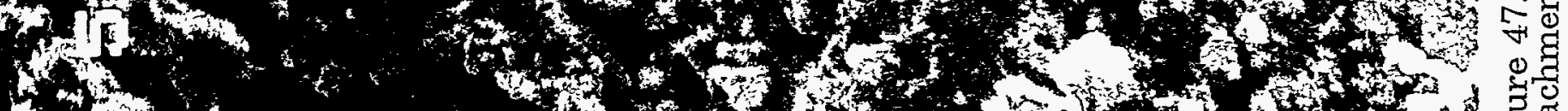
4.

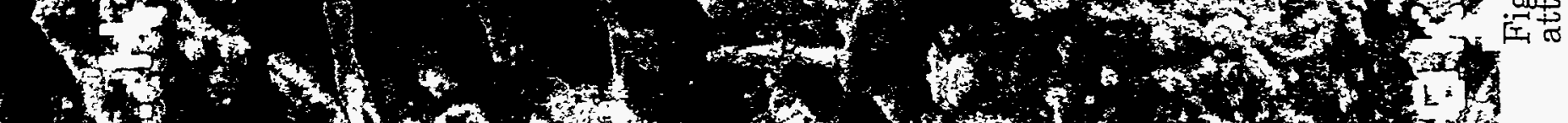

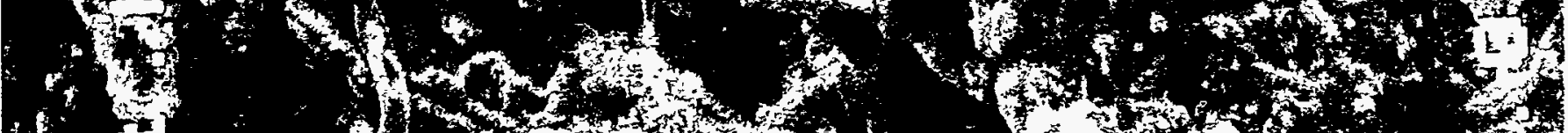

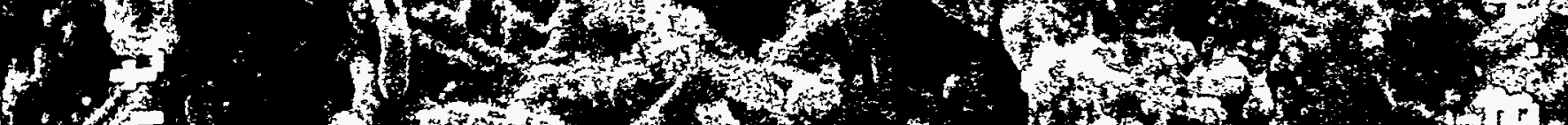

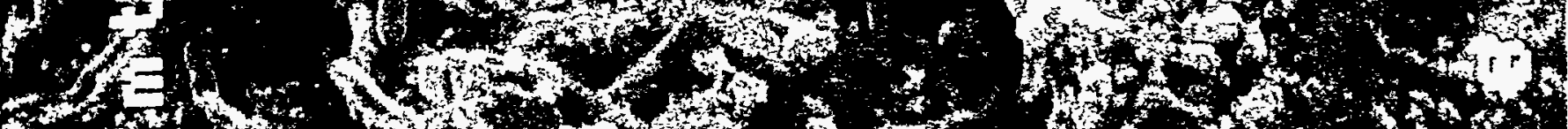

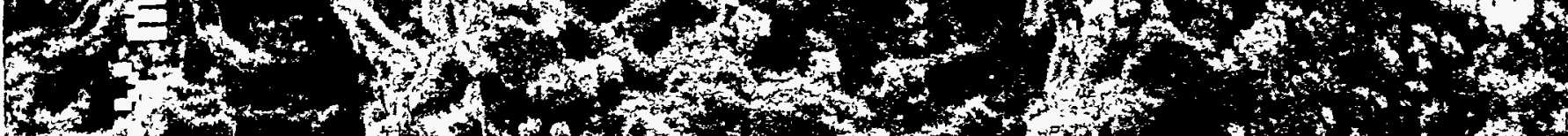

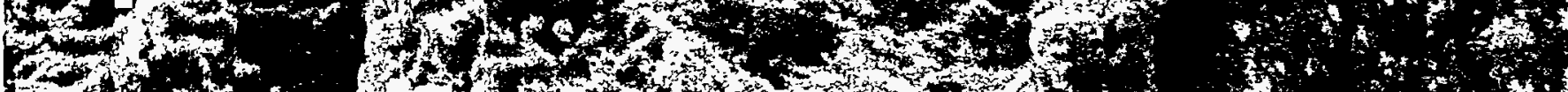
$2 x-2 x=3$ Con 


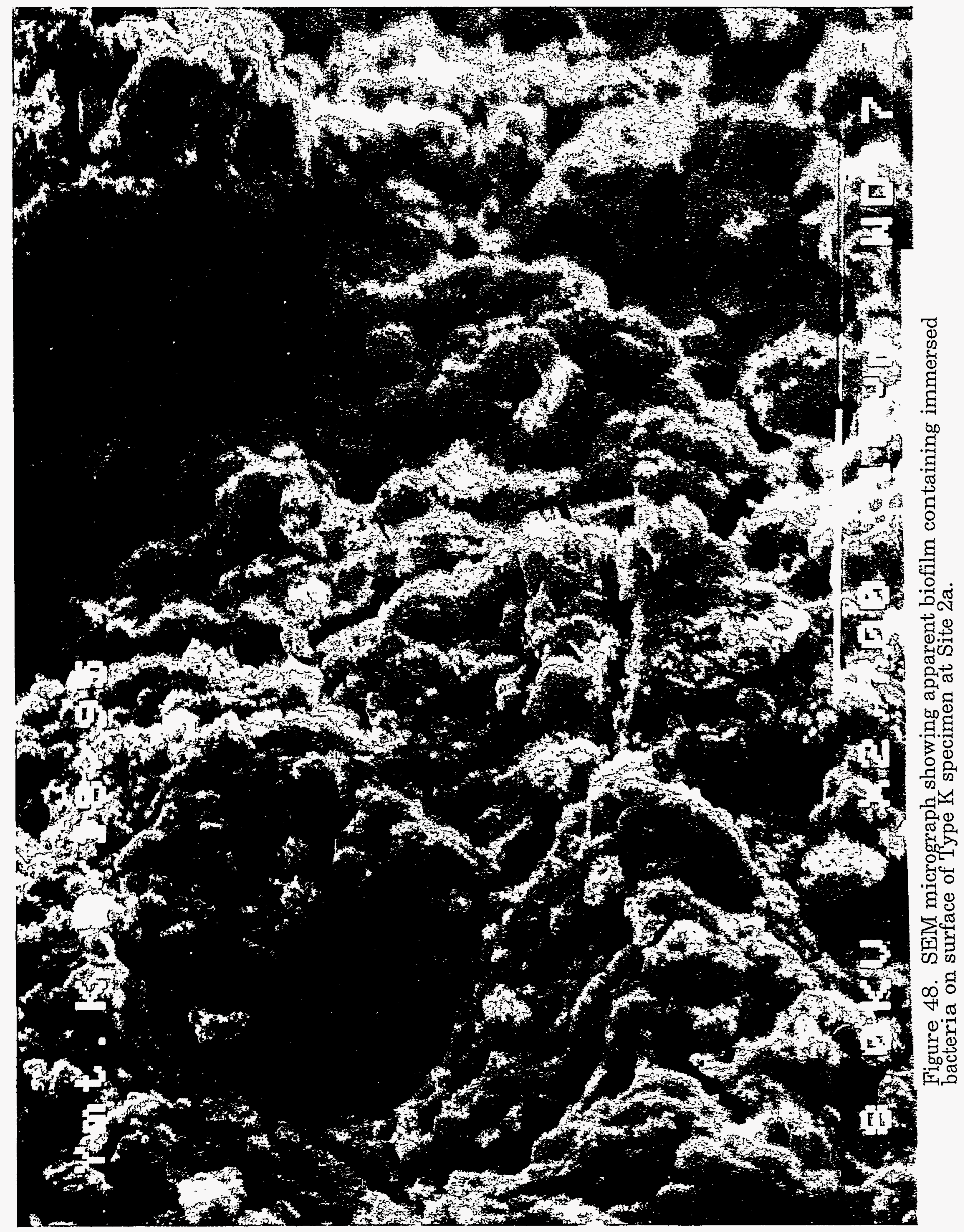




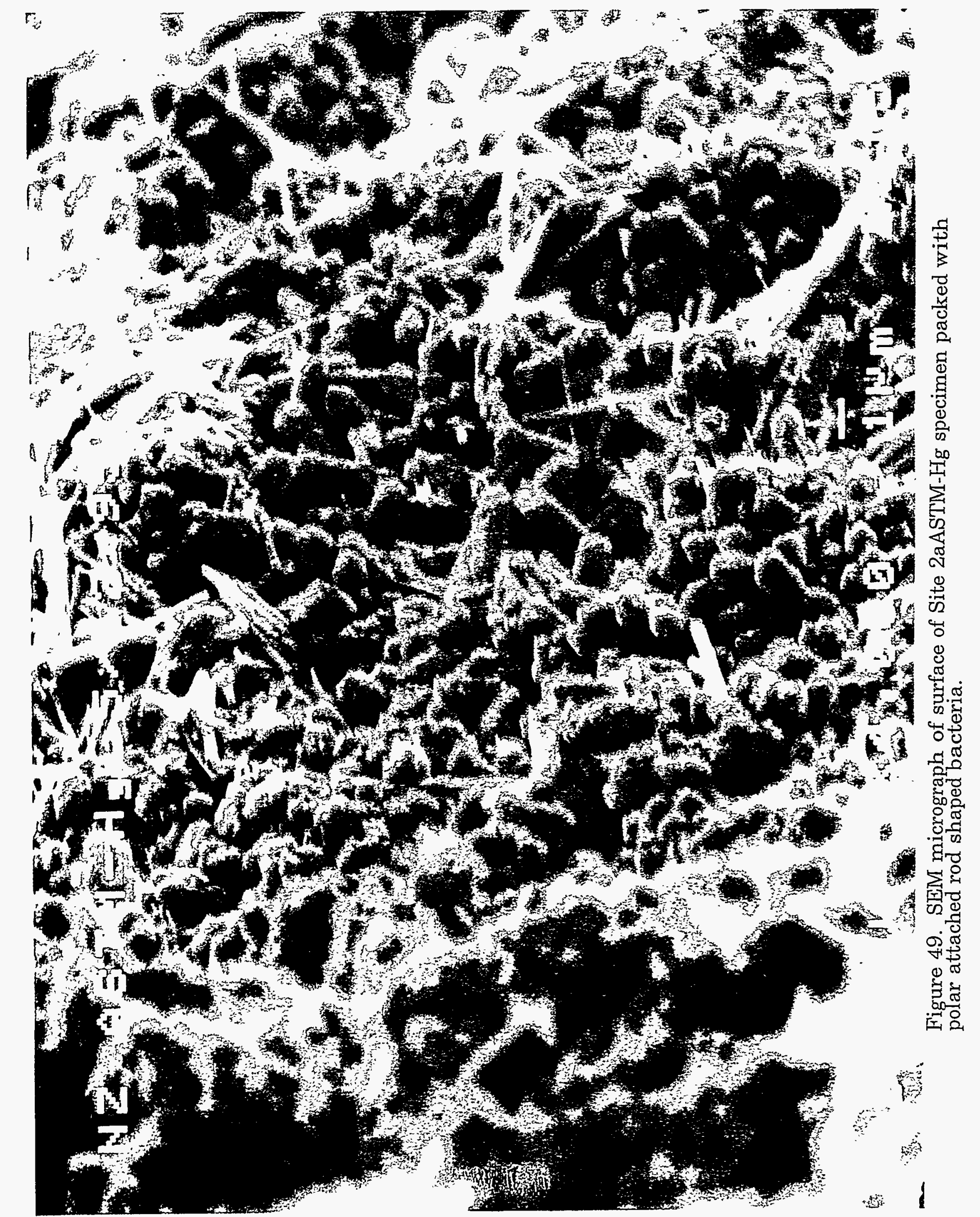




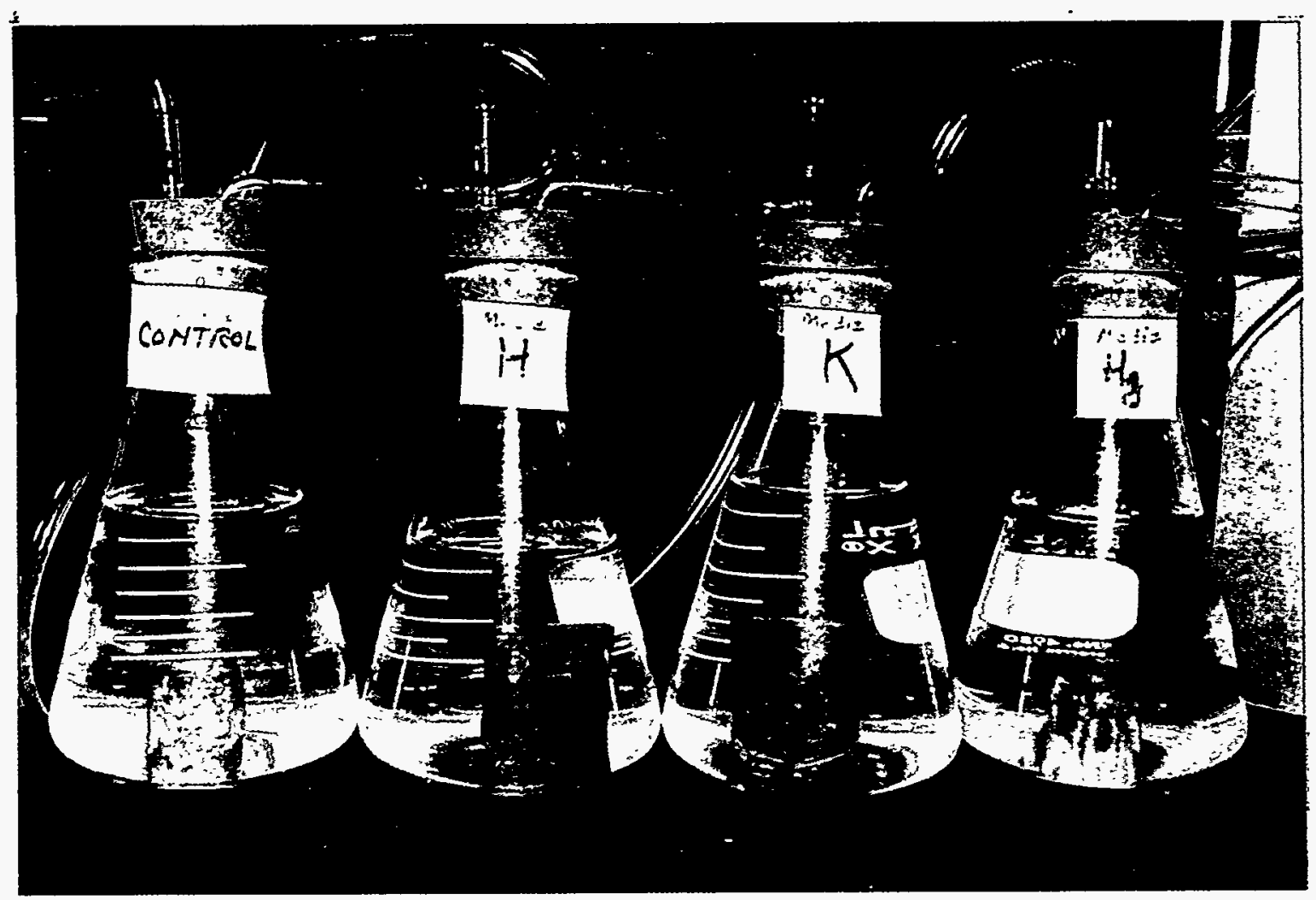

Figure 50. Test specimens after 1 day immersion in sterile medium.

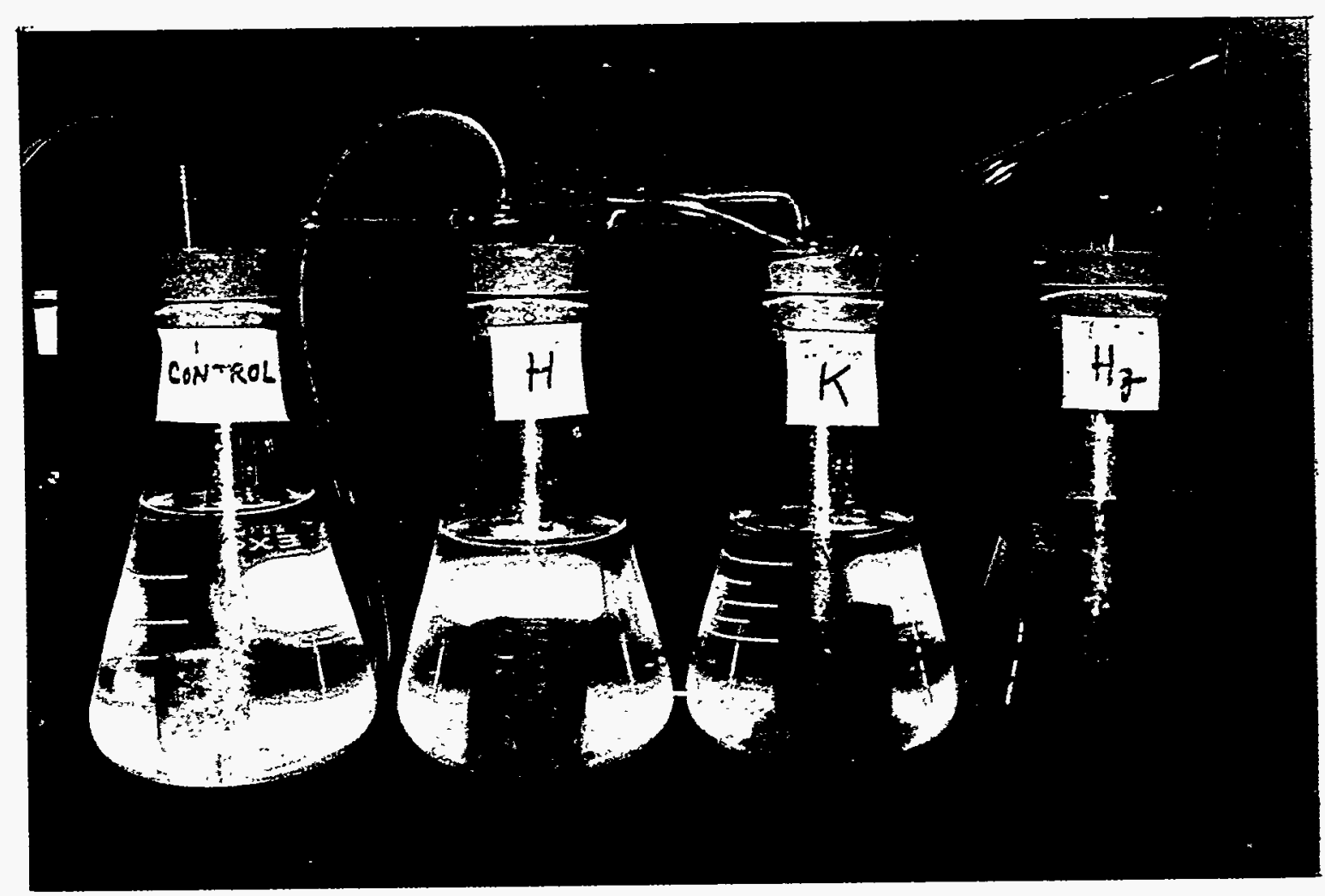

Figure 51. Test specimens after 1 day immersion in thiobacilli lixiviant. 


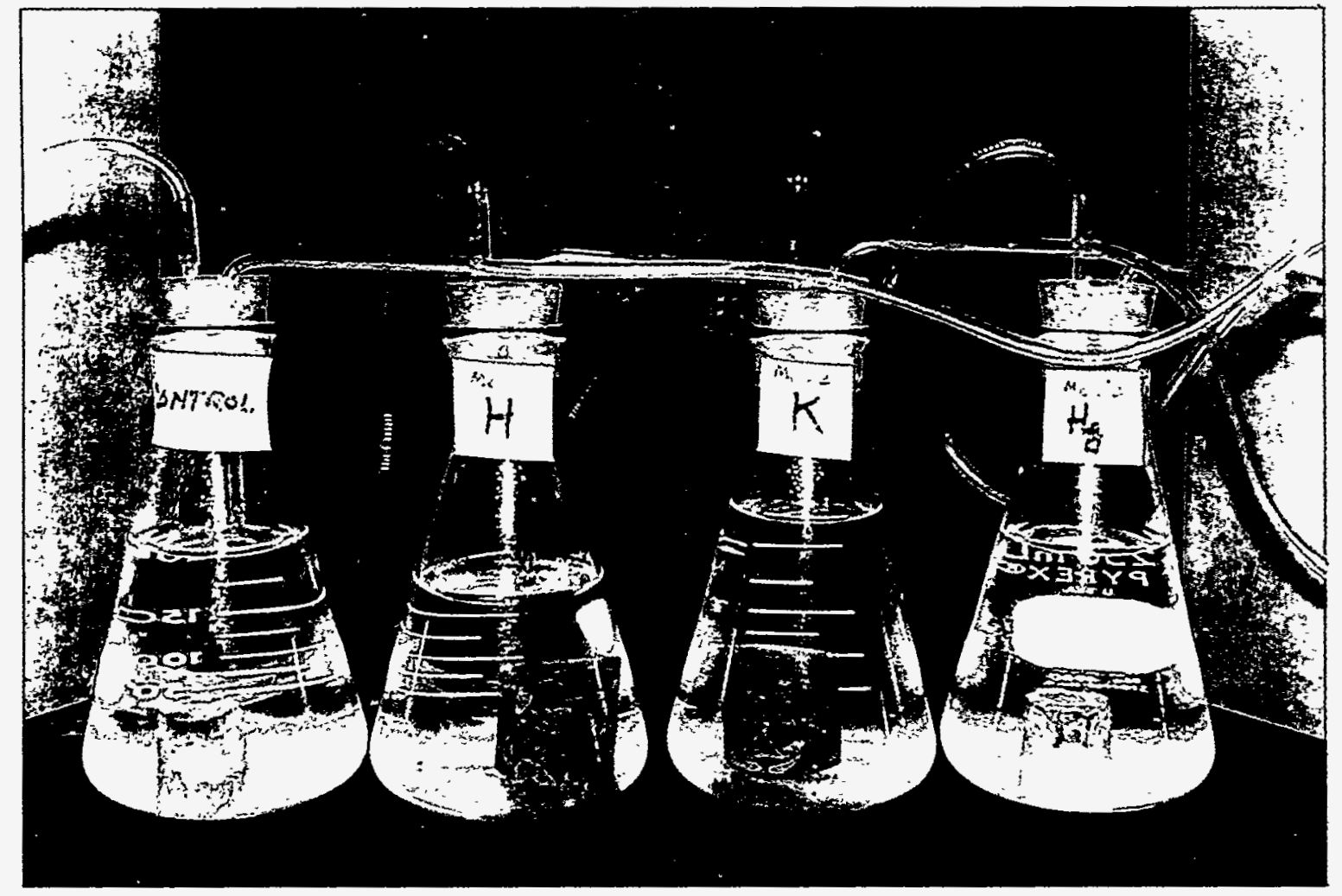

Figure 52. Test specimens after 29 days immersion in sterile medium.

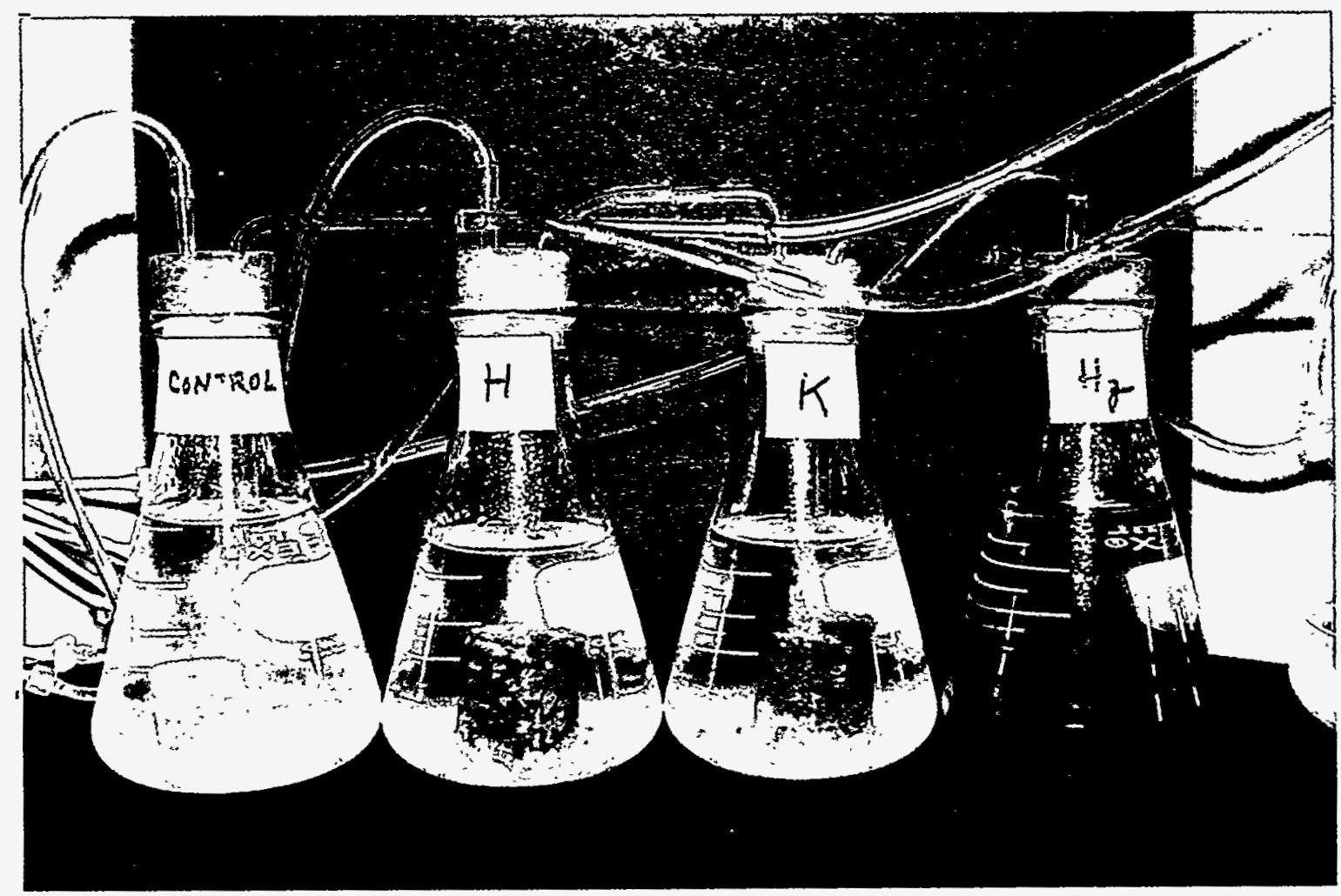

Figure 53. Test specimens after 29 days immersion in thiobacilli lixiviant. 

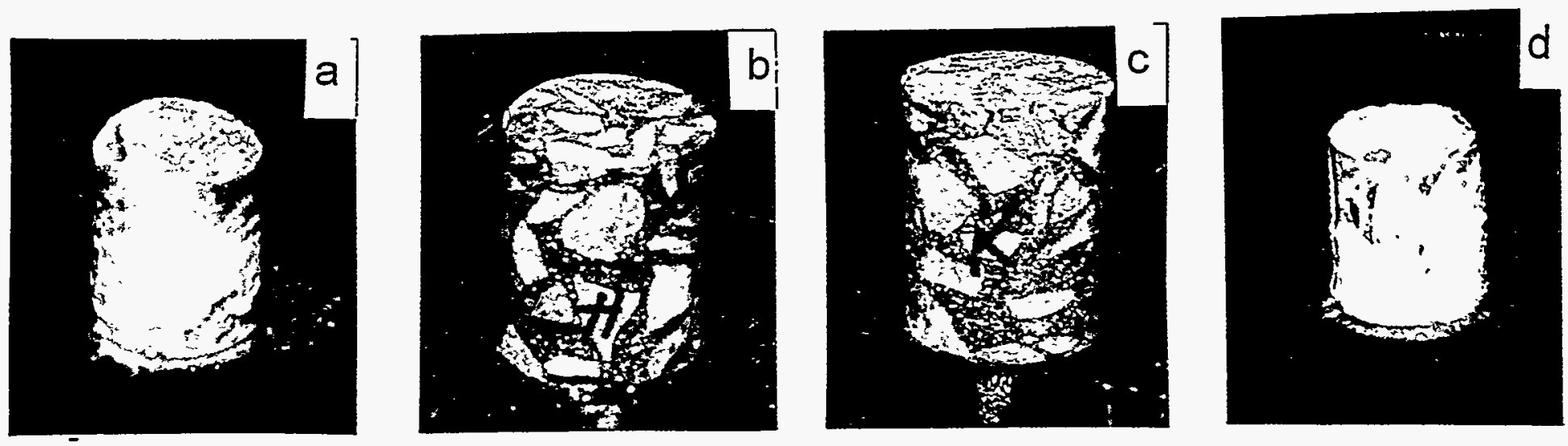

Figure 54. Test specimens after 61 days immersion in sterile medium.
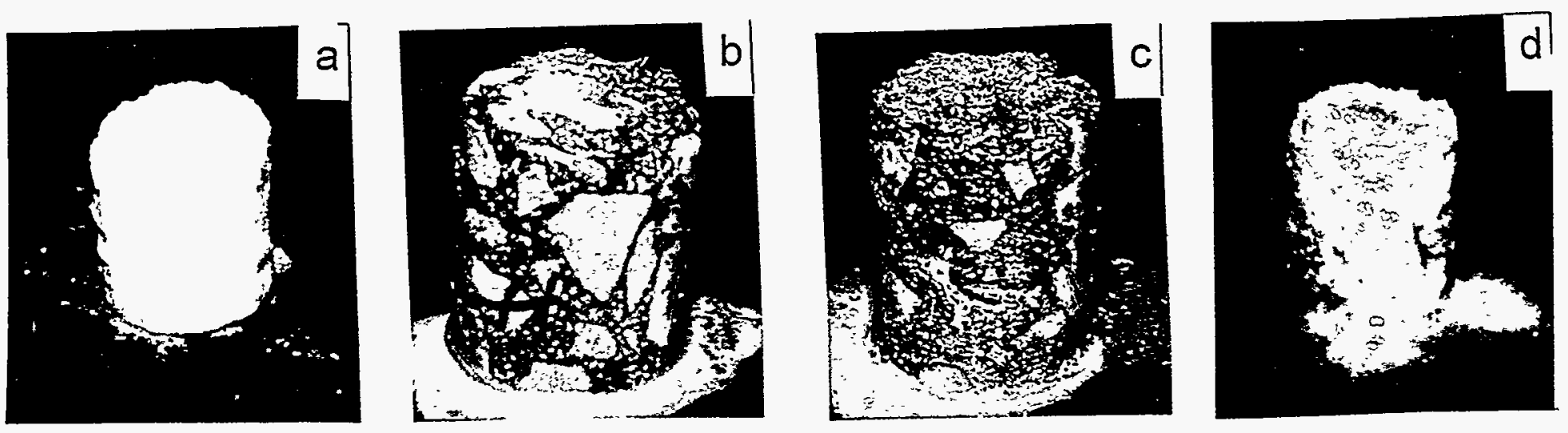

Figure 55. Test specimens after 61 days immersion in thiobacilli lixiviant. 


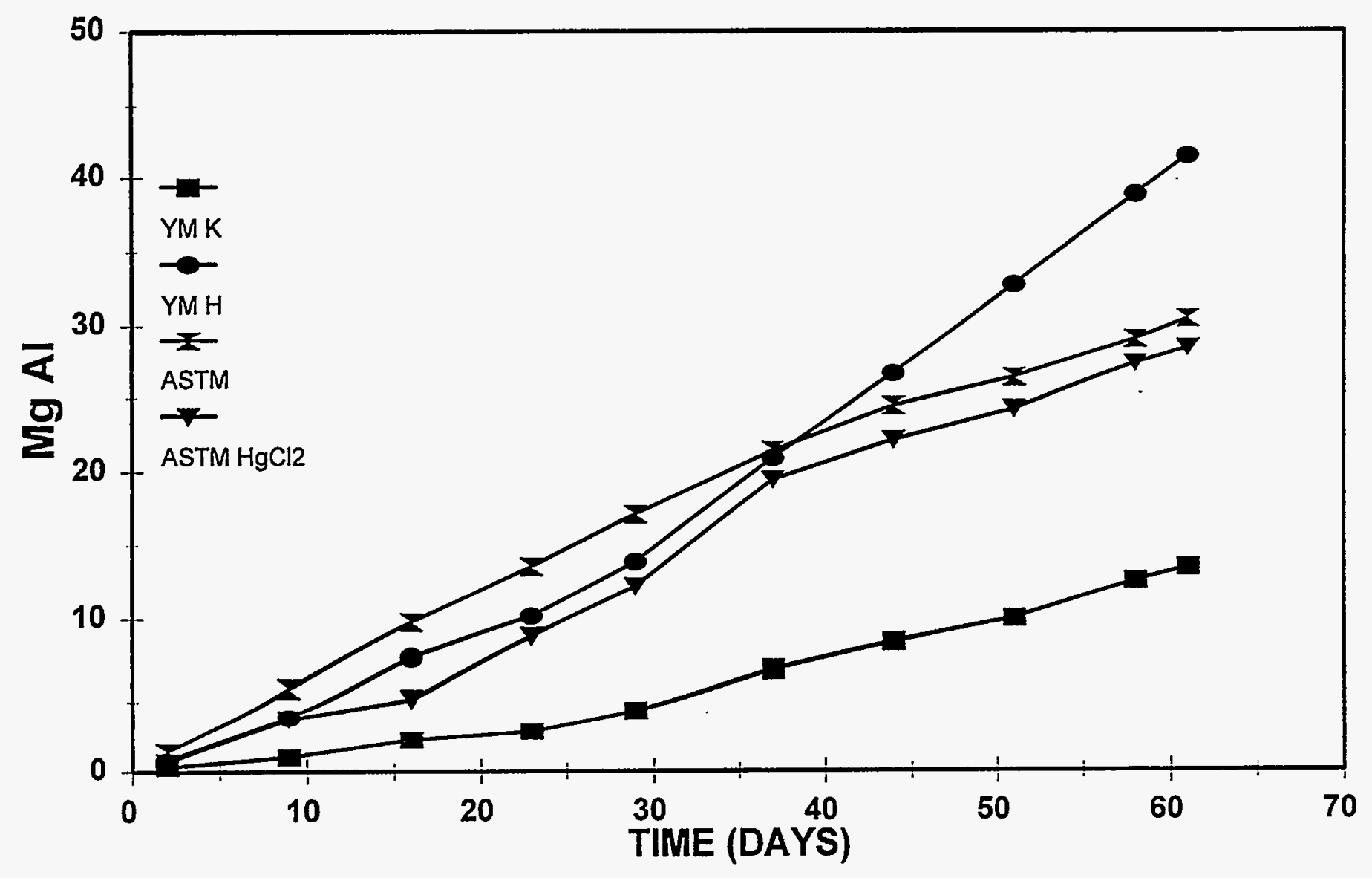

Figure 56. Cumulative quantity of $\mathrm{Al}$ leached over time from test specimens exposed to thiobacilli lixiviant. 


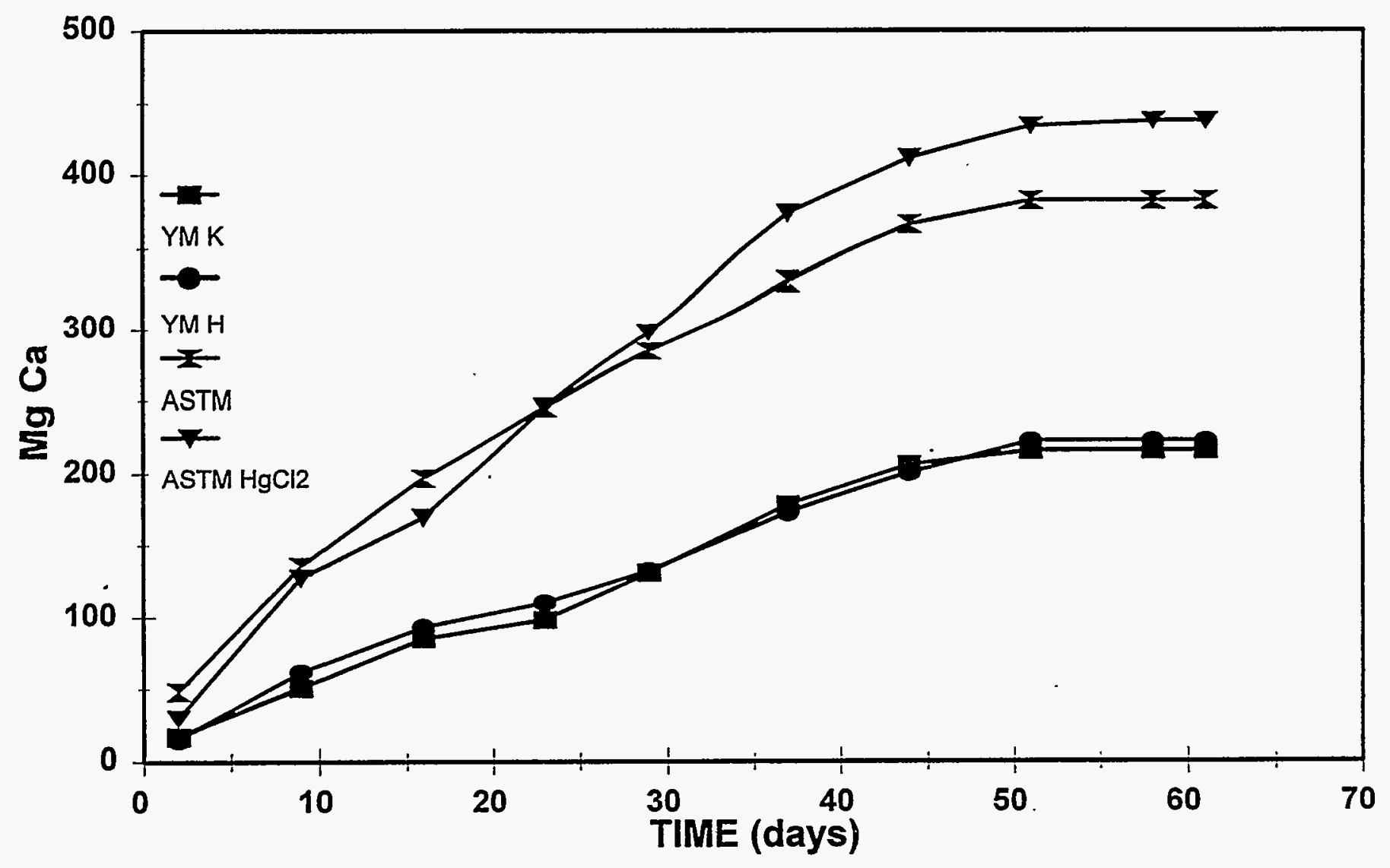
Figure 57. Cumulative quantity of $\mathrm{Ca}$ leached over time from test specimens
exposed to thiobacilli lixiviant. 


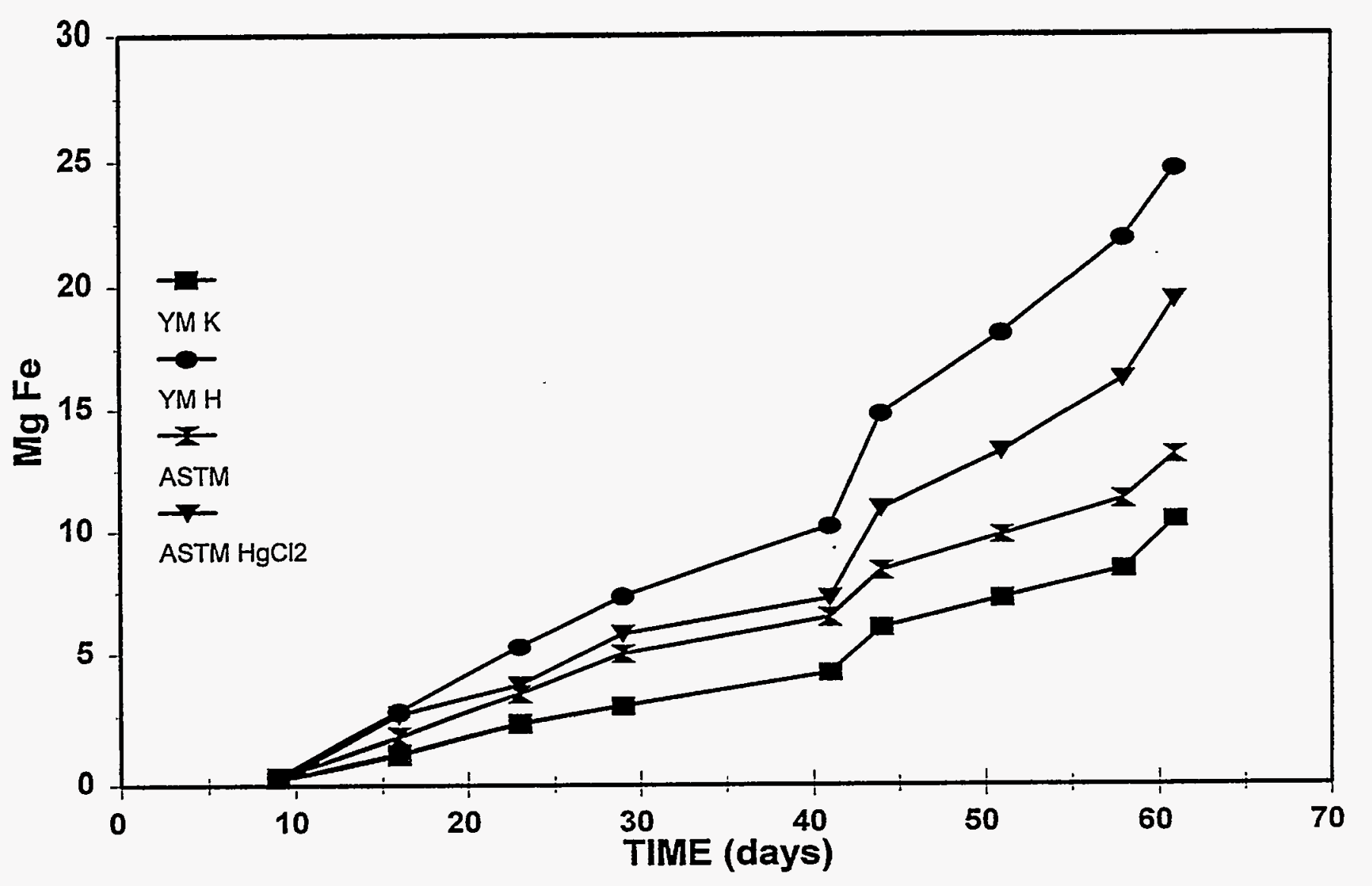

Figure 58. Cumulative quantity of $\mathrm{Fe}$ leached over time from test specimens exposed to thiobacilli lixiviant. 


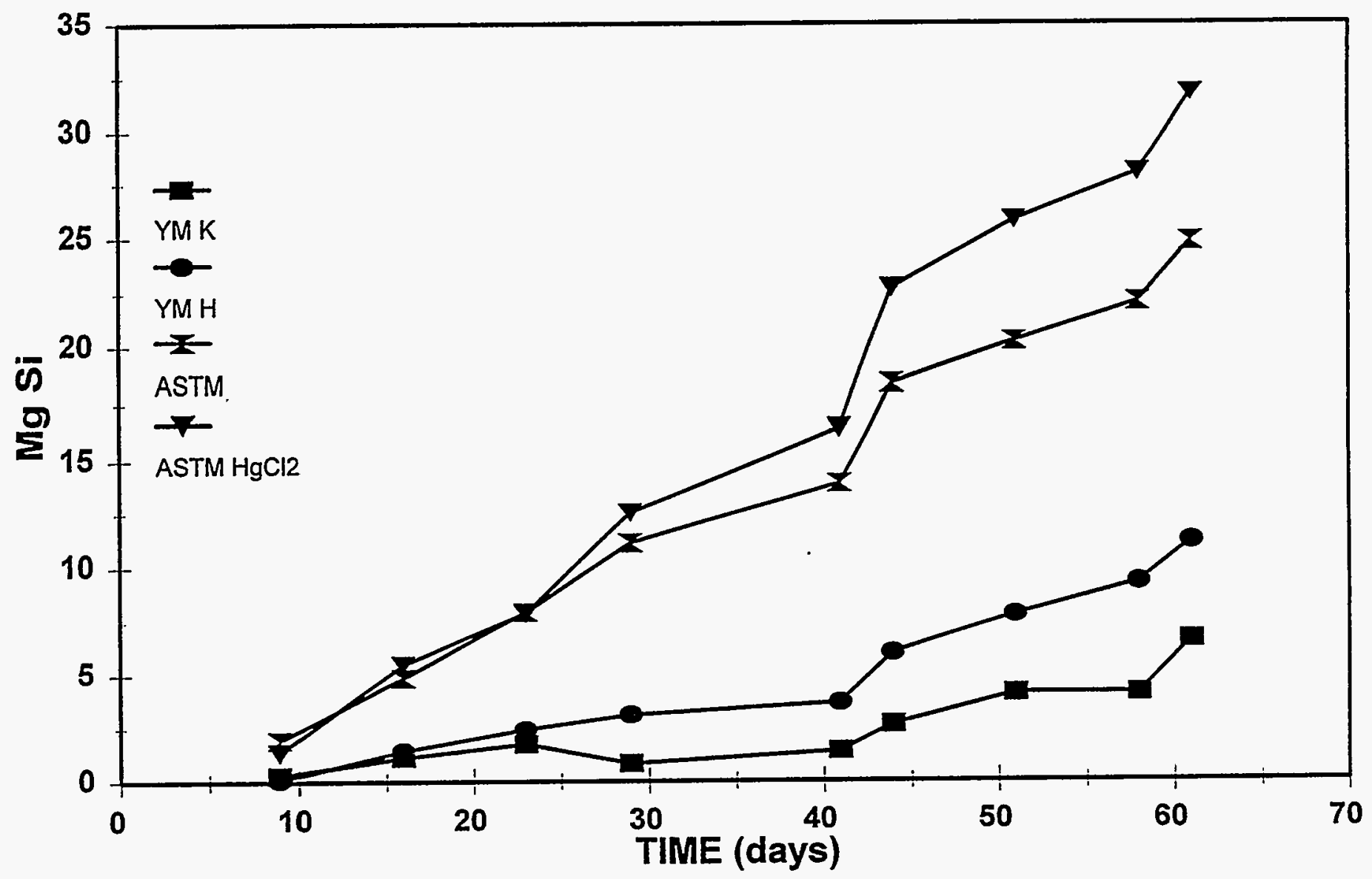

Figure 59. Cumulative quantity of Si leached over time from test specimens exposed to thiobacilli lixiviant. 